Pacific Northwest

National Laboratory

Operated by Battelle for the

U.S. Department of Energy

\title{
Physical and Liquid Chemical Simulant Formulations for Transuranic Wastes in Hanford Single-Shell Tanks
}

\author{
S. D. Rassat \\ L. M. Bagaasen \\ L. A. Mahoney \\ R. L. Russell \\ D. D. Caldwell \\ D. P. Mendoza
}

July 2003

Prepared for the U.S. Department of Energy

under Contract DE-AC06-76RL01830 


\title{
DISCLAIMER
}

This report was prepared as an account of work sponsored by an agency of the United States Government. Neither the United States Government nor any agency thereof, nor Battelle Memorial Institute, nor any of their employees, makes any warranty, express or implied, or assumes any legal liability or responsibility for the accuracy, completeness, or usefulness of any information, apparatus, product, or process disclosed, or represents that its use would not infringe privately owned rights. Reference herein to any specific commercial product, process, or service by trade name, trademark, manufacturer, or otherwise does not necessarily constitute or imply its endorsement, recommendation, or favoring by the United States Government or any agency thereof, or Battelle Memorial Institute. The views and opinions of authors expressed herein do not necessarily state or reflect those of the United States Government or any agency thereof.

\author{
PACIFIC NORTHWEST NATIONAL LABORATORY \\ operated by \\ BATTELLE \\ for the \\ UNITED STATES DEPARTMENT OF ENERGY \\ under Contract DE-ACO6-76RLO183O
}

Printed in the United States of America
Available to DOE and DOE contractors from the
Office of Scientific and Technical Information,
P.O. Box 62, Oak Ridge, TN 37831-0062;
ph: (865) 576-8401
fax: (865) 576-5728
email: reports@adonis.osti.gov

\author{
Available to the public from the National Technical Information Service, \\ U.S. Department of Commerce, 5285 Port Royal Rd., Springfield, VA 22161 \\ ph: (800) 553-6847 \\ fax: (703) 605-6900 \\ email: orders@ntis.fedworld.gov \\ online ordering: http://www.ntis.gov/ordering.htm
}

This document was printed on recycled paper. 


\title{
Physical and Liquid Chemical Simulant Formulations for Transuranic Wastes in Hanford Single-Shell Tanks
}

\author{
S. D. Rassat \\ L. M. Bagaasen \\ L. A. Mahoney \\ R. L. Russell \\ D. D. Caldwell \\ D. P. Mendoza
}

July 2003

Prepared for

the U.S. Department of Energy

under Contract DE-AC06-76RL01830

Pacific Northwest National Laboratory

Richland, WA 99352 


\section{Executive Summary}

CH2M HILL Hanford Group, Inc. (CH2M HILL) is in the process of identifying and developing supplemental process technologies to accelerate the tank waste cleanup mission. A range of technologies is being evaluated to allow disposal of Hanford waste types, including transuranic (TRU) process wastes. Ten Hanford single-shell tanks (SSTs) have been identified whose contents may meet the criteria for designation as TRU waste: the B-200 series (241-B-201, -B-202, -B-203, and B-204), the T-200 series (241-T-201, -T-202, -T-203, and -T-204), and Tanks 241-T-110 and -T-111. ${ }^{\text {(a) }}$ CH2M HILL continues to evaluate the wastes stored in the SSTs and may identify additional tanks that contain TRU wastes. $\mathrm{CH} 2 \mathrm{M}$ HILL has requested vendor proposals to develop a system to transfer and package the contacthandled TRU (CH-TRU) waste retrieved from the SSTs for subsequent disposal at the Waste Isolation Pilot Plant (WIPP).

Current plans call for a modified "dry" retrieval process in which a liquid stream is used to help mobilize the waste for retrieval and transfer through lines and vessels. This retrieval approach requires that a significant portion of the liquid be removed from the mobilized waste sludge in a "dewatering" process such as centrifugation prior to transferring to waste packages in a form suitable for acceptance at WIPP. In support of CH2M HILL's effort to procure a TRU waste handling and packaging process, Pacific Northwest National Laboratory (PNNL) developed waste simulant formulations to be used in evaluating the vendor's system.

For the SST CH-TRU wastes, the suite of simulants includes 1) nonradioactive chemical simulants of the liquid fraction of the waste, 2) physical simulants that reproduce the important dewatering properties of the waste, and 3) physical simulants that can be used to mimic important rheological properties of the waste at different points in the TRU waste handling and packaging process. To validate the simulant formulations, their measured properties were compared with the limited data for actual TRU waste samples. PNNL developed the final simulant formulations through a series of screening and scoping experimental studies, ultimately completing a set of physical simulant validation studies that were conducted in accordance with NQA-1 requirements for quality assurance. Only simple, commercially available feedstock is used in the simulant formulations. Readily available kaolin and bentonite clays mixed with water in specific proportions are the basis of the physical simulants, and the liquid simulants contain no exotic chemicals.

The chemical composition of the liquid fraction of the TRU waste is likely to control the compatibility of the waste with the process equipment and the final disposal packaging materials, including any added sorbent (if needed to prevent liquid separation in the package), as well as sorbent effectiveness. Three liquid chemical simulants were developed to represent the $\mathrm{pH}$ range and composition variation reported for liquids in the SST TRU wastes. The T-110 (and presumably T-111) waste and simulant contain more sulfur (as sulfate) and phosphorous (as phosphate) by an order of magnitude and have a considerably lower $\mathrm{pH}(\sim 8.3)$ than the B-200 and T-200 series waste liquids. Two liquid chemical simulant recipes for the B-200 and T-200 series tanks are necessary to capture the large differences in reported carbonate concentrations and $\mathrm{pHs}$ from $\sim 10$ to more than 12. In addition to matching $\mathrm{pH}$ and composition targets, the measured density of liquid simulants is representative of the actual waste $(\sim 1.05$ to $1.1 \mathrm{~g} / \mathrm{mL})$.

(a) Hanford waste tanks are designated with the prefix 241 -followed by the tank farm identifier and the individual tank number. In this report, as in common usage, the prefix is omitted. 
The purpose of the physical simulants is to represent important dewatering and rheological properties, primarily shear strength and viscosity, of the TRU waste at different points in the handling and packaging process. Waste physical properties are a function of many factors, including waste handling, chemistry, solids content, material microstructure, particle/agglomerate size, solid and liquid densities, and liquid viscosity. In simulant development, no attempt was made to match these properties individually; rather, an overall match of the significant actual waste dewatering and transport characteristics was sought. Because the simulants are intended to support long-term transport and dewatering/packaging system acceptance tests, reusable simulants are valued to reduce the amount of material required. Also from a practicality standpoint, the simulant formulations were kept as simple as possible to minimize the number of ingredients and the sensitivity to preparation techniques. Purely physical simulants prepared from kaolin and bentonite clay solids meet these key criteria.

An $80-w t \%$ kaolin: $20-w t \%$ bentonite clay solids mixture with water is the preferred simulant for matching centrifugal dewatering and rheological properties. An 80:20 kaolin:bentonite mixture provides a good match of the centrifuged sludge volume-solids content and shear strength-solids content relationships reported for actual TRU waste from the B-200 and T-200 tanks. The shear strength and dewatering behavior of the simulant is reproducible and varies in a consistent manner as a function of moisture content and other experimental factors (e.g., centrifugation time). The viscosity of diluted 80:20 kaolin:bentonite simulant slurries also compares reasonably with similarly diluted actual waste. To represent the TRU waste at various locations in the transport and packaging process, a series of 80:20 kaolin:bentonite solids/water formulations is provided. The baseline formulation, representing TRU waste of typical shear strength $(\sim 1000 \mathrm{~Pa})$, is $42.5 \mathrm{wt} \%$ kaolin:bentonite solids in water. The inclusion of bentonite in the formulations reduces the solids content needed to achieve $\sim 1000 \mathrm{~Pa}$ shear strength compared with a pure kaolin/water simulant system (60-62.5 wt\% solids).

Although a TRU waste dewatering process is likely to use centrifugation, other approaches such as gravity settling/compaction are possible. Mixtures of kaolin and water provide a better match of the TRU waste gravity settling behavior (settling rate and settled/compacted sludge volumes) than 80:20 kaolin:bentonite formulations. As with the kaolin:bentonite simulant, a series of kaolin/water formulations is given to represent the TRU waste at various locations in a handling/packaging process.

Other factors such as simulant aging, source of clay, and water quality affect the properties of the physical simulants to varying degree:

- Aging - The shear strength and centrifugation behavior of 80:20 kaolin:bentonite clay simulants varies with the duration since preparation (age). The age effect is associated with the bentonite clay.

- Source of Clay - Some manageable differences in measured physical properties (e.g., shear strength and centrifuged sludge volumes) were attributed to the variation in bentonite clay lots used in scoping and validation tests.

- Water Quality - The effect of water quality on simulant shear strength was examined briefly, using local potable water for a few and deionized water for the bulk of the simulant preparations. Small $(\sim 5 \%)$ differences in shear strength were measured.

Owing to the potential variation in properties with simulant materials, it is recommended that physical properties of laboratory-scale simulant preparations using the specific clay and water sources be evaluated prior to the preparation of large-scale simulant batches for vendor process testing. Minor formulation adjustments (e.g., solids/water ratio) may be required to achieve target properties for specific studies. 
Additionally, it is suggested that the simulant be aged about a week prior to process testing to achieve more consistent properties.

In developing the physical simulants, the strength of centrifuged products and the ability to reuse the simulants in multiple simulated process cycles were also evaluated. Because the clay/water mixtures are purely physical simulants in the sense that they have no appreciable water-soluble species, they show repeatable physical properties independent of dilution. These characteristics and the reasonable agreement of physical properties with actual TRU waste make the clay/water simulants well-suited to testing a TRU waste dewatering/packaging process. 


\section{Acknowledgments}

The authors wish to thank several other PNNL staff who made technical contributions to simulant development and testing. Phil Gauglitz gave helpful guidance in the creation of practical physical simulant formulations and the assessment of simulant rheological properties. Cal Delegard and Joel Tingey made actual waste chemistry and physical property data available prior to reporting. Cal also provided expertise in the assessment of data leading to development of the liquid chemical simulant formulations and reviewed the final recipes. Beric Wells reviewed the physical simulant formulations and properties and provided some insightful comments, particularly related to factors likely to affect waste processing. John Mucha helped generate a workable graded quality approach that allowed the efficient use of scoping studies with focused validation testing. Johnway Gao and Lynette Jagoda completed high-quality physical simulant rheology validation tests on a tight schedule, and student Craig Denney assisted with the preparation of physical simulants used in early screening tests. We also wish to thank Sheila Bennett for her editorial support in the preparation of this document. 


\section{Contents}

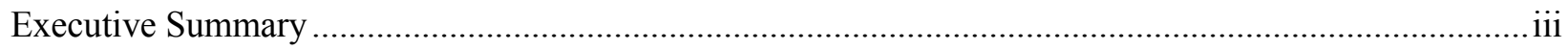

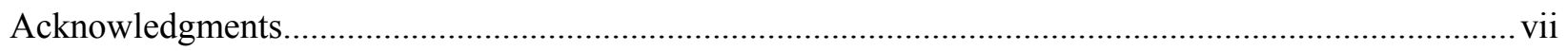

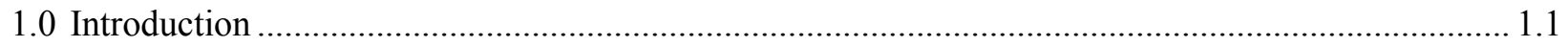

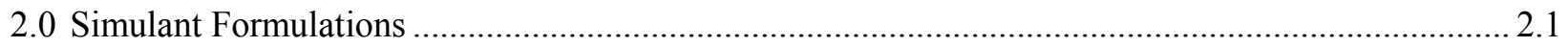

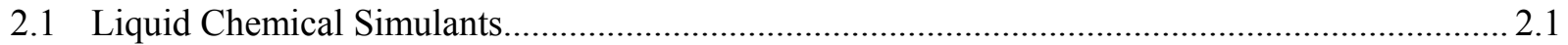

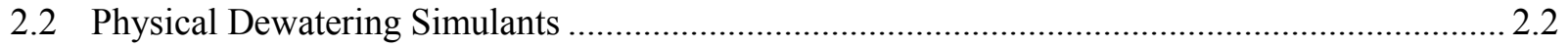

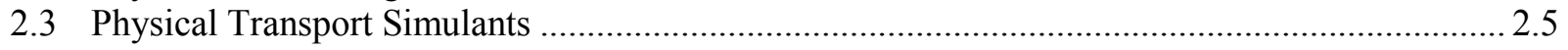

3.0 Technical Justification for Liquid Chemical Simulants ................................................................. 3.1

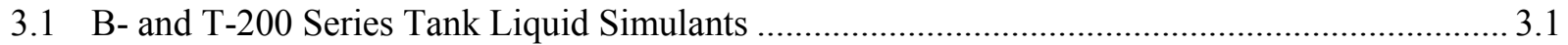

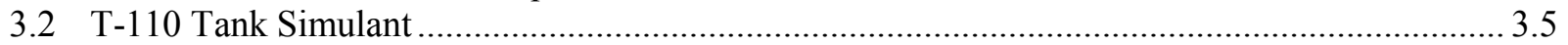

4.0 Technical Justification of Physical Simulants_-Dewatering and Rheological Properties ................. 4.1

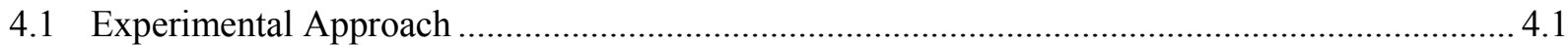

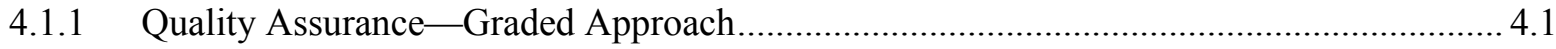

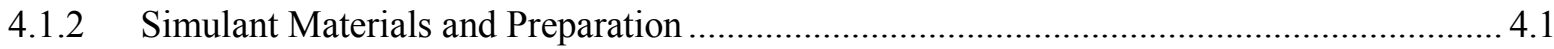

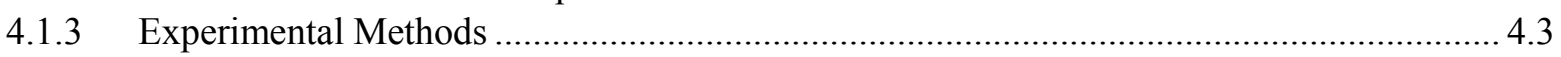

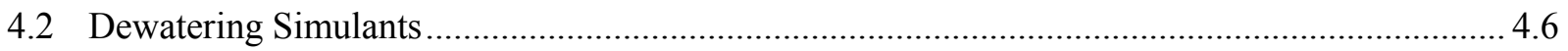

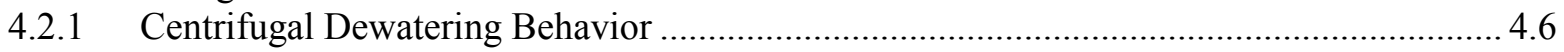

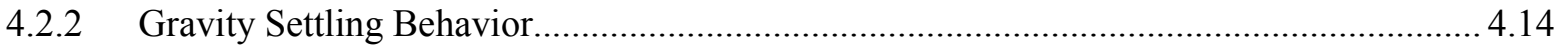

4.2.3 Strengths of Centrifuged Products ......................................................................................... 4.16

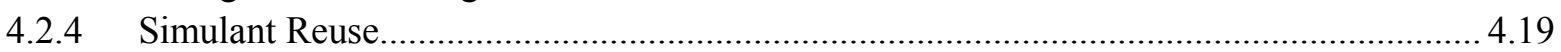

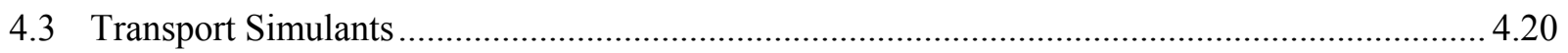

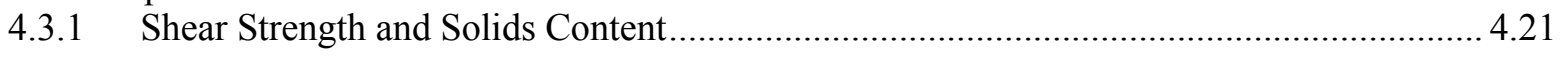

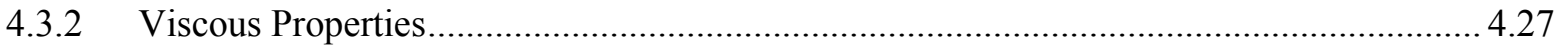

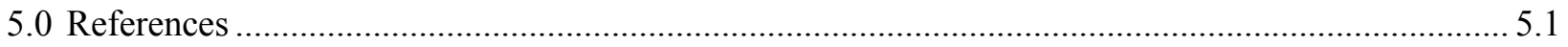

Appendix: Additional Details of Physical Simulant Property Measurements ....................................... A.1 


\section{Figures}

4.1 Relative Quantity of Centrifuged B-201 TRU Sludge Recovered as a Function of Water Dilution Level

4.2 Centrifuged Sludge Volume Fraction as a Function of Initial Solids Content

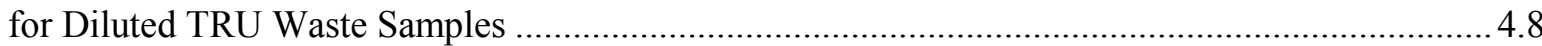

4.3 Final Settled Solids Content as a Function of Original Dilution and Applied G Force ...................4.9

4.4 Clay Simulant and TRU Waste Centrifuged Sludge Volumes ........................................................ 4.9

4.5 Comparison of Clay Simulant and TRU Waste Centrifugation Rates at 1000-G....................... 4.10

4.6 Centrifuged Kaolin:Bentonite Simulant Solids Content as a Function of Centrifugation Time..... 4.12

4.7 Effect of Aging on Centrifuged Kaolin:Bentonite Simulant Solids Content ............................... 4.13

4.8 Gravity Settling of Kaolin Simulants of Varying Initial Solids Content .................................... 4.15

4.9 Measured Shear Strength for Centrifuged, Remixed, and Reconstituted Kaolin/Water Simulant . 4.18

4.10 Measured Shear Strength for Centrifuged, Remixed, and Reconstituted 80:20

Kaolin:Bentonite/Water Simulants

4.11 Consistency of Centrifuged Dewatering Behavior of Kaolin/Water Mixtures after

Multiple Centrifuge and Reconstitution Cycles....

4.12 Consistency of Centrifuged Dewatering Behavior of Diluted Kaolin:Bentonite/Water

Simulant after Multiple Centrifuge and Reconstitution Cycles

4.13 Measured Shear Strength for Kaolin/Water Mixtures Prepared by Different Operators ............... 4.22

4.14 Measured Shear Strength for 80:20 Kaolin:Bentonite Solids and Water Mixtures ...................... 4.23

4.15 Shear Strength as Function of Solids Content in TRU Waste Samples and Clay Simulants......... 4.26

4.16 Apparent Viscosity of Diluted TRU Samples and Diluted Clay Simulants................................. 4.29

4.17 Apparent Viscosity of Diluted TRU Samples and Diluted Clay Simulants.................................. 4.29

\section{Tables}

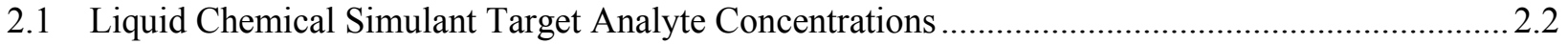

2.2 Reagent Masses for $1 \mathrm{~L}$ of Liquid Chemical Simulant ................................................................. 2.3

2.3 Kaolin:Bentonite/Water Formulations Required to Simulate Centrifugal

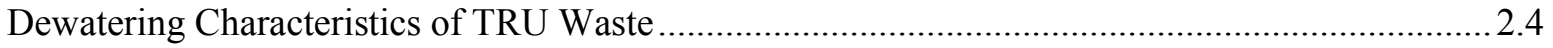

2.4 Kaolin/Water Formulation Required to Simulate Gravity-Settling Characteristics of TRU ........... 2.4

2.5 Kaolin:Bentonite/Water Formulation Required to Simulate Rheological Properties of

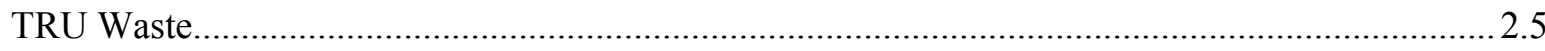

3.1 TWINS Database Reported Composition and Properties for B-200 and T-200 Series

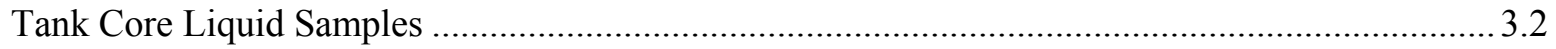

3.2 Charge Balance for B-200 and T-200 Series Liquid Simulant ..................................................... 3.4

3.3 Charge Balance for B-200 and T-200 Series Liquid Simulant .........................................................

3.4 Reported Composition and Properties for Tank T-110 Liquid ................................................... 3.6

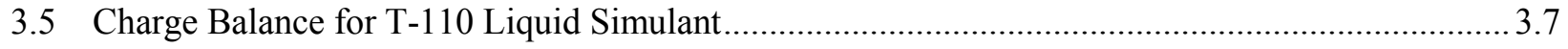

4.1 Summary of Bentonite and Kaolin Clays Used in Simulant Development ................................... 4.2

4.2 Measured and Calculated Bulk Densities of 80:20 Kaolin:Bentonite Simulants.............................4.5

4.3 Long-Time Gravity Settling Characteristics of Kaolin/Water Simulants .................................... 4.15

4.4 Effects of Water Type on 80:20 Kaolin:Bentonite Simulant Shear Strength .............................. 4.25

4.5 Rheological Properties of Diluted TRU Waste Samples and Clay Simulants .............................. 4.28 


\subsection{Introduction}

CH2M HILL Hanford Group, Inc. (CH2M HILL) is identifying and developing supplemental process technologies to accelerate the tank waste cleanup mission. A range of technologies is being evaluated to allow disposal of Hanford waste types, including transuranic (TRU) process wastes. Gasper et al. (2002) identified 12 Hanford waste tanks that may meet the criteria for designation as TRU waste, including three double-shell tanks (AW-103, AW-105, and SY-102) and nine single-shell tanks (SSTs): the B-200 series (B-201, B-202, B-203, and B-204), the T-200 series (T-201, T-202, T-203, and T-204), and Tank T-111. The SST T-110 waste has recently received attention as a candidate for designation as a TRU waste type. If not designated as TRU waste, it may be defined as low-level waste that could be handled and packaged with the same process used for other contact-handled TRU (CH-TRU) wastes from the SSTs. CH2M HILL continues to evaluate the wastes stored in the SSTs and may identify additional tanks that contain TRU wastes. CH2M HILL has requested vendor proposals to develop a system to transfer and package the contact-handled TRU (CH-TRU) waste retrieved from the SSTs for subsequent disposal at the Waste Isolation Pilot Plant (WIPP).

Current retrieval plans call for a modified "dry" retrieval process in which a liquid stream flowing at $\sim 1.4$ to $5.0 \mathrm{gpm}$ is used to help mobilize the waste for retrieval and transfer through lines and vessels. This retrieval approach requires that a significant portion of the liquid be removed from the mobilized waste sludge in a "dewatering" process such as centrifugation prior to transferring to waste packages. Additionally, adsorbent might be added to the waste packages (e.g., drums) to prevent formation of a free liquid layer.

In support of CH2M HILL's effort to procure a TRU waste handling and packaging process, Pacific Northwest National Laboratory (PNNL) was tasked with developing waste simulant formulations. For the SST CH-TRU wastes, the suite of simulants includes 1) nonradioactive chemical simulants of the liquid fraction of the waste, 2) physical simulants that reproduce the important dewatering properties of the waste, and 3) physical simulants that can be used to mimic the mechanical strength and flow characteristics of the waste at different points in the TRU waste handling and packaging process. To validate the simulant formulations, measured properties of the simulants were compared with those obtained from results on actual TRU waste samples. ${ }^{\text {(a) }}$ However, after the final vendor has been selected, additional physical property tests on the TRU waste samples that are specifically applicable to the vendor's proposed process may be conducted. Thus, the simulant recipes supplied in this report represent the best estimate of the final simulants, but these may be modified later if necessary to better match the predicted behavior of the TRU waste in the vendor's equipment.

Much of the data described in this report was gathered as part of scoping tests to help direct final TRU waste sample and simulant property testing and to support the development of final simulant

(a) Tingey JM, J Gao, LM Bagaasen, and BE Wells. May 2003. Physical Property and Rheological Testing of Actual Transuranic Waste from Hanford Single-Shell Tanks, letter report ST03.016, PNNL. (A publicly available version of this document is scheduled for release in late summer of 2003.) Tingey et al. collected data on composited archived samples from four different tanks: T-203, T-204, B-203, and T-110. The composite sample from T-110 was drier than the original tank material, and adding water back to this sample resulted in physical properties that were significantly different than those found for newly collected T-110 tank samples (e.g., Rassat et al. 2003). Here, we consider only the Tingey et al. data from the T-203, T-204, and B-203 composite samples. 
formulations. While the data from these scoping studies meet the guidelines of the PNNL Standards Based Management System, they do not necessarily meet the rigorous quality assurance (QA) requirements of NQA-1 with supplements. After final simulant recipes were identified, numerous simulant batches were prepared and physical property tests were conducted in accordance with the NQA1 requirements. In the report, these higher QA level data are identified as results from "validation" tests and studies. Most of the scoping test data were obtained with comparable procedures and using the same instrumentation and test equipment. However, lacking the QA rigor, the "scoping" test data contained herein are being supplied for information only and may not be referenced in any reports requiring NQA-1 level data without the proper caveats.

As noted, the primary focus of this work was on the identification of suitable simulant formulations for subsequent vendor process testing. The recipes for both liquid chemical and physical simulants are summarized in Section 2 of this report. The rationale and development steps for the liquid chemical simulants are further identified in Section 3. Similarly, the technical justification and experimental results for the physical simulants are described in Section 4. 


\subsection{Simulant Formulations}

This section discusses the purpose of each set of simulants and specifies the anticipated simulant formulations that will be used in the vendor tests. While these recipes are subject to change pending final vendor selection and the results of additional actual TRU waste experiments, future modifications to the proposed simulants are not expected to require the addition of exotic or costly chemicals or modifiers. Only simple, commercially available feedstock is used in the present simulant formulations. Where possible, simulants that represent the range of properties that are seen in all the Hanford SST CH-TRU tanks are supplied, but in the case of liquid chemical simulants, wastes in different tanks vary enough that three recipes are provided.

In this section, liquid chemical simulant formulations are discussed first, followed by recipes for physical simulants intended for dewatering studies and physical simulants representing key rheological properties. The technical data and rationale for choosing each simulant recipe are discussed in the subsequent sections.

\subsection{Liquid Chemical Simulants}

The liquid simulant is intended to represent the chemical properties of the interstitial liquid within the TRU waste, which will mix with the liquid stream used to aid retrieval. It is anticipated that the chemical composition of this liquid fraction of the waste will control the sorbent effectiveness as well as the chemical compatibility of the waste with the sorbent, the process equipment, and the final disposal packaging materials. The vendor may need to use these simulants in tests to verify that their selected sorbents are effective and to test any parts of their process equipment or disposal packaging materials where chemical compatibility could be a question.

An evaluation of existing tank waste data ${ }^{(a)}$ along with recent TRU waste analyses of archived composited samples from Tanks B-203, T-203, T-204, and T-110, suggests that two liquid chemical simulant recipes are needed to adequately represent the $\mathrm{pH}$ range and carbonate concentration of waste in the $\mathrm{B}-200$ and $\mathrm{T}$ 200 series tanks. Composition data ${ }^{(b)}$ for the liquid in the T-110 tank waste are sufficiently different from the B- and T-200 series wastes to warrant a third simulant recipe. Table 2.1 shows the target chemical compositions of the three liquid chemical simulants. While sodium (Na), fluoride (F), and nitrate $\left(\mathrm{NO}_{3}\right)$ are key components in all solutions, the $\mathrm{NO}_{3}$ is about $30 \%$ more concentrated in the $\mathrm{T}-110$ liquid than it is in the other simulants. The most significant differences are in the phosphate $\left(\mathrm{PO}_{4}\right)$, sulfate $\left(\mathrm{SO}_{4}\right)$, and potassium $(\mathrm{K})$ concentrations: the $\mathrm{PO}_{4}$ and $\mathrm{SO}_{4}$ are more than an order of magnitude greater and the $\mathrm{K}$ an order of magnitude less in the T-110 liquid. In addition, no carbonate $\left(\mathrm{CO}_{3}\right)$ is present in the T-110 liquid, unlike the other simulants. The bases of these simulant compositions are provided under Technical Justification, Section 3.

(a) Data obtained from the Tank Characterization Database (TCD) in the Hanford Tank Waste Information Network System (TWINS) in January 2003. These data were based on core and grab samples that were performed shortly after the samples were taken from the tank.

(b) Only one data set of liquid composition data for a grab sample from Tank T-110 was available in the TCD in January 2003, and no liquid composition data were found for Tank T-111. 
Table 2.1. Liquid Chemical Simulant Target Analyte Concentrations

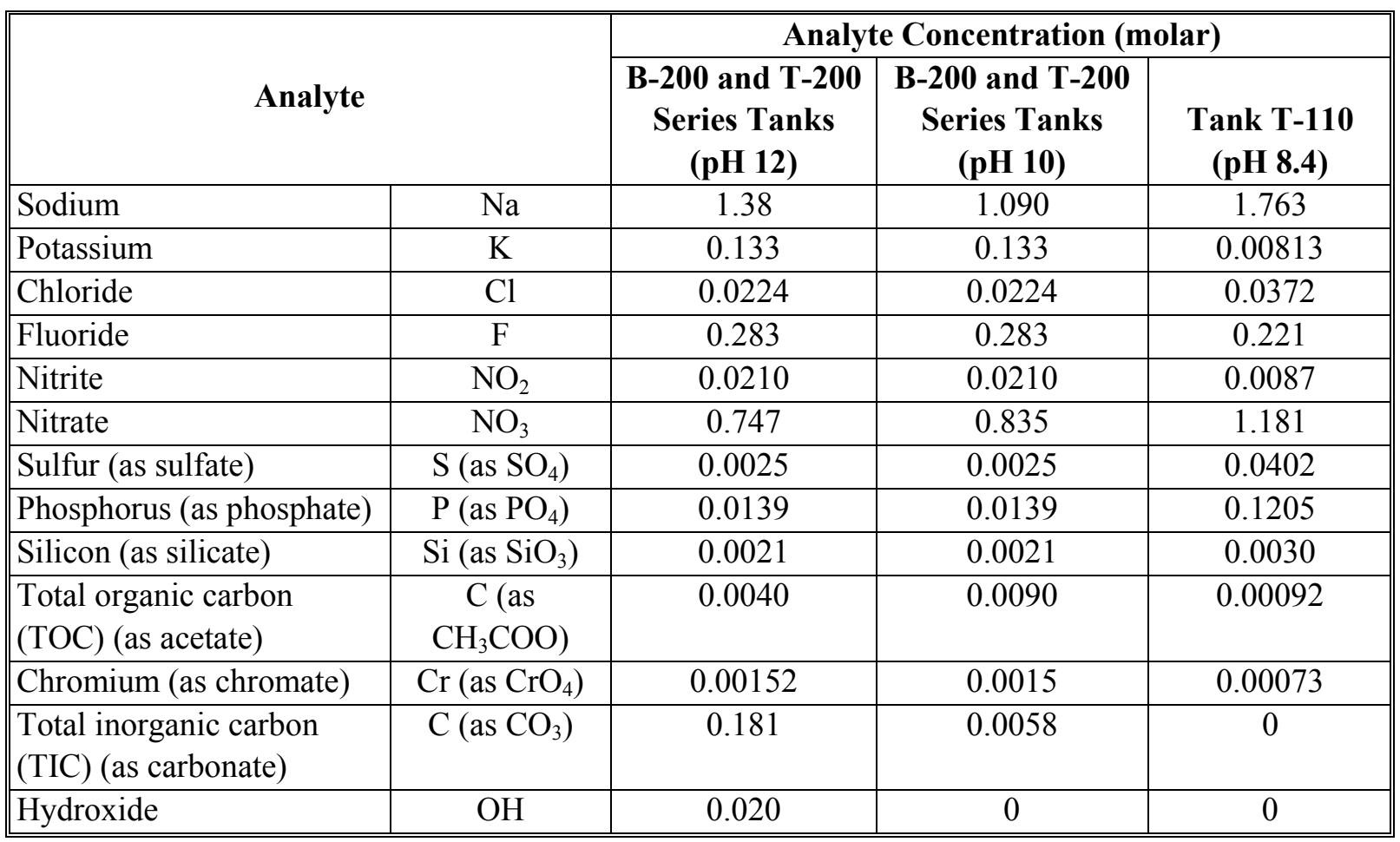

Table 2.2 shows the masses of each reagent, except deionized water, required to produce $1 \mathrm{~L}$ of simulant solution with the target chemical compositions shown in Table 2.1. The reagents are added in the order specified in Table 2.2 into $\sim 0.5 \mathrm{~L}$ of deionized water and mixed to dissolve each component after addition. Deionized water is used to dilute the simulant to a final volume of $1 \mathrm{~L}$.

Preliminary experimental simulant formulations, nominally prepared according to the recipes shown in Table 2.2, had measured densities of 1.06 to $1.10 \mathrm{~g} / \mathrm{mL}$, in reasonable agreement with the range of densities reported for all the tank waste liquids $(1.04$ to $1.09 \mathrm{~g} / \mathrm{mL})$. The measured $\mathrm{pH}$ of these test solutions was also appropriate; $\mathrm{pH}$ values of 12.4 and 10.3 were measured for the B-200 and T-200 tank series simulants, matching the target values. After two months of aging, the measured $\mathrm{pHs}$ of these simulants (11.9 and 10.2 respectively) were similar to the original values. The $\mathrm{pH}$ of the T-110 simulant solution was $\sim 8.3$ when prepared and 8.3 on measurement 2 months later, consistent with reported actual waste measurements.

\subsection{Physical Dewatering Simulants}

The primary physical dewatering simulant is intended to represent the centrifugal dewatering behavior of the TRU waste. In case the vendor relies on gravity-settling process steps, a second simulant formulation is provided. The bases of the physical dewatering simulant compositions are provided in the technical justification section (4.2). The simulants may be used to support long-term dewatering/packaging tests that are required for system acceptance and cold startup testing. 
Table 2.2. Reagent Masses for $1 \mathrm{~L}$ of Liquid Chemical Simulant

\begin{tabular}{|c|c|c|c|c|c|c|c|c|}
\hline \multirow[t]{2}{*}{ Compound } & \multirow[t]{2}{*}{ Formula } & \multirow{2}{*}{$\begin{array}{l}\text { Formula } \\
\text { Weight, } \\
\text { (g) }\end{array}$} & \multicolumn{2}{|c|}{$\begin{array}{c}\text { B- and T-200 } \\
\text { Series Tanks } \\
\text { (pH } 12 \text { Target) }\end{array}$} & \multicolumn{2}{|c|}{$\begin{array}{c}\text { B- and T-200 } \\
\text { Series Tanks } \\
\text { (pH } 10 \text { Target) }\end{array}$} & \multicolumn{2}{|c|}{$\begin{array}{c}\text { Tank T-110 } \\
\text { (pH 8.4 Target) }\end{array}$} \\
\hline & & & $\begin{array}{c}\text { Mass } \\
\text { (g) }\end{array}$ & $\begin{array}{c}\text { Conc. } \\
\text { (M) }\end{array}$ & $\begin{array}{c}\text { Mass } \\
\text { (g) }\end{array}$ & $\begin{array}{c}\text { Conc. } \\
\text { (M) }\end{array}$ & $\begin{array}{c}\text { Mass } \\
\text { (g) }\end{array}$ & $\begin{array}{l}\text { Conc. } \\
\text { (M) }\end{array}$ \\
\hline Sodium acetate & $\mathrm{NaO}_{2} \mathrm{CCH}_{3}$ & 82.04 & 0.328 & 0.00400 & 0.741 & 0.0090 & 0.0751 & 0.00092 \\
\hline Sodium chloride & $\mathrm{NaCl}$ & 58.44 & 1.307 & 0.0224 & 1.307 & 0.0224 & 2.176 & 0.0372 \\
\hline Sodium fluoride & $\mathrm{NaF}$ & 41.99 & 11.904 & 0.284 & 11.904 & 0.284 & 9.283 & 0.221 \\
\hline Sodium phosphate & $\mathrm{Na}_{3} \mathrm{PO}_{4} \cdot 12 \mathrm{H}_{2} \mathrm{O}$ & 380.12 & 5.289 & 0.0139 & NA & NA & NA & NA \\
\hline $\begin{array}{l}\text { Sodium } \\
\text { phosphate, dibasic }\end{array}$ & $\mathrm{Na}_{2} \mathrm{HPO}_{4} \cdot 7 \mathrm{H}_{2} \mathrm{O}$ & 268.07 & NA & NA & 3.730 & 0.0139 & 30.53 & 0.1139 \\
\hline $\begin{array}{l}\text { Sodium } \\
\text { phosphate, } \\
\text { monobasic }\end{array}$ & $\mathrm{NaH}_{2} \mathrm{PO}_{4} \cdot \mathrm{H}_{2} \mathrm{O}$ & 137.99 & NA & NA & NA & NA & 0.911 & 0.0066 \\
\hline Sodium sulfate & $\mathrm{Na}_{2} \mathrm{SO}_{4}$ & 142.04 & 0.354 & 0.0025 & 0.3544 & 0.0025 & 5.715 & 0.0402 \\
\hline Sodium nitrate & $\mathrm{NaNO}_{3}$ & 84.99 & 52.42 & 0.617 & 59.69 & 0.702 & 99.64 & 1.172 \\
\hline Potassium nitrate & $\mathrm{KNO}_{3}$ & 101.11 & 13.463 & 0.133 & 13.463 & 0.133 & 0.822 & 0.00813 \\
\hline Sodium silicate & $\mathrm{Na}_{2} \mathrm{SiO}_{3} \cdot 5 \mathrm{H}_{2} \mathrm{O}$ & 212.14 & 0.446 & 0.0021 & 0.446 & 0.0021 & 0.642 & 0.00303 \\
\hline Sodium chromate & $\mathrm{Na}_{2} \mathrm{CrO}_{4} \cdot 4 \mathrm{H}_{2} \mathrm{O}$ & 234.04 & 0.356 & 0.00152 & 0.356 & 0.00152 & 0.171 & 0.000731 \\
\hline Sodium hydroxide & $\mathrm{NaOH}$ & 40.00 & 0.800 & 0.020 & NA & NA & NA & NA \\
\hline Sodium nitrite & $\mathrm{NaNO}_{2}$ & 69.00 & 1.447 & 0.021 & 1.447 & 0.021 & 0.600 & 0.0087 \\
\hline Sodium carbonate & $\mathrm{Na}_{2} \mathrm{CO}_{3}$ & 105.99 & 19.15 & 0.181 & 0.615 & 0.0058 & NA & NA \\
\hline
\end{tabular}

The proposed simulant for centrifugal process testing consists of an $80-w t \%$ kaolin: $20-w t \%$ bentonite clay mixture combined with water in different proportions to represent TRU waste properties at various points in the TRU waste handling and packaging process. The kaolin:bentonite/water mixtures consistently dewater to nominally the same end moisture content in the settled sludge under given centrifuge conditions as the actual TRU waste samples, regardless of starting water content. These mixtures also exhibit reproducible dewatering behavior when dewatered in a centrifuge and reconstituted with added liquid multiple times. This is important from a practical standpoint because the simulant material might be recycled indefinitely to support long-term, high-throughput testing of the TRU waste handling and packaging process. The kaolin:bentonite/water mixtures also centrifuge to various end water contents to yield dewatered materials that have shear strengths similar to those expected for the actual TRU waste. This will allow the vendor to demonstrate that their dewatering system can work with dewatered material shear strengths in the range expected for TRU wastes.

Table 2.3 shows the expected clay and water contents that will be required to simulate the centrifugal dewatering nature of the TRU waste at different points in the process. Should the vendor process rely on separation by gravity settling, the kaolin/water formulations shown in Table 2.4 are representative of SST CH-TRU waste. PNNL may modify the moisture content and/or the ratio of the two clays when data from additional tests on TRU waste samples or further information on the vendor's process become available but does not anticipate including additional ingredients in the dewatering simulants. The clay used in laboratory studies was pulverized kaolin (available from EPK Division of Feldspar, Edgar, FL), 
Table 2.3. Kaolin:Bentonite/Water Formulations Required to Simulate Centrifugal Dewatering Characteristics of TRU Waste

\begin{tabular}{|l|c|c||}
\hline \multicolumn{1}{|c|}{ TRU Waste Property Simulated } & \multicolumn{2}{c|}{ Dewatering Simulant Recipes } \\
\cline { 2 - 3 } & $\begin{array}{c}\text { Clay }^{\text {(a) }} \text { (wt\%) } \\
\text { Minimum-Maximum }\end{array}$ & $\begin{array}{c}\text { Water (wt\%) } \\
\text { Maximum-Minimum }\end{array}$ \\
\hline $\begin{array}{l}\text { Typical undiluted TRU sludge in tank (shear strength } \\
\text { match) }\end{array}$ & 42.5 & 57.5 \\
\hline $\begin{array}{l}\text { Centrifuging behavior of nominally diluted TRU } \\
\text { ludges as received from retrieval }\end{array}$ & $20-22$ & $80-78$ \\
\hline $\begin{array}{l}\text { Centrifuging behavior of highly diluted TRU sludges } \\
\text { received from retrieval (highest water fraction) }\end{array}$ & $8-10$ & $92-90$ \\
\hline Strongest expected dewatered TRU sludge & 55 & 45 \\
\hline (a) The clay content is a mixture of 80 -wt\% kaolin and 20-wt\% bentonite. \\
\hline
\end{tabular}

Table 2.4. Kaolin/Water Formulations Required to Simulate Gravity-Settling Characteristics of TRU Waste

\begin{tabular}{|l|c|c|}
\hline \multicolumn{1}{|c|}{ TRU Waste Property Simulated } & \multicolumn{2}{c|}{ Dewatering Simulant Recipes } \\
\cline { 2 - 3 } & $\begin{array}{c}\text { Kaolin (wt\%) } \\
\text { Minimum-Maximum }\end{array}$ & $\begin{array}{c}\text { Water (wt\%) } \\
\text { Maximum-Minimum }\end{array}$ \\
\hline $\begin{array}{l}\text { Typical undiluted TRU sludge in tank (shear } \\
\text { Strength) }\end{array}$ & $60-62.5$ & $40-37.5$ \\
\hline $\begin{array}{l}\text { Onset of free liquid with gravity settling } \\
\begin{array}{l}\text { Settling behavior of nominally diluted TRU } \\
\text { sludges as received from retrieval }\end{array}\end{array}$ & $47.5-50$ & $52.5-50$ \\
\hline $\begin{array}{l}\text { Settling behavior of highly diluted TRU sludges } \\
\text { received from retrieval (highest water fraction) }\end{array}$ & $15-5-42.5$ & $62.5-57.5$ \\
\hline
\end{tabular}

and the bentonite clay was Big Horn ${ }^{\circledR}$ brand, $\mathrm{CH}-200$ grade (sodium bentonite powder available from WYO-BEN, Inc., Billings, MT). Laboratory batches of clay simulants were prepared by weighing the required amounts of kaolin and bentonite and thoroughly mixing the clay powders before combining them with deionized (DI) water and mixing the ingredients with a kitchen-type stand mixer. The formulations specified are for as-received "dry" clay powders, no adjustment in material weights being made for the typical clay moisture content. DI water $(>17 \mathrm{M} \Omega-\mathrm{cm}$ resistivity) was used for consistency; further evaluation would be needed to assess the potential impacts of trace constituents and $\mathrm{pH}$ of other water sources (e.g., local potable water) on the simulant physical properties. ${ }^{(a)}$

(a) Very limited testing of the shear strength of simulants prepared with laboratory tap water was completed, as described in Section 4.3.1. 


\subsection{Physical Transport Simulants}

The physical transport simulants are intended to represent the rheological properties, particularly shear strength and flow characteristics, of the TRU waste. The bases of the physical transport simulant compositions are provided in Section 4.3. The simulants may be used to support long-term transport tests that are required for system acceptance and cold startup testing.

Like the centrifugal dewatering simulants, the transport simulants consist of an 80-wt $\%$ kaolin:20-wt $\%$ bentonite clay mixture combined with different amounts of water to represent the shear strength/viscosity of the TRU waste at different points in the TRU waste handling and packaging process. The clay-water mixtures can consistently supply a wide variety of strengths by varying the moisture content, and the full range of strengths expected for the in-tank TRU sludges are readily obtained. The solids loading (weight fraction) required to obtain a given simulant shear strength provides a reasonably close match to the strength-to-solids content relationship of SST CH-TRU waste. These higher-strength simulant materials may support packaging equipment tests that assure that sorbent can be added in the desired fashion and that dewatered material can be packaged without excessive voids. Higher dilutions of the clay water mixtures produce a wide range of viscous slurries that have shear stress to shear rate relationships similar to TRU waste that was diluted 1:1 with water. These viscosity simulants may be used to show that retrieved wastes can be maintained in a mixed state and effectively delivered to the dewatering system.

Table 2.5 shows the expected clay and water contents that will be required to simulate the strength and flow characteristics of TRU waste at different points in the process. PNNL may modify the range of moisture contents and/or the ratio of the two clays when the data from additional TRU waste tests become available but does not currently anticipate a need for additional ingredients in the transport simulants. Clay/water physical transport simulants were prepared in the laboratory with the same materials and procedures described above for dewatering simulants.

Table 2.5. Kaolin:Bentonite/Water Formulations Required to Simulate Rheological Properties of TRU Waste

\begin{tabular}{|c|c|c|}
\hline \multirow[b]{2}{*}{ TRU Waste Property Simulated } & \multicolumn{2}{|c|}{ Transport Simulant Recipes } \\
\hline & $\begin{array}{c}\text { Clay }^{(\mathbf{a})}(\mathbf{w t} \%) \\
\text { Minimum-Maximum }\end{array}$ & $\begin{array}{c}\text { Water (wt\%) } \\
\text { Maximum-Minimum }\end{array}$ \\
\hline $\begin{array}{l}\text { Viscosity of nominally diluted TRU sludge received } \\
\text { from retrieval }\end{array}$ & $15-21$ & $85-79$ \\
\hline $\begin{array}{l}\text { Viscosity of highly diluted TRU sludge received from } \\
\text { retrieval (highest water fraction) }\end{array}$ & $8-10$ & $92-90$ \\
\hline $\begin{array}{l}\text { Shear strength of TRU material likely to meet free } \\
\text { liquid requirements (e.g., }>60 \mathrm{~Pa} \text { shear strength) }\end{array}$ & 30 & 70 \\
\hline Shear strength of weak undiluted TRU sludge in tank & 25 & 75 \\
\hline Shear strength of typical undiluted TRU sludge in tank & 42.5 & 57.5 \\
\hline $\begin{array}{l}\text { Shear strength of strongest expected dewatered TRU } \\
\text { sludge }\end{array}$ & 55 & 45 \\
\hline
\end{tabular}




\subsection{Technical Justification for Liquid Chemical Simulants}

This section discusses the rationale and data that were used to support the recommended liquid chemical simulant formulations shown in Tables 2.1 and 2.2. The data were gathered as part of scoping tests that led to the development of the final simulant formulations.

\subsection{B- and T-200 Series Tank Liquid Simulants}

As noted previously, three liquid simulant formulations were developed: two for the B-200 and T-200 series tanks and another for Tank T-110. The latter is assumed to represent Tank T-111 as well because Tanks T-110 and T-111 have similar waste histories. This section summarizes the available composition information, identifies assumptions in the liquid simulant formulations made to match the measured waste composition data, and describes the results for the laboratory preparation of preliminary simulant batches.

Information on the compositions of SST TRU waste liquids was derived from two sources. The first source comprised data downloaded from the Tank Characterization Database (TCD) in the Hanford Tank Waste Information Network System (TWINS). These data came from analyses of core and grab samples that were performed within months of the samples' acquisition and do not always include results for all constituents but are expected to be free of archiving artifacts. The second data source consisted of results from recent analyses conducted at the Hanford 222-S Laboratory on archived core samples from Tanks B203, T-203, T-204, and T-110. These samples had been stored in Pyrex ${ }^{\mathrm{TM}}$ jars for five or more years and were then composited, diluted, and centrifuged to produce liquid for analysis. Some archiving and dilution artifacts (e.g., evaporation, atmospheric $\mathrm{CO}_{2}$ absorption to form carbonate, etc.) could affect the analytical results for these samples.

As an approach to defining the TRU liquid simulant, PNNL estimated a composition for the average waste liquid in the B-200 and T-200 series waste tanks based on the TCD core sample data. Table 3.1 shows the reported liquid analyte concentration data used in this estimate, the liquid density, the weight fraction water, and appearance. The data are summarized for 11 samples taken from four of the eight B200 and T-200 series tanks. Each sample represents a unique location (different core and segment numbers) within the tanks. The data are generally consistent across the samples, with the possible exception of Tank T-203 core 190, segment 1R, which tends to be uniformly higher in analyte concentrations and density.

Table 3.1 also shows the simple numerical average concentration for the analytes, weighting each tabulated sample composition equally. In the cases of total inorganic carbon (TIC) and total organic carbon (TOC), the single available result in TCD from Tank B-203 core 120, segment 1 was assumed representative of all the waste samples. The recent analysis of archived B-203 samples showed lower values for TIC and similar results for TOC. In a few cases (e.g., oxalate, $\mathrm{C}_{2} \mathrm{O}_{4}$; manganese, $\mathrm{Mn}$; and uranium, $\mathrm{U}$ ), the majority of the analyte concentration data were reported as less than the minimum detection limit (shown in Table 3.1 with a "<" before a value). No average was calculated for these analytes. Oxalate, manganese, uranium, and all constituents that were uniformly below detection limits (aluminum, $\mathrm{Al}$; bismuth, $\mathrm{Bi}$; calcium, $\mathrm{Ca}$; iron, $\mathrm{Fe}$; lanthanum, $\mathrm{La}$; lead, $\mathrm{Pb}$; and zirconium, $\mathrm{Zr}$ ) were excluded from the liquid simulants. 
Table 3.1. TWINS Database Reported Composition and Properties for B-200 and T-200 Series Tank Core Liquid Samples (tank-core:segment)

\begin{tabular}{|c|c|c|c|c|c|c|c|c|c|c|c|c|}
\hline \multirow[b]{2}{*}{ Analyte } & \multicolumn{12}{|c|}{ Concentration $(\mu \mathrm{g} / \mathrm{mL})$} \\
\hline & $\begin{array}{c}\text { B-203- } \\
120: 1\end{array}$ & $\begin{array}{c}\text { B-203- } \\
122: 1\end{array}$ & $\begin{array}{c}\text { B-203- } \\
122: 3\end{array}$ & $\begin{array}{l}\text { B-204- } \\
112: 1\end{array}$ & $\begin{array}{c}\text { B-204- } \\
114: 1\end{array}$ & $\begin{array}{l}\text { T-201- } \\
\text { 192:1 }\end{array}$ & $\begin{array}{l}\text { T-201- } \\
192: 2\end{array}$ & $\begin{array}{l}\text { T-201- } \\
192: 3\end{array}$ & $\begin{array}{l}\text { T-201- } \\
192: 4\end{array}$ & $\begin{array}{l}\text { T-201- } \\
192: 5\end{array}$ & $\begin{array}{l}\text { T-203- } \\
\text { 190:1R }\end{array}$ & Average \\
\hline $\mathrm{Al}$ & $<10$ & $<10$ & $<10$ & $<10$ & $<5$ & $<10$ & $<2.6$ & $<2.6$ & $<2.6$ & $<2.6$ & $<5$ & NA \\
\hline $\mathrm{Bi}$ & $<20$ & $<20$ & $<20$ & $<20$ & $<10$ & $<20$ & $<5.1$ & 14 & 8.9 & 5.9 & $<10$ & NA \\
\hline $\mathrm{Ca}$ & $<20$ & $<20$ & $<20$ & $<20$ & $<10$ & $<20$ & $<5.1$ & $<5.1$ & $<5.1$ & $<5.1$ & $<10$ & NA \\
\hline $\mathrm{Cl}$ & 675 & 679 & 677 & 681 & 539 & 965 & 1020 & 895 & 900 & 989 & 707 & 793 \\
\hline $\mathrm{Cr}$ & 151 & 151 & 183 & 153 & 158 & 6.8 & 6.8 & 6.9 & 7.9 & 4.7 & 43 & 79 \\
\hline $\mathrm{C}_{2} \mathrm{O}_{4}$ & $<117$ & $<117$ & 486 & 753 & $<223$ & $<223$ & 135 & $<117$ & $<223$ & $<223$ & $<223$ & NA \\
\hline $\mathrm{F}$ & 5,920 & 6,080 & 6,110 & 6,770 & 5,860 & 4,210 & 4,430 & 3,870 & 4,280 & 4,700 & 7,020 & 5,390 \\
\hline $\mathrm{Fe}$ & $<10$ & $<10$ & $<10$ & $<10$ & $<<5$ & $<10$ & $<2.6$ & $<2.6$ & $<2.6$ & $<2.6$ & $<<5$ & NA \\
\hline $\mathrm{K}$ & 5,450 & 5,420 & 5,440 & 6,050 & 6,390 & 4,280 & 4,120 & 3,760 & 3,930 & 4,040 & 8,390 & 5,210 \\
\hline $\mathrm{La}$ & $<10$ & $<10$ & $<10$ & $<10$ & $<<5$ & $<10$ & $<2.6$ & 4.2 & $<2.6$ & $<2.6$ & $<<5$ & NA \\
\hline $\mathrm{Mn}$ & $<2$ & $<2$ & $<2$ & $<2$ & $<1$ & $<2$ & $<0.5$ & 3.9 & 1.8 & 1.1 & $<1$ & NA \\
\hline $\mathrm{Na}$ & 31,100 & 31,100 & 31,300 & 28,400 & 28,500 & 26,400 & 25,900 & 23,400 & 24,700 & 25,500 & 41,200 & 28,900 \\
\hline $\mathrm{NO}_{2}$ & 1,750 & 1,570 & 1,390 & 2,200 & 1,680 & 311 & 231 & 200 & 471 & 464 & 353 & 965 \\
\hline $\mathrm{NO}_{3}$ & 55,900 & 56,700 & 57,600 & 49,100 & 45,800 & 47,400 & 48,300 & 43,100 & 44,500 & 47,600 & 73,700 & 51,800 \\
\hline$\overline{\mathrm{OH}}$ & NA & NA & NA & NA & NA & NA & NA & NA & NA & NA & NA & NA \\
\hline $\mathrm{P}$ & 502 & 531 & 508 & 689 & 682 & 246 & 241 & 201 & 197 & 191 & 750 & 431 \\
\hline $\mathrm{Pb}$ & $<20$ & $<20$ & $<20$ & $<20$ & $<10$ & $<20$ & $<5.1$ & $<5.1$ & $<5.1$ & $<5.1$ & $<10$ & NA \\
\hline $\mathrm{S}$ & 101 & 96 & 92 & 134 & 139 & 37 & 41 & 37 & 38 & 39 & 125 & 80 \\
\hline $\mathrm{Si}$ & 88 & 63 & 66 & 50 & 67 & 41 & 55 & 58 & 63 & 42 & 52 & 59 \\
\hline TIC & 2,170 & NA & NA & NA & NA & NA & NA & NA & NA & NA & NA & 2,170 \\
\hline TOC & 96 & NA & NA & NA & NA & NA & NA & NA & NA & NA & NA & 96 \\
\hline $\mathrm{U}$ & 182 & 169 & 163 & 187 & 151 & $<100$ & $<26$ & $<26$ & $<26$ & $<26$ & $<50$ & NA \\
\hline $\mathrm{Zr}$ & $<2$ & $<2$ & $<2$ & $<2$ & $<1$ & $<2$ & $<0.5$ & $<0.5$ & $<0.5$ & $<0.5$ & $<1$ & NA \\
\hline Density $(\mathrm{g} / \mathrm{mL})$ & 1.05 & 1.06 & 1.06 & 1.06 & 1.04 & 1.05 & 1.06 & 1.05 & 1.06 & 1.06 & 1.09 & 1.06 \\
\hline $\mathrm{wt} \% \mathrm{H}_{2} \mathrm{O}$ & 89.7 & 89.8 & 89.3 & 89.2 & 88.9 & 91.0 & 91.1 & 91.8 & 91.3 & 91.0 & 85.3 & 89.8 \\
\hline Appearance & $\begin{array}{c}\text { clear } \\
\text { light } \\
\text { yellow }\end{array}$ & $\begin{array}{c}\text { opaque } \\
\text { black, } \\
\text { suspended } \\
\text { solids }\end{array}$ & $\begin{array}{c}\text { opaque } \\
\text { black }\end{array}$ & $\begin{array}{l}\text { clear } \\
\text { yellow }\end{array}$ & $\begin{array}{l}\text { opaque } \\
\text { brownish } \\
\text { gray }\end{array}$ & $\begin{array}{l}\text { slightly } \\
\text { cloudy } \\
\text { yellow }\end{array}$ & $\begin{array}{c}\text { opaque } \\
\text { black, } \\
\text { low } \\
\text { solids } \\
\end{array}$ & $\begin{array}{c}\text { opaque } \\
\text { black, } \\
\text { low } \\
\text { solids } \\
\end{array}$ & $\begin{array}{l}\text { opaque } \\
\text { black, } \\
\text { low } \\
\text { solids } \\
\end{array}$ & $\begin{array}{c}\text { opaque } \\
\text { black, } \\
\text { low } \\
\text { solids } \\
\end{array}$ & $\begin{array}{l}\text { opaque } \\
\text { black }\end{array}$ & NA \\
\hline
\end{tabular}


Based on the difference in TIC between the TCD data $(2,170 \mu \mathrm{g} / \mathrm{mL})$ and the recent archival analyses [67.2, 61.8, and $80.0 \mu \mathrm{g} / \mathrm{mL}$ for tanks B-203, T-203, and T-204, respectively (Cooke 2003)], we opted to vary the carbonate concentrations in the simulants. Because carbonate is more soluble in higher $\mathrm{pH}$ solutions, it was decided that the higher carbonate concentration given in the TCD for Tank B-203 (see Table 3.1) would be used in the target $\mathrm{pH} 12$ simulant and the average of the lower carbonate values from the recent archival analyses would be used in the target $\mathrm{pH} 10$ simulant. There was also a difference in the TOC values in the TCD $(96 \mu \mathrm{g} / \mathrm{mL})$ and the recent archival analyses [111, 122, and $417 \mu \mathrm{g} / \mathrm{mL}$ for tanks B-203, T-203, and T-204, respectively (Cooke 2003)]. We opted to vary the acetate concentrations in the simulants, using the TCD value in the $\mathrm{pH} 12$ simulant and the average of the archival analyses in the $\mathrm{pH} 10$ simulant. Owing to doubts about the effect of archiving and dilution of the samples upon the measured composition, the recent analyses of B-203, T-203, and T-204 were not used in simulant definition except for the TIC, TOC, and $\mathrm{pH}$ data (the latter are discussed below).

Although hydroxide concentrations were not reported for the samples shown in Table 3.1, $\mathrm{pH}$ values for a few Tank B-202 core composite samples were obtained from the TCD. The values ranged from $\mathrm{pH} 12.0$ to 12.4. The $\mathrm{pH}$ values measured in the recent analysis of archived samples from Tanks B-203, T-203, and T-204 ranged from 9.8 to 10.9 (Cooke 2003). The $\mathrm{pH}$ values measured at PNNL on the liquid recovered from water-diluted composite samples for these tanks ranged from 11.0 to 11.5 . ${ }^{\text {(a) }}$ Higher $\mathrm{pH}$ solutions tend to be less corrosive to steel, and lower $\mathrm{pH}$ solutions may be required to evaluate the full range of performance for handling and packaging the various TRU tank wastes. Therefore, the target $\mathrm{pH}$ 10 simulant is considered to be necessary. However, because the vulnerability of sorbents and final packaging materials to more alkaline solutions is unknown and given the higher historical $\mathrm{pH}$ values for B-202 samples, a pH 12 target simulant is also considered necessary.

A species charge balance calculation was conducted using the average analyte concentrations shown in Table 3.1, treating sodium $(\mathrm{Na})$ and potassium $(\mathrm{K})$ as metal cations and all other species as typical anion forms [e.g., sulfur as sulfate $\left(\mathrm{SO}_{4}{ }^{2-}\right)$, phosphorus as phosphate $\left(\mathrm{PO}_{4}{ }^{3-}\right)$, and chromium as chromate $\left(\mathrm{CrO}_{4}{ }^{2-}\right)$. Carbonate $\left(\mathrm{CO}_{3}{ }^{2-}\right)$ and acetate $\left(\mathrm{CH}_{3} \mathrm{COO}^{-}\right)$were used to represent TIC and TOC, respectively. Initial charge balance calculations for the target $\mathrm{pH} 12$ simulant indicated that the average actual waste solution contained an excess of anions ( $\sim 0.2 \mathrm{M}$ equivalents). Therefore, the nitrate concentration was decreased by $11 \%$ and the $\mathrm{Na}$ concentration was increased by $10 \%$ to achieve a charge balance. Because these two constituents had the highest concentrations, the charge balance could be adjusted by a less significant percentage change in their concentrations than in lower-concentration constituents. The charge-balanced formulation is shown in Table 3.2. The table also shows the small concentration of hydroxide $\left(0.02 \mathrm{M} \mathrm{OH}^{-}\right)$that was added to bring the $\mathrm{pH}$ to a target of approximately 12 or greater.

Initial charge balance calculations for the target $\mathrm{pH} 10$ simulant indicated that it contained an excess of cations ( $\sim 0.2 \mathrm{M}$ equivalents). Therefore, the $\mathrm{Na}$ concentration was decreased $13 \%$ to achieve a charge balance. As noted before, adjustment in $\mathrm{Na}$ was chosen because it is present in the highest concentration. The charge-balanced formulation is shown in Table 3.3.

The charge-balanced analyte concentrations for the target $\mathrm{pH} 12$ and target $\mathrm{pH} 10$ simulants in Tables 3.2 and 3.3 are summarized in Table 2.1 and are the basis for the simulant formulation given in Table 2.2. A $250-\mathrm{mL}$ test batch of the target $\mathrm{pH} 12$ simulant was found to have a $\mathrm{pH}$ of 12.4 and a density of

(a) Personal communication from C. Delegard and J. Gao of PNNL on June 20 and 23, 2003. 
Table 3.2. Charge Balance for B-200 and T-200 Series Liquid Simulant (target $\mathrm{pH} 12$ )

\begin{tabular}{|c|c|c|c|c|}
\hline Analyte & Analyte MW (g/mol) & $\begin{array}{c}\text { Analyte } \\
\text { Conc. }(\mu \mathrm{g} / \mathrm{mL})\end{array}$ & $\begin{array}{c}\text { Analyte } \\
\text { Conc. (M) }\end{array}$ & $\begin{array}{l}\text { "+ Charge" } \\
\text { Conc. (M) }\end{array}$ \\
\hline $\mathrm{K}+$ & 39.10 & 5,210 & 0.133 & 0.133 \\
\hline $\mathrm{Na}^{+}$ & 22.99 & $31,700^{\text {(a) }}$ & 1.38 & 1.38 \\
\hline Total & & & & 1.513 \\
\hline Analyte & Analyte MW (g/mol) & $\begin{array}{c}\text { Analyte } \\
\text { Conc. }(\mu \mathrm{g} / \mathrm{mL})\end{array}$ & $\begin{array}{c}\text { Analyte } \\
\text { Conc. (M) }\end{array}$ & $\begin{array}{l}- \text { Charge" } \\
\text { Conc. (M) }\end{array}$ \\
\hline $\mathrm{Cl}^{-}$ & 35.45 & 793 & 0.0224 & 0.0224 \\
\hline $\mathrm{F}^{-}$ & 19.00 & 5,390 & 0.283 & 0.283 \\
\hline $\mathrm{NO}_{2}^{-}$ & 46.01 & 965 & 0.0210 & 0.0210 \\
\hline $\mathrm{NO}_{3}^{-}$ & 62.00 & $46,300^{(\mathrm{b})}$ & 0.747 & 0.747 \\
\hline $\mathrm{S}\left(\right.$ as $\left.\mathrm{SO}_{4}{ }^{2-}\right)$ & 32.06 & 80 & 0.0025 & 0.00499 \\
\hline $\mathrm{P}\left(\right.$ as $\left.\mathrm{PO}_{4}^{3-}\right)$ & 30.97 & 431 & 0.0139 & 0.0417 \\
\hline $\mathrm{Si}\left(\right.$ as $\left.\mathrm{SiO}_{3}{ }^{2-}\right)$ & 28.09 & 59 & 0.0021 & 0.0042 \\
\hline TOC (as $\left.\mathrm{CH}_{3} \mathrm{COO}^{-}\right)$ & 12.01 & 96 & 0.00800 & 0.00400 \\
\hline $\mathrm{Cr}\left(\right.$ as $\left.\mathrm{CrO}_{4}^{2-}\right)$ & 52.00 & 79 & 0.00152 & 0.00304 \\
\hline $\mathrm{TIC}\left(\right.$ as $\left.\mathrm{CO}_{3}{ }^{2-}\right)$ & 12.01 & 2,170 & 0.181 & 0.361 \\
\hline $\mathrm{OH}^{-}$ & 17.01 & NA & $0.020^{(\mathrm{c})}$ & 0.020 \\
\hline Total & & & & 1.513 \\
\hline
\end{tabular}

Table 3.3. Charge Balance for B- 200 and T-200 Series Liquid Simulant (target $\mathrm{pH} 10$ )

\begin{tabular}{|c|c|c|c|c|}
\hline Analyte & $\begin{array}{c}\text { Analyte MW } \\
(\mathrm{g} / \mathrm{mol})\end{array}$ & $\begin{array}{c}\text { Analyte } \\
\text { Conc. }(\mu \mathrm{g} / \mathrm{mL})\end{array}$ & $\begin{array}{c}\text { Analyte } \\
\text { Conc. (M) }\end{array}$ & $\begin{array}{l}\text { "+ Charge" } \\
\text { Conc. (M) }\end{array}$ \\
\hline $\mathrm{K}+$ & 39.10 & 5,210 & 0.133 & 0.133 \\
\hline $\mathrm{Na}^{+}$ & 22.99 & $25,100^{\text {(a) }}$ & 1.090 & 1.090 \\
\hline Total & & & & 1.223 \\
\hline Analyte & $\begin{array}{c}\text { Analyte MW } \\
(\mathrm{g} / \mathrm{mol})\end{array}$ & $\begin{array}{c}\text { Analyte } \\
\text { Conc. }(\mu \mathrm{g} / \mathrm{mL})\end{array}$ & $\begin{array}{l}\text { Analyte } \\
\text { Conc. (M) }\end{array}$ & $\begin{array}{l}- \text { Charge" } \\
\text { Conc. (M) }\end{array}$ \\
\hline $\mathrm{Cl}^{-}$ & 35.45 & 793 & 0.0224 & 0.0224 \\
\hline $\mathrm{F}^{-}$ & 19.00 & 5,390 & 0.283 & 0.283 \\
\hline $\mathrm{NO}_{2}^{-}$ & 46.01 & 965 & 0.0210 & 0.0210 \\
\hline $\mathrm{NO}_{3}^{-}$ & 62.00 & 51,800 & 0.835 & 0.835 \\
\hline $\mathrm{S}\left(\right.$ as $\left.\mathrm{SO}_{4}{ }^{2-}\right)$ & 32.06 & 80 & 0.0025 & 0.00499 \\
\hline $\mathrm{P}\left(\right.$ as $\left.\mathrm{HPO}_{4}{ }^{2-}\right)$ & 30.97 & 431 & 0.0139 & 0.0278 \\
\hline $\mathrm{Si}\left(\right.$ as $\left.\mathrm{SiO}_{3}{ }^{2-}\right)$ & 28.09 & 59 & 0.0021 & 0.0042 \\
\hline TOC (as $\mathrm{CH}_{3} \mathrm{COO}^{-}$) & 12.01 & 217 & 0.0181 & 0.00903 \\
\hline $\mathrm{Cr}\left(\right.$ as $\left.\mathrm{CrO}_{4}{ }^{2-}\right)$ & 52.00 & 79 & 0.00152 & 0.00304 \\
\hline $\mathrm{TIC}\left(\right.$ as $\left.\mathrm{CO}_{3}{ }^{2-}\right)$ & 12.01 & 70 & 0.006 & 0.012 \\
\hline Total & & & & 1.223 \\
\hline
\end{tabular}


$1.073 \mathrm{~g} / \mathrm{mL}$, in good agreement with the tank waste average of $1.06 \mathrm{~g} / \mathrm{mL}$ (Table 3.1). A $250-\mathrm{mL}$ test batch of the target $\mathrm{pH} 10$ simulant was found to have a $\mathrm{pH}$ of 10.3 and a density of $1.060 \mathrm{~g} / \mathrm{mL}$, matching the observed average.

\subsection{T-110 Tank Simulant}

The Tank T-110 liquid simulant formulation was developed by considering both the original grab sample data from the TCD and the recent analysis of the diluted archived T-110 sample composite (Cooke 2003). Table 3.4 summarizes the composition and property information from the two sources. Both sources were considered in the case of T-110 because of the limited amount of data in the TCD. Additionally, initial charge balance calculations based on the TCD data indicated that the T-110 actual waste solution contained $\sim 0.6-\mathrm{M}$ equivalent excess of cations. Anionic species appeared to be significantly underrepresented by the TCD data. As indicated below, the decision to use the results of recent analyses was not clear-cut.

A comparison of the two analyses for T-110 shown in Table 3.4 led to two questions. First, was the original supernatant grab sample representative of the interstitial liquid in the sludge at the bottom of the tank, or only of the liquid layer at the top of the waste? And second, was the liquid centrifuged from the diluted composite of archived core samples representative of liquid existing in the tank? The archived composite sample was clearly severely dried out. Was the addition of water to the archived sample sufficient to reconstitute the waste to its original moisture content, or was the sample perhaps overdiluted? A density of $1.28 \mathrm{~g} / \mathrm{mL}$ was reported for a sample of the centrifuged liquid recovered from the diluted archive sample (Cooke 2003), much higher than is typical of other Hanford SST TRU liquids (e.g., 1.05 to $1.1 \mathrm{~g} / \mathrm{mL}$ ). Additionally, the concentrations of many of the species in the composite liquid were roughly triple the grab sample values (e.g., $\mathrm{Na}$ ). We concluded that the net effect of archiving and diluting had been to concentrate the original liquid by about a factor of three. Accordingly, we set most of the constituent concentrations in the simulant to $1 / 3$ of the values measured on the composite liquid. The exception was fluoride. The fluoride concentration was similar in the two analyses and was therefore considered saturated; it was set to the grab sample value. The recent archival analysis of T-110 showed such a low value for TIC that it was decided to completely eliminate it from the simulant composition.

Initial charge balance calculations for the Tank T-110 simulant indicated that it contained an excess of anions ( $\sim 0.2 \mathrm{M}$ equivalents). Therefore, the nitrate concentration was decreased by $7 \%$, and the $\mathrm{Na}$ concentration was increased by $8 \%$ to achieve a charge balance. Again, because these two constituents had the highest concentrations, the charge balance could be adjusted by a less significant percentage change in their concentrations than in lower-concentration constituents. Furthermore, reducing the nitrate concentration shifted the value toward the grab sample result. Table 3.5 shows the modified analyte concentrations used to obtain a charge balance for the T-110 simulant. 
Table 3.4. Reported Composition and Properties for Tank T-110 Liquid

\begin{tabular}{|c|c|c|}
\hline Analytes & $\begin{array}{c}\text { T-110 “Grab 1" } \\
\text { Conc. } \\
(\mu \mathrm{g} / \mathrm{mL}))^{(a)}\end{array}$ & $\begin{array}{c}\text { Diluted Archived T-110 } \\
\text { Core Composite } \\
(\mu \mathrm{g} / \mathrm{mL})^{(\mathrm{b})}\end{array}$ \\
\hline$\overline{\mathrm{Al}}$ & $<5$ & $<5$ \\
\hline $\mathrm{Bi}$ & $<10$ & $<10$ \\
\hline$\overline{\mathrm{Ca}}$ & $<10$ & $<10$ \\
\hline $\mathrm{Cl}$ & 958 & 3,960 \\
\hline $\mathrm{Cr}$ & 34 & 113 \\
\hline $\mathrm{C}_{2} \mathrm{O}_{4}$ & 0 & 0 \\
\hline $\mathrm{F}$ & 4,220 & 4,200 \\
\hline $\mathrm{Fe}$ & $<5$ & $<5$ \\
\hline $\mathrm{K}$ & 327 & 953 \\
\hline $\mathrm{La}$ & $<5$ & $<5$ \\
\hline $\mathrm{Mn}$ & $<1$ & $<1$ \\
\hline $\mathrm{Na}$ & 37,000 & 113,000 \\
\hline $\mathrm{NO}_{2}$ & 59 & 1,200 \\
\hline $\mathrm{NO}_{3}$ & 18,300 & 237,000 \\
\hline $\mathrm{OH}$ & $(\mathrm{pH} \mathrm{8.4)}$ & $\left(\mathrm{pH} \mathrm{8.4;8.9^{( \textrm {c } ) } )}\right.$ \\
\hline $\mathrm{P}$ & 5,555 & 11,200 \\
\hline $\mathrm{Pb}$ & $<10$ & $<10$ \\
\hline $\mathrm{S}$ & 1,590 & 3,870 \\
\hline $\mathrm{Si}$ & 64 & 256 \\
\hline TIC & not available & 7 \\
\hline TOC & 45 & 66 \\
\hline $\mathrm{U}$ & $<50$ & $70 \mu \mathrm{g} / \mathrm{g}$ \\
\hline $\mathrm{Zr}$ & $<1$ & $<1$ \\
\hline Density $(\mathrm{g} / \mathrm{mL})$ & 1.05 & $1.28^{(\mathrm{d})}$ \\
\hline $\mathrm{wt} \% \mathrm{H}_{2} \mathrm{O}$ & 86.8 & $65.7^{(\mathrm{d})}$ \\
\hline Appearance & clear dark yellow & not available \\
\hline \multicolumn{3}{|c|}{$\begin{array}{l}\text { (a) As reported in the Hanford TCD in January } 2003 \text {. } \\
\text { (b) Results of analyses completed at the Hanford } 222-\mathrm{S} \text { Lab (Cooke 2003). } \\
\text { (c) Higher } \mathrm{pH} \text { value measured on minimally diluted composite sample using } \\
\text { the solid pH method (Cooke 2003). } \\
\text { (d) Result for undiluted centrifuged liquid (Cooke 2003). }\end{array}$} \\
\hline
\end{tabular}

The $\mathrm{pH}$ values reported for the T-110 liquid grab sample in the TCD and for diluted archived composite (Cooke 2003) were both 8.4. A slightly higher $\mathrm{pH} 8.9$ value was reported for undiluted liquid recovered from centrifuged composite sample (Cooke 2003). In the interest of covering extreme $\mathrm{pH}$ values for liquids that might be retrieved from the Hanford SST TRU tanks, the Tank T-110 simulant target pH was set to the lower 8.4 value. 
Table 3.5. Charge Balance for $\mathrm{T}-110$ Liquid Simulant (target $\mathrm{pH} 8.4$ )

\begin{tabular}{|c|c|c|c|c|}
\hline Analyte & $\begin{array}{c}\text { Analyte MW } \\
\text { (g/mol) }\end{array}$ & $\begin{array}{l}\text { Analyte Conc. } \\
(\mu \mathrm{g} / \mathrm{mL})\end{array}$ & $\begin{array}{l}\text { Analyte } \\
\text { Conc. (M) }\end{array}$ & $\begin{array}{l}+ \text { Charge" } \\
\text { Conc. (M) }\end{array}$ \\
\hline $\mathrm{K}+$ & 39.10 & 318 & 0.00813 & 0.00813 \\
\hline $\mathrm{Na}^{+}$ & 22.99 & $40,500^{(\mathrm{a})}$ & 1.763 & 1.763 \\
\hline Total & & & & 1.771 \\
\hline Analyte & $\begin{array}{c}\text { Analyte MW } \\
\text { (g/mol) }\end{array}$ & $\begin{array}{c}\text { Analyte } \\
\text { Conc. }(\mu \mathrm{g} / \mathrm{mL})\end{array}$ & $\begin{array}{c}\text { Analyte } \\
\text { Conc. (M) }\end{array}$ & $\begin{array}{l}- \text { Charge" } \\
\text { Conc. (M) }\end{array}$ \\
\hline $\mathrm{Cl}^{-}$ & 35.45 & 1,320 & 0.0372 & 0.0372 \\
\hline $\mathrm{F}^{-}$ & 19.00 & 4,200 & 0.221 & 0.221 \\
\hline $\mathrm{NO}_{2}^{-}$ & 46.01 & 400 & 0.00869 & 0.00869 \\
\hline $\mathrm{NO}_{3}^{-}$ & 62.00 & $73,200^{(b)}$ & 1.181 & 1.181 \\
\hline $\mathrm{S}\left(\right.$ as $\left.\mathrm{SO}_{4}{ }^{2-}\right)$ & 32.06 & 1,290 & 0.0402 & 0.0805 \\
\hline $\mathrm{P}\left(\right.$ as $\left.\mathrm{HPO}_{4}{ }^{2-}\right)$ & 30.97 & 3,730 & 0.1139 & 0.2278 \\
\hline $\mathrm{P}\left(\right.$ as $\left.\mathrm{H}_{2} \mathrm{PO}_{4}^{-}\right)$ & 30.97 & & 0.0066 & 0.0066 \\
\hline $\mathrm{Si}\left(\right.$ as $\left.\mathrm{SiO}_{3}{ }^{2-}\right)$ & 28.09 & 85 & 0.00303 & 0.00605 \\
\hline $\begin{array}{l}\mathrm{TOC} \text { (as } \\
\left.\mathrm{CH}_{3} \mathrm{COO}^{-}\right)\end{array}$ & 12.01 & 22 & 0.00183 & 0.000916 \\
\hline $\mathrm{Cr}\left(\right.$ as $\left.\mathrm{CrO}_{4}{ }^{2-}\right)$ & 52.00 & 38 & 0.00073 & 0.00146 \\
\hline Total & & & & 1.771 \\
\hline
\end{tabular}

The charge-balanced analyte concentrations for the T-110 simulant shown in Table 3.5 are reflected in the composition and formulation values given in Tables 2.1 and 2.2 (Section 2.1). Note that the T-110 simulant uses a combination of dibasic sodium phosphate $\left(\mathrm{Na}_{2} \mathrm{HPO}_{4}\right)$ and monobasic sodium phosphate $\left(\mathrm{NaH}_{2} \mathrm{PO}_{4}\right)$ rather than the sodium phosphate $\left(\mathrm{Na}_{3} \mathrm{PO}_{4}\right)$ that was used in the target $\mathrm{pH} 12$ liquid simulant or the $\mathrm{Na}_{2} \mathrm{HPO}_{4}$ that was used in the target $\mathrm{pH} 10$ simulant. Early attempts to use $\mathrm{Na}_{3} \mathrm{PO}_{4}$ in the T-110 simulant provided approximately $10 \%$ more $\mathrm{Na}$ but also resulted in a solution $\mathrm{pH}$ of $\sim 12.5$, much higher than that reported $\left(\mathrm{pH}\right.$ 8.4). Using $\mathrm{Na}_{2} \mathrm{HPO}_{4}$ as the sole phosphate source also provided more $\mathrm{Na}$ but resulted in a $\mathrm{pH}$ of $\sim 10$ instead of 8.4. Using a combination of $\mathrm{Na}_{2} \mathrm{HPO}_{4}$ and $\mathrm{NaH}_{2} \mathrm{PO}_{4}$ and other reagents as specified in Table 2.2, the final $\mathrm{pH}$ of a $100-\mathrm{mL} \mathrm{T}-110$ simulant test batch was 8.3 . The $\mathrm{pH}$ of this waste and the corresponding simulants are controlled by the relatively abundant dissolved phosphate species. Dilution with water has little impact on the $\mathrm{pH}$ of these highly buffered solutions. This was observed in analyses performed at PNNL on the archived composites; there was virtually no change in the $\mathrm{pH}(\sim 8.3)$ in a nominal 4 to 1 dilution of the composite with water. ${ }^{(\mathrm{a})}$ The T-110 simulant solution density was measured at $1.096 \mathrm{~g} / \mathrm{mL}$.

(a) Personal communications from C. Delegard and J. Gao of PNNL on June 20 and 23, 2003. 


\subsection{Technical Justification of Physical Simulants-Dewatering and Rheological Properties}

This section provides the basis for the physical simulant recipes shown in Tables 2.3 through 2.5. Following a discussion of the experimental approach, sections are devoted to the development of clay simulants intended for testing dewatering processes (Section 4.2, centrifugal and gravity settling) and physical simulants representing key rheological properties (Section 4.3, shear strength and viscosity). Experimentally determined clay simulant physical properties are compared to reported properties for Hanford SST TRU waste samples.

\subsection{Experimental Approach}

This section describes the experimental approach for developing and testing physical simulants representative of key physical properties of Hanford CH-TRU wastes. The graded quality assurance (QA) approach is reiterated, leading to a discussion of the materials used to prepare the simulants and the experimental methods applied to evaluate the simulant physical properties.

\subsubsection{Quality Assurance-Graded Approach}

Experiments to develop physical simulants started with clays and other materials readily available in the laboratory. In these scoping studies, methods and standard experimental approaches were developed to prepare and assess the simulant physical properties. These methods and the available materials were used to screen a variety of simulant formulations. A few selected simulants were run through a full suite of "scoping" tests to assess dewatering and rheological properties. After final simulant formulations were identified, established written procedures and traceable materials were used in physical property validation tests. As noted in the Introduction (Section 1), these "validation" tests were conducted in accordance with NQA-1 requirements for quality assurance. Thus, the physical simulant development effort represents a graded QA approach, progressing from scoping to validation studies. In the QA validation tests, greater precautions were taken to assure that reproducible preparation and measurement procedures were followed and carefully documented. However, the scoping test data were typically obtained with comparable procedures and using the same instrumentation and test equipment.

Although some differences in scoping and validation test results were observed, they were not sufficient to warrant significant formulation adjustments. As presented in Sections 4.2 and 4.3 to follow, the differences appear to be due primarily to changes in the bentonite clay source and not to the simulant preparation or measurement methods.

\subsubsection{Simulant Materials and Preparation}

Clay/water mixtures are purely physical simulants in the sense that they have no appreciable watersoluble species and therefore are likely to show repeatable physical properties independent of dilution. Two clay types, bentonite and kaolin, were investigated in various combinations to provide the best match of limited actual waste properties. Physical simulant development was based on known attributes of the 
individual clays. Bentonite clay is typically composed of very thin $(0.001$ to $0.01 \mu \mathrm{m})$, small-diameter ( 0.1 to $1 \mu \mathrm{m})$, plate-shaped montmorillonite particles; when mixed with water, their sheet structures are known to produce somewhat elastic pastes that have relatively high shear strength at low solids content (Powell et al. 1997). The bentonite strength/solids relationship allows for an improved match of actual TRU waste bulk density (see Section 4.3.1). Kaolin clay, composed of the mineral kaolinite, has somewhat larger $(0.3$ to $3 \mu \mathrm{m})$ and thicker $(0.03$ to $1 \mu \mathrm{m})$ plate-shaped particles (Powell et al. 1997). Because the kaolin particles are expected to be somewhat larger and rounder than bentonite particles and both clays have roughly the same particle density, kaolin/water suspensions were expected to settle and separate water more readily than their bentonite counterparts. Further, bentonite clays are known to undergo osmotic swelling when exposed to water (Powell et al. 1997), and therefore dewatering of bentonite/water mixtures is less energetically favored.

Commercial off-the-shelf materials were used in the physical simulants. To assure the clays used in the simulants were traceable for QA purposes, new bags of clay were acquired for the QA validation studies. Unless otherwise specified, opened bags of (old) kaolin and bentonite available in the laboratory were used in all scoping tests, and previously unopened bags of clay, identified as 'new', were used in all QA validation studies. Table 4.1 summarizes source and product information for the kaolin and sodium bentonite clays used in simulant development.

Table 4.1. Summary of Bentonite and Kaolin Clays Used in Simulant Development

\begin{tabular}{|l|c|c|c|c|}
\hline \multirow{2}{*}{ Information/Property } & \multicolumn{2}{|c|}{ Bentonite Clay } & \multicolumn{2}{c|}{ Kaolin Clay } \\
\cline { 2 - 5 } & Scoping Tests & $\begin{array}{c}\text { Validation } \\
\text { Tests }\end{array}$ & Scoping Tests & $\begin{array}{c}\text { Validation } \\
\text { Tests }\end{array}$ \\
\hline Age Reference in Report & 'old' & 'new' & 'old' & 'new' \\
\hline Brand & Big Horn ${ }^{\circledR}$ & Big Horn & EPK & EPK \\
\hline Grade & $\begin{array}{c}\text { CH-200, } \\
\text { Powdered }\end{array}$ & $\begin{array}{c}\text { CH-200, } \\
\text { Powdered }\end{array}$ & Pulverized & Pulverized \\
\hline Supplier & $\begin{array}{c}\text { WYO-BEN, } \\
\text { Inc. }\end{array}$ & $\begin{array}{c}\text { WYO-BEN, } \\
\text { Inc. }\end{array}$ & $\begin{array}{c}\text { EPK Div. of } \\
\text { Feldspar }\end{array}$ & $\begin{array}{c}\text { EPK Div. of } \\
\text { Feldspar }\end{array}$ \\
\hline Lot No. or Other Bag ID & 07199522 & 05050121 & Not available ${ }^{(\mathrm{a})}$ & $319261-01$ \\
\hline Expected Moisture Content $(\%)^{(b)}$ & 6 to 9 & 6 to 9 & 1 to 3 & 1 to 3 \\
\hline $\begin{array}{l}\text { Measured Moisture Content at } 105^{\circ} \mathrm{C} \\
\text { (wt\%) }\end{array}$ & 6.3 & 7.0 & 0.9 & 1.0 \\
\hline $\begin{array}{l}\text { Measured Moisture Content at } 250^{\circ} \mathrm{C} \\
\text { (wt\%) }\end{array}$ & 6.8 & 7.6 & 1.5 & 1.5 \\
\hline
\end{tabular}

(a) The bag of old clay was obtained from the same supply as the new material, so they are likely from the same lot.

(b) As reported in current supplier technical or product information.

The clay moisture content was spot checked by oven drying samples. Approximately 1.2-g of each clay was dried over multiple nights in a forced convection oven, first at $105^{\circ} \mathrm{C}$ and then at $250{ }^{\circ} \mathrm{C}$. The change in sample mass from the initial value was measured for each drying temperature. All mass loss was assumed to be due to release of moisture, and the measured moisture contents are tabulated in Table 4.1. Little obvious difference was found between the clays used in scoping and validation tests. However, 
bentonite clay has a somewhat higher moisture content (6-8 \%) than the kaolin (1-2\%). This difference is expected based on product information sheets available from the suppliers.

Depending on the experimental requirements, $\sim 150 \mathrm{~mL}$ to $1.5 \mathrm{~L}$ laboratory batches of clay simulants were prepared by weighing the required amounts of kaolin and bentonite and thoroughly mixing the clay powders before combining them with a weighed amount of deionized ( $>17 \mathrm{M} \Omega$-cm resistivity) water. In the formulations reported, the "dry" clay powders were used as-is with no adjustment in material weights for the clay moisture content. The dry ingredients were slowly added to the water while the batch was mixed with a kitchen-type stand mixer (e.g., KitchenAid ${ }^{\circledR}$ with a $41 / 2$-qt-mixing bowl). The mixer speed set to avoid splattering material out of the bowl. To achieve complete mixing, the sides and bottom of the mixing bowl were occasionally scraped and the simulant folded back to the center of the bowl. The total mixing time was typically 10 to $20 \mathrm{~min}$.

\subsubsection{Experimental Methods}

Scoping and validation tests were completed to assess the dewatering and rheological properties of prepared simulants. The dewatering tests are gravity settling and centrifugal settling/compaction, and the rheology tests are shear strength for more concentrated slurries and sludges and viscosity for more dilute slurries. The experimental methods are described below.

\subsubsection{Dewatering}

Numerous bench-scale laboratory tests were completed on simulants with varying kaolin:bentonite clay ratios and water contents to assess their dewatering behavior. Centrifuge tests were run with $\sim 50 \mathrm{~g}$ of prepared simulant weighed into $50-\mathrm{mL}$ graduated plastic centrifuge tubes with lids. Similarly, either $\sim 35 \mathrm{~mL}$ (scoping tests) or $\sim 50 \mathrm{~mL}$ (validation tests) simulant was added to centrifuge tubes for gravity settling experiments. Generally, simulant was added to the centrifuge tubes immediately after preparation while still mixed; if not, stored or aged material was re-mixed by hand with a spatula or by shaking in a closed container before placing an aliquot of simulant in the centrifuge tube. In all cases, dilute simulant slurries and aged materials were mixed just prior to the start of gravity settling and centrifuge tests.

Just after final mixing, gravity-settling experiments were started by placing the centrifuge tubes on a bench top in a vertical orientation. The samples were left undisturbed and the settling progress was monitored in time by recording the volume at the solid/liquid interface, if present. The volume fraction of settled/compacted material at a given time was determined by dividing the volume of settled solids by the total sample volume.

Centrifugal dewatering tests were completed using a Damon IEC HN-SII bench top centrifuge. This centrifuge was set with an eight-position $30^{\circ}$ fixed-angle rotor (catalogue number 816) holding 50-mL centrifuge tubes. In this configuration, the minimum, average, and maximum distances of a centrifuge tube from the center of the rotor (radius $r$ ) are approximately 5.3, 8.4, and $11.4 \mathrm{~cm}$. The centrifugal force was controlled by the rotational speed $(v)$ of the centrifuge which was read from an analog gauge on the centrifuge; the maximum speed was $3500 \mathrm{rpm}$ with the installed rotor. The $\mathrm{G}$ force is given by 


$$
\operatorname{Force}(\mathrm{G})=\frac{(2 \pi v r)^{2}}{r g}
$$

where $g$ is the gravitational acceleration constant. At the maximum centrifuge speed and the average sample radius, the centrifugal force calculated using Eq. 4.1 is $1150 \mathrm{G}$, which is subsequently identified as $\sim 1000 \mathrm{G}$. In some experiments, the centrifuge speed was reduced to either $1700 \mathrm{rpm}$ or $2500 \mathrm{rpm}$, corresponding to average centrifuge forces of $270 \mathrm{G}(\sim 250 \mathrm{G})$ and $585 \mathrm{G}(\sim 500 \mathrm{G})$, respectively.

The settling and compaction effectiveness in the centrifuge was quantified by decanting and weighing the liquid separated by centrifugation or, alternatively, by weighing the centrifuge tube (tare weight measured separately) and compacted sludge after the liquid was decanted. Assuming the decanted liquid is water with negligible solids (density of $1.00 \mathrm{~g} / \mathrm{mL}$ ), the masses of solids and water in the residual sludge can be calculated from the mass of sample added to the centrifuge tube and the proportions of solids and water in the prepared simulant. This method was used to calculate the reported weight fractions of solids in the residual settled sludge. In centrifuge dewatering validation tests, the volume of decanted liquid was also measured in graduated cylinders, and within the experimental error $(\sim \pm 0.02 \mathrm{~g} / \mathrm{mL})$, liquid densities near water were confirmed. In most experiments, the decanted liquid was returned to the centrifuge tube and the centrifuge was run for additional time. The cumulative run time for the series of centrifuge operations is reported.

As noted above, simulant experiments were quantified on a mass basis, and many results presented below are given in mass terms. However, for waste processing purposes and for comparison with actual waste data, the volumes of as-prepared and settled simulant are also of interest. The volume and mass are simply related through the simulant sludge density. The kaolin and/or bentonite clay/water sludge density is readily estimated from the clay particle and water densities, assuming minimal air is entrained in the sludge matrix

$$
\rho_{\text {bulk }}(g / m L)=\frac{1}{x_{k} / \rho_{k}+x_{b} / \rho_{b}+\left(1-x_{k}-x_{b}\right) / \rho_{w}}
$$

In Eq. 4.2, $\rho_{\mathrm{k}}$ is the kaolin particle density $\left(2.65 \mathrm{~g} / \mathrm{mL}\right.$; Powell et al. 1997), $\rho_{\mathrm{b}}$ is the bentonite particle density $\left(2.55 \pm 0.1 \mathrm{~g} / \mathrm{mL}^{(a)}\right)$, and $\rho_{\mathrm{w}}$ is the density of water, and $\mathrm{x}_{\mathrm{k}}$ and $\mathrm{x}_{\mathrm{b}}$ are the mass fractions of kaolin and bentonite in the sludge matrix [where the mass fraction of water is given by $\left(1-x_{k}-x_{b}\right)$ ].

In centrifuge dewatering validation studies, many simulants consisting of $80-w t \%$ kaolin: 20 -wt $\%$ bentonite solids mixed in various proportions with water were prepared and centrifuged. The total volume of material was measured after centrifugation, and using the mass of simulant added to the centrifuge tube, a measured bulk sample density is determined. The measured densities for samples ranging from 8.5 to 42.5 -wt $\%$ total kaolin and bentonite solid contents are shown in Table 4.2 along with the densities calculated using Eq. $4.2\left(\rho_{\mathrm{w}}=0.998 \mathrm{~g} / \mathrm{mL}\right)$. Where standard deviations are reported, three samples of nominally the same composition were analyzed. The agreement in calculated and measured densities justifies the use of Eq. 4.2 to convert sludge solids contents from a mass to a volume basis.

(a) As reported on the WYO-BEN Technical Information Sheet for CH 200 grade bentonite, Rev 6/99. 
Table 4.2. Measured and Calculated Bulk Densities of 80:20 Kaolin:Bentonite Simulants

\begin{tabular}{||c|c|c||}
\hline $\begin{array}{c}\text { Solids } \\
\mathbf{( w t} \%)\end{array}$ & $\begin{array}{c}\text { Calculated } \\
\text { Density }(\mathbf{g} / \mathbf{m L})\end{array}$ & $\begin{array}{c}\text { Measured Density } \\
\mathbf{\pm} \text { Std. Dev. }(\mathbf{g} / \mathbf{m L})\end{array}$ \\
\hline 8.5 & 1.05 & $1.043 \pm 0.008$ \\
\hline 21.25 & 1.15 & $1.145 \pm 0.005$ \\
\hline 25 & 1.18 & 1.17 \\
\hline 30 & 1.23 & 1.22 \\
\hline 35 & 1.27 & 1.30 \\
\hline 42.5 & 1.36 & 1.35 \\
\hline
\end{tabular}

\subsubsection{Rheology}

The viscosity and shear strengths of various simulant preparations were measured on Haake rheometers. The validation study rheology tests were made in accordance with the PNNL procedure "Measurement of Physical and Rheological Properties of Solutions, Slurries and Sludges," RPL-COLLOID-02 Rev. 0 (or, equivalently, TPR-RPP-WTP-211 Rev. 0). A key aspect of the procedure is that the system performance is checked within $\sim 30$ days of the test using certified viscosity standards. In the validation studies, the system checks were performed within days of the analyses. Scoping studies were generally performed on the same instruments and followed the guidelines of the formal procedure.

Both scoping and validation study shear strength measurements were made on a Haake rheometer with an M5 head and 4-bladed, cross-pattern shear vanes. Just prior to completing the shear strength validation measurements, the torque measurement system had been calibrated on-site, and as noted above, a viscosity standard $(100 \mathrm{cP})$ was used to confirm acceptable performance. The shear strength is determined from the maximum torque required to rotate a shear vane submerged at least one vane height into the test material. A nominally 1.6-cm high and 1.6-cm diameter shear vane was used for all validation test measurements. Additional details of the shear strength calculation and the dimensions of other vanes used in scoping tests are provided in the Appendix (A.2). Shear strength measurements were made on samples stored at room temperature $\left(\sim 22{ }^{\circ} \mathrm{C}\right)$, and typically, $\sim 300 \mathrm{~mL}$ of simulant was contained in 1-pint glass jars.

The viscosity validation test measurements for diluted kaolin and 80:20 kaolin:bentonite simulants were made on a Haake RS600 rheometer with a concentric-cylinder geometry system. The concentric cylinder gap was $0.99 \mathrm{~mm}$, and the jacketed cell was temperature controlled at $25^{\circ} \mathrm{C}$. A 10-cP viscosity standard was used to check the system performance. As discussed in Section 4.3.2, the apparent viscosity is determined from the measured shear stress as a function of shear rate. Shear stress measurements were made as the shear rate was adjusted from 0 to $1000 \mathrm{~s}^{-1}$ (up curve) and back to 0 (down curve) at scan rates of $200 \mathrm{~s} \mathrm{~s}^{-1} / \mathrm{min}$. Two up and down curves were recorded consecutively for each sample. Significant hysteresis in the first and second up curves was noted for most of the simulant samples. This is not unusual for slurry rheology as particle and fluid orientation is established during the initial shearing cycle. The $2^{\text {nd }}$ up curves, which were generally comparable to both down curves, indicated higher viscosity for most of the simulants. Therefore, these more conservative experimental results are presented in the summary given in Section 4.3.2. The detailed experimental results for all viscosity validation runs are provided in the Appendix (A.3). 
A few viscosity scoping tests were completed on the Haake M5 rheometer with an MV1 sensor system. Only first up and down curves were obtained and the viscosity cell was held at room temperature. Because of the hysteresis in the first and second cycles noted in validation tests and the sensitivity of slurry viscosity measurements to factors such as sample loading technique and temperature, only the validation test results are included here.

\subsection{Dewatering Simulants}

Several desirable properties of a dewatering simulant were determined from the TRU waste behavior noted in the limited dewatering data available from earlier tests on SST TRU waste core samples and from recent preliminary results from tests on archived TRU waste samples. Other desirable properties of the dewatering simulant are based on the planned acceptance testing for the Hanford SST CH-TRU waste handling and packaging system. Also, from a practicality standpoint, the dewatering simulants were kept as simple as possible to minimize the number of ingredients and the sensitivity to preparation techniques.

Waste settling (and compaction) is a function of many factors including particle/agglomerate size, ${ }^{(a)}$ solid and liquid densities, and liquid viscosity. No attempt was made to match these properties individually, but rather a general match of the significant actual waste settling characteristics (i.e., settled sludge volumes and/or settling rates) was sought. This section summarizes available actual waste centrifugedsettling and gravity-settling characteristics as a basis for comparison with experiments conducted with kaolin:bentonite/water and kaolin/water simulants. The dewatering behavior of the simulants is shown to be reproducible and to vary in a consistent manner as a function of initial moisture content, applied settling force, and time. For a centrifugal dewatering process, an 80:20 wt\% kaolin:bentonite clay solids mixture with water is shown to be the preferred simulant, whereas a mixture of kaolin and water is a better match for gravity settling process steps. The simulants are also noted to be reusable, a benefit for long-term testing requiring large quantities of material.

\subsubsection{Centrifugal Dewatering Behavior}

A summary of available dewatering data for SST TRU wastes determined from gravity and centrifugal settling/compaction studies is presented in Rassat et al. (2003). Figure 4.1 is derived from those data and shows the volume of compacted TRU sludge (solids and interstitial liquid) obtained after centrifuging as a percentage of the quantity of sludge expected for two dilutions of waste with water (volume ratios 1:1 and 3:1 water:waste). ${ }^{\text {(b) }}$ As-received and two diluted TRU sludge samples from Tank B-201 were centrifuged for 1 hour at $>1000 \mathrm{G}$ ( $1 \mathrm{G}$ is the force of gravity on Earth). In all but one case, the volume of settled sludge after centrifuging was near $( \pm 20 \%)$ the expected level based on the volume of sludge added to each dilution. The unexpectedly low settled sludge volume for the 3:1 diluted sample (Tank B-201, core 26, segment 1) could only result from more efficient packing or dissolution of some of the waste solids into the dilution water. Because this particular sample also had a reduced settled sludge density, indicating less efficient packing, the low settled sludge volume was likely caused by dissolution of solids.

(a) Particle size distribution data for waste samples from Tanks B-201 and T-111 are summarized in Rassat et al. (2003). For both wastes, the mean and median number densities range from 0.9 to $1.6 \mu \mathrm{m}$ and 0.8 to $1 \mu \mathrm{m}$, respectively. On a volume basis, the mean particle sizes are 7 to $70 \mu \mathrm{m}$.

(b) The "expected" amount is estimated from the volume fraction of centrifuged sludge obtained by centrifuging undiluted, as-received waste. By definition, the expected volume fraction for as-received waste is 1. 


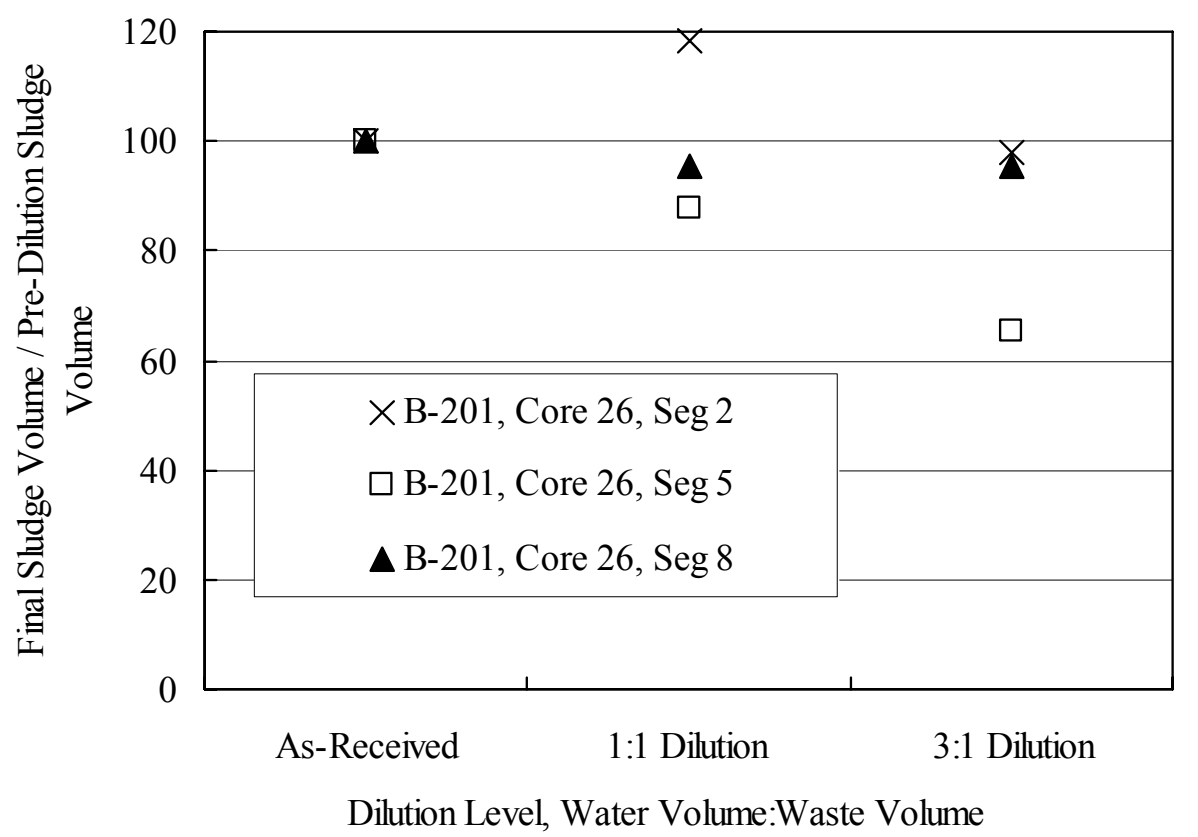

Figure 4.1. Relative Quantity of Centrifuged B-201 TRU Sludge Recovered as a Function of Water Dilution Level

Additional centrifuge settling tests were recently conducted and reported by Tingey et al. ${ }^{(a)}$ Samples from three different tanks were diluted to obtain different starting total solids ${ }^{(b)}$ contents and centrifuged at $\sim 1000 \mathrm{G}$ for 15,30 , and 90 minutes. These tests showed that the volume of centrifuged solids quickly ( $<15 \mathrm{~min}$ ) reached a final value for the samples with lower total solids contents, while samples with higher total solids loading took up to 90 minutes to reach a final value. The final centrifuged solids volume obtained after 90 minutes is plotted as a function of total solids content in the sample in Figure 4.2. The straight-line fits in these plots show that, with sufficient time in the centrifuge, the volume of centrifuged sludge varies consistently with the solids mass in the sample. This linear relationship is possible for a centrifuged sludge product attaining a constant density regardless of initial dilution. ${ }^{\left({ }^{(}\right)}$ However, as suggested by the different slopes for the three waste samples, the end-state settled sludge properties may be different for each tank. The data in Figures 4.1 and 4.2 suggest that the ability of a dewatering simulant to return to the same settled sludge consistency (e.g., sludge volume occupied for a given solids content) regardless of initial dilution is a desirable property.

(a) Tingey JM, J Gao, LM Bagaasen, and BE Wells. May 2003. Physical Property and Rheological Testing of Actual Transuranic Waste from Hanford Single-Shell Tanks. Letter report ST03.016, PNNL. A publicly-released PNNL-report version of this document is expected in late summer of 2003.

(b) The total solids of actual waste, measured by heating and drying samples, includes a small contribution from salt solids initially dissolved in the interstitial liquid.

(c) A constant sludge density is not a requirement for the linear relationship shown in Figure 4.2. It could also result for centrifuged sludge densities that vary linearly with total solids content. 


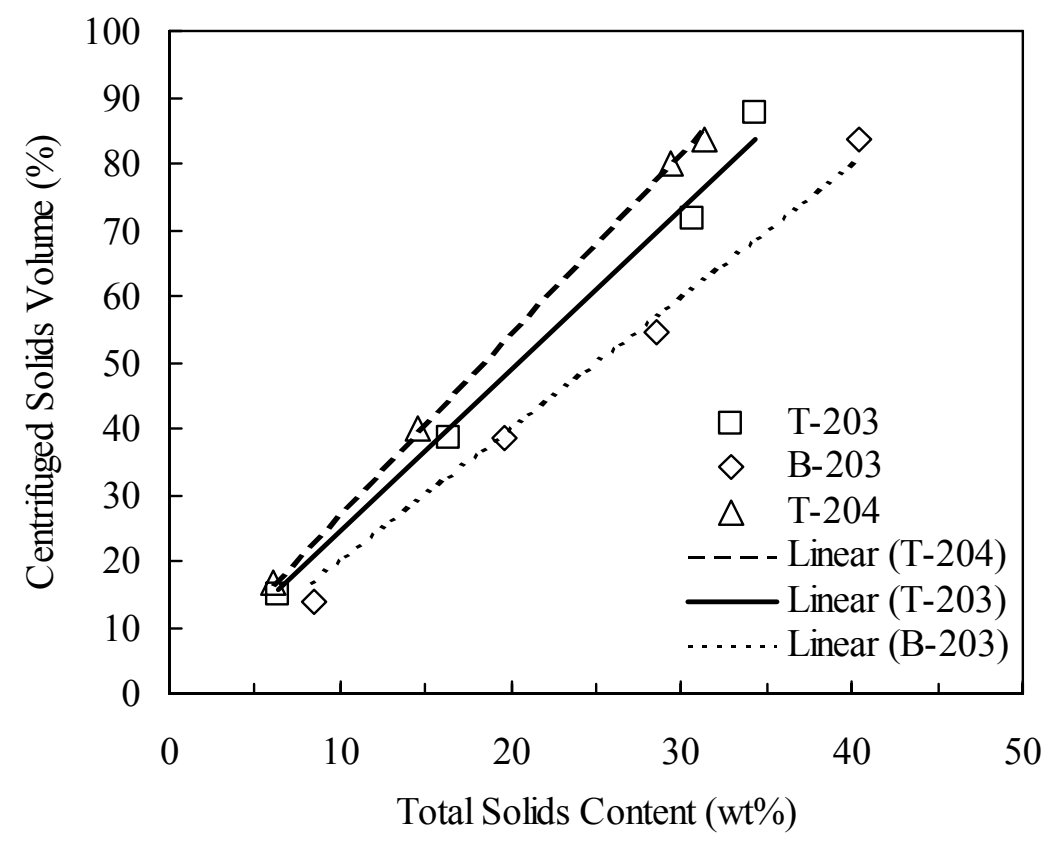

Figure 4.2. Centrifuged Sludge Volume Fraction as a Function of Initial Solids Content for Diluted TRU Waste Samples

Initial investigations looked at single-component clay systems in combination with water. Bentonite/ water mixtures were very difficult to centrifuge, producing uncharacteristically small volumes of separable liquid and large volumes of centrifuged sludge in 90 minutes or longer, and were dismissed as a possible physical simulant. Kaolin/water mixtures showed more promise and were extensively studied to understand the centrifugal and settling behavior. The kaolin/water mixtures consistently dewatered to nominally the same end moisture content under given centrifuge conditions (i.e., residence time and force), regardless of starting moisture content. These simulants also behaved predictably when different settling forces were applied for constant periods of time in that higher solids contents were obtained with higher applied settling force and that simulants having lower initial solids content dewater to lower settled solids loading. This behavior is shown in Figure 4.3, which presents the final settled solids contents of different kaolin/water mixtures after centrifuging for 90 minutes at different applied settling forces. At $\sim 1000 \mathrm{G}$, the settled sludge solids content varies in a narrow range ( $\sim 60$ to $70 \mathrm{wt} \%$ solids) for initial kaolin/water slurries ranging from 15.4 to $62.5 \mathrm{wt} \%$ solids. This variation in final settled solids may be due to the samples with higher starting solids content creating deeper beds of settled solids that exert more lithostatic load on the lower segments of the settled layer, resulting in greater compaction and higher solids loading. Additional experimental results for the centrifugal dewatering of kaolin/water mixtures as a function of applied settling force and time are provided in the appendix (A.1).

While Figure 4.3 depicts predictable centrifuge dewatering performance for the kaolin/water system, Figure 4.4 shows that the centrifuged sludge volume for a given starting solids content was significantly lower for the kaolin/water mixtures than for the B- and T-200 series tank waste samples. (The linear regression TRU waste data are reproduced from Figure 4.2.) Figure 4.4 indicates that the volume of centrifuged kaolin sludge for a given solid content is considerably lower than the actual wastes. This prompted additional experiments to see if combinations of kaolin and bentonite clay in water would better 


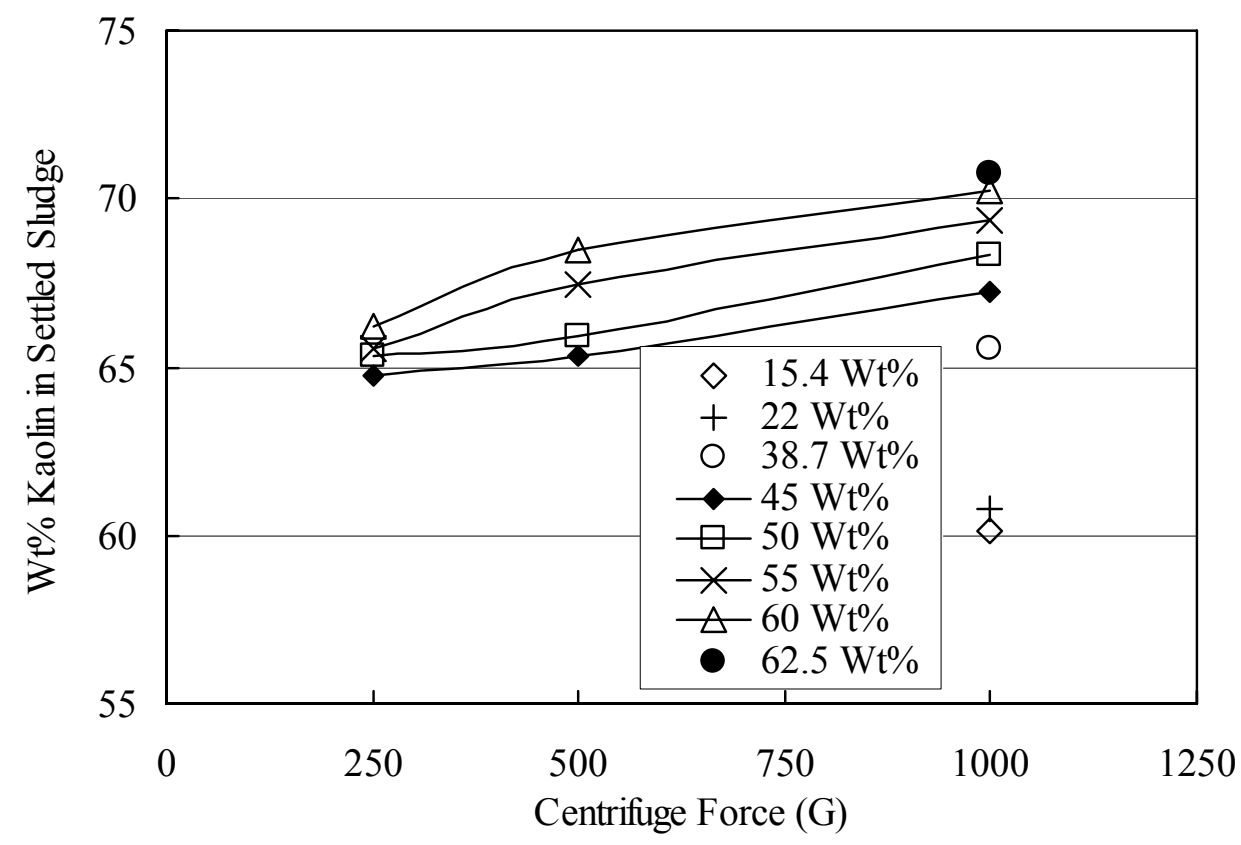

Figure 4.3. Final Settled Solids Content as a Function of Original Dilution and Applied G Force for Kaolin/Water Simulants Centrifuged for 90 min.

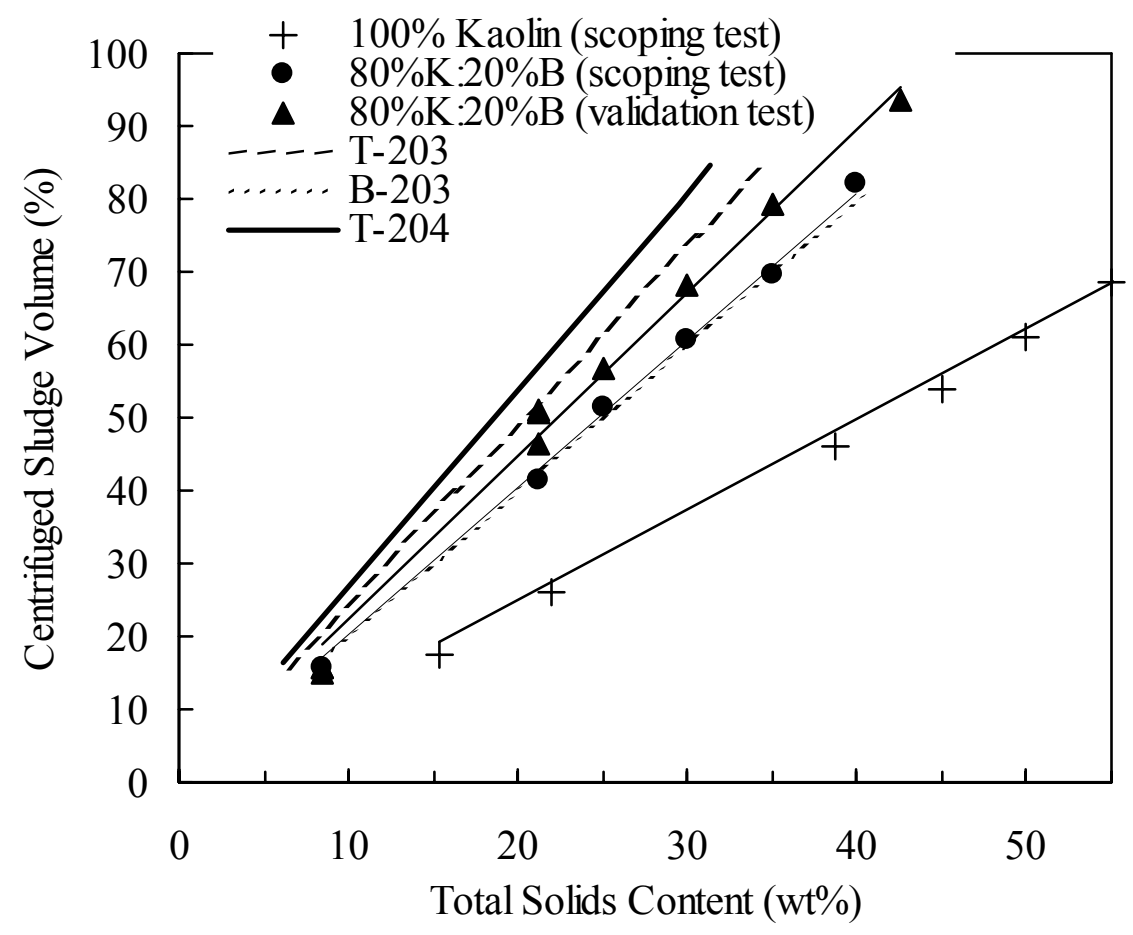

Figure 4.4. Clay Simulant and TRU Waste Centrifuged Sludge Volumes (90 min. centrifugation) 
match the centrifuged sludge properties of the TRU waste. Figure 4.4 shows that adding bentonite to the simulant tends to increase the centrifuged solids volume and better match the TRU centrifuged waste properties. A solids clay ratio of $80-\mathrm{wt} \%$ kaolin and $20-\mathrm{wt} \%$ bentonite generated a centrifuge behavior curve that fell within the range of behaviors measured for the three different TRU wastes represented. The 90-minute centrifuge data for 80:20 kaolin:bentonite nearly fall on top of the results for B-203 waste. Validation tests with the $80-\mathrm{wt} \%$ kaolin and $20-\mathrm{wt} \%$ bentonite mixture showed slightly higher centrifuged sludge volumes than the scoping tests, but the results also fall within the TRU waste data. Thus, given sufficient time (i.e., 90 minutes) to centrifuge to near the final settled consistency, the $80-w t \%$ kaolin and 20 -wt $\%$ bentonite mixture generates centrifuged sludge properties that better simulate the TRU waste centrifuged sludge properties than kaolin/water alone.

Still higher fractions of bentonite tend to produce higher centrifuged sludge volume fractions for a given solid content that better match the upper range of sludge volume fractions represented by the T-204 data in Figures 4.2 and 4.4. However, as shown in Figure 4.5, the inclusion of bentonite slows the centrifugation rate to levels below that seen for the TRU waste and the 80:20 mixture is already a conservatively difficult simulant to centrifuge. Thus, the 80:20 kaolin:bentonite simulant mixture represents a good compromise that centrifuges to the same range of final sludge volumes as the TRU waste at a rate that is lower than the TRU waste but is not excessively slow.

Although a variety of materials can have similar centrifuged sludge properties, differences in particle size, shape, and density can affect the rate of settling. Figure 4.5 shows the extent of settling as a function of time for a TRU waste from B-203, ${ }^{(a)}$ a 100\% kaolin simulant, and an 80:20 kaolin:bentonite simulant.

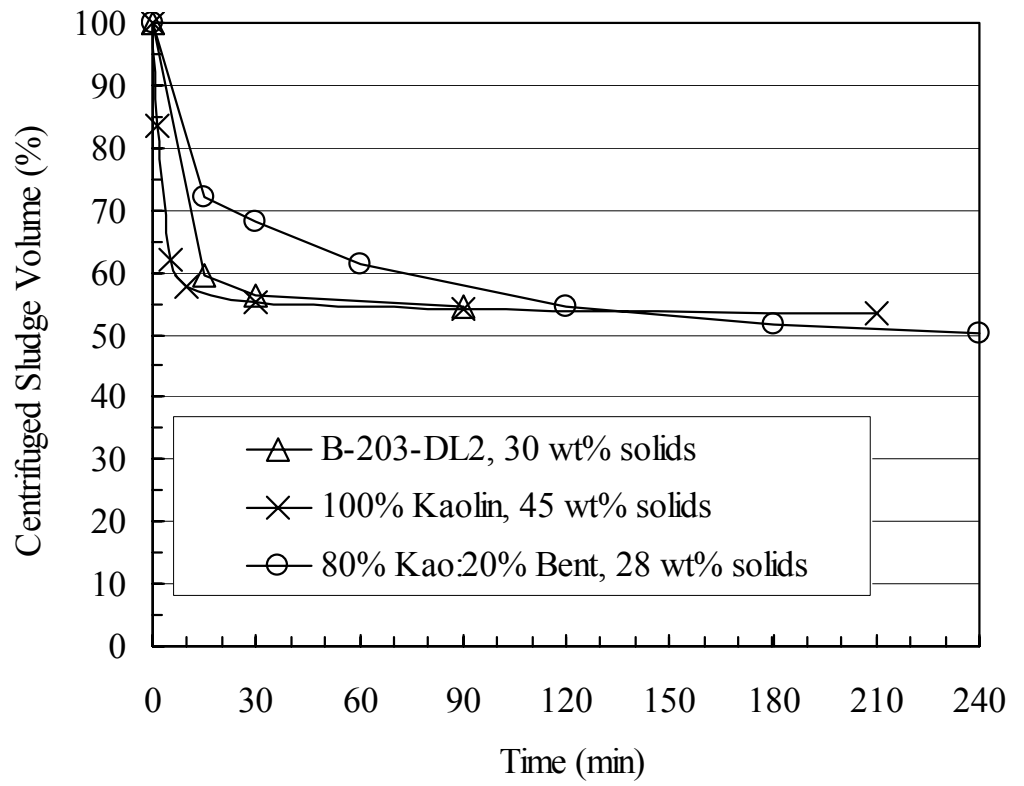

Figure 4.5. Comparison of Clay Simulant and TRU Waste Centrifugation Rates at $\sim 1000-\mathrm{G}$

(a) Tingey JM, J Gao, LM Bagaasen, and BE Wells. May 2003. Physical Property and Rheological Testing of Actual Transuranic Waste from Hanford Single-Shell Tanks, letter report ST03.016, PNNL. 
The initial moisture content of these samples had been adjusted to obtain shear strengths of about $60 \mathrm{~Pa}$. (Note: The solids content of the TRU waste and 80:20 kaolin:bentonite simulant were similar, while the solids content of the kaolin simulant was appreciably higher.) The kaolin simulant centrifuged slightly faster than TRU waste, but both materials centrifuge significantly faster than the 80:20 kaolin:bentonite simulant. This indicates that the 80:20 kaolin:bentonite simulant does not match the centrifugation rate of the TRU material as well as the kaolin simulant. However, the 80:20 kaolin:bentonite simulant provides a more difficult challenge for the vendor's equipment and may help ensure that the packaging equipment has sufficient capacity to meet the required throughput.

Scoping and validation tests were run to determine the extent of settling at centrifugation forces of $\sim 1000 \mathrm{G}$ for times ranging from 15 to 360 minutes for kaolin:bentonite/water mixtures with initial solids contents ranging between 21.25 and $42.5 \mathrm{wt} \%$. Scoping and validation results are shown in Figures 4.6a and $4.6 \mathrm{~b}$, respectively. These figures show that at long times, the solids content in the centrifuged sludge levels out in the 40 to $55 \mathrm{wt} \%$ solids range. The solids contents in the validation tests were slightly lower than the scoping tests but not significantly different. As with the kaolin/water simulant results in Figure 4.3, the final sludge solids content tends to increase with increasing initial solids loading. While the applied settling force was not varied in kaolin:bentonite simulant centrifuge studies, the trend toward increased compaction and faster settling rates with increased $G$ force observed in kaolin/water mixtures (Figure 4.3) is expected. These factors should allow the vendor to control the solids content and other simulant properties by adjusting the applied settling force and residence time in their equipment.

Figure 4.7 shows that the centrifuging behavior of the kaolin:bentonite simulants change for the waterdiluted, lower solids content starting samples. 21.25 -wt $\%$ solids simulants that were centrifuged within a day of preparation tended to produce centrifuged sludges with slightly higher solids contents than samples that had been prepared and allowed to age for six days even though all samples were well-mixed by hand just prior to starting the centrifuge tests.

As shown in Figure 4.7, 8.5-wt\% samples produce centrifuged sludge at short times (15 min) with higher solids contents than a sample that started with solids loadings as high as $42.5 \mathrm{wt} \%$. However, the $8.5-\mathrm{wt} \%$ samples ultimately produce centrifuged sludges with lower solids contents at longer centrifuge times. At 360 minutes, the final centrifuged sludge solids fractions for the 8.5 -wt $\%$ samples are lower than the $21.25-w t \%$ samples and conform to the trends seen in all the other samples (Figure 4.6b). An $8.5-\mathrm{wt} \%$ sample that was allowed to age for five days produced centrifuged sludge with high solids content at short times but low solids content at longer times. Estimates of centrifuged sludge solids contents become less accurate for samples with lower solids loadings due to the larger relative volume of liquid, but the effects noted in Figure 4.7 for the $8.5-\mathrm{wt} \%$ samples were repeated in several experiments.

The differences in centrifuging behavior for diluted samples is probably related to: (a) the slow adsorption of water by the bentonite clay that results in swelling; and (b) a shift in the settling/compaction behavior when moving from solid liquid ratios that act like a slurry of suspended particles (compaction) to ratios that act more like independent particles in liquid (settling). The settling information discussed in the following section supports this explanation since 21.25-wt\% samples of the 80:20 kaolin:bentonite simulant undergo little gravity settling while the $8.5-\mathrm{wt} \%$ samples gravity settle and show significant particle size segregation. Apparently, samples with higher solids loading have solids that act as a uniform mixture and the bentonite prevents rapid settling and segregation of the larger kaolin particles while the larger kaolin particles tend to act as a filter bed and remove the smaller bentonite particles during the high 

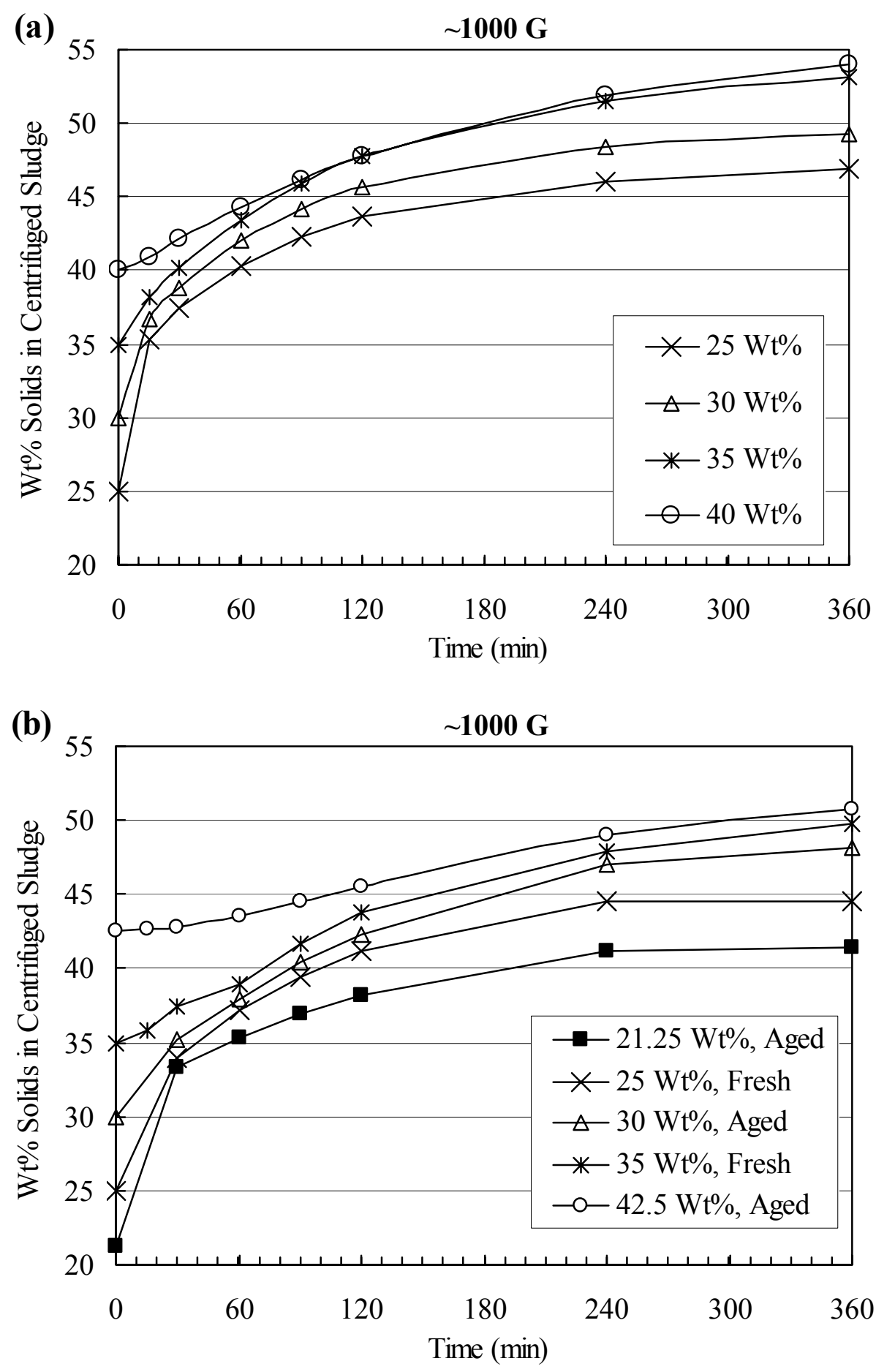

Figure 4.6. Centrifuged ( 1000-G) Kaolin:Bentonite Simulant Solids Content as a Function of Centrifugation Time for Various Initial Simulant Solids Loadings: (a) Scoping Studies; and (b) Validation Studies 


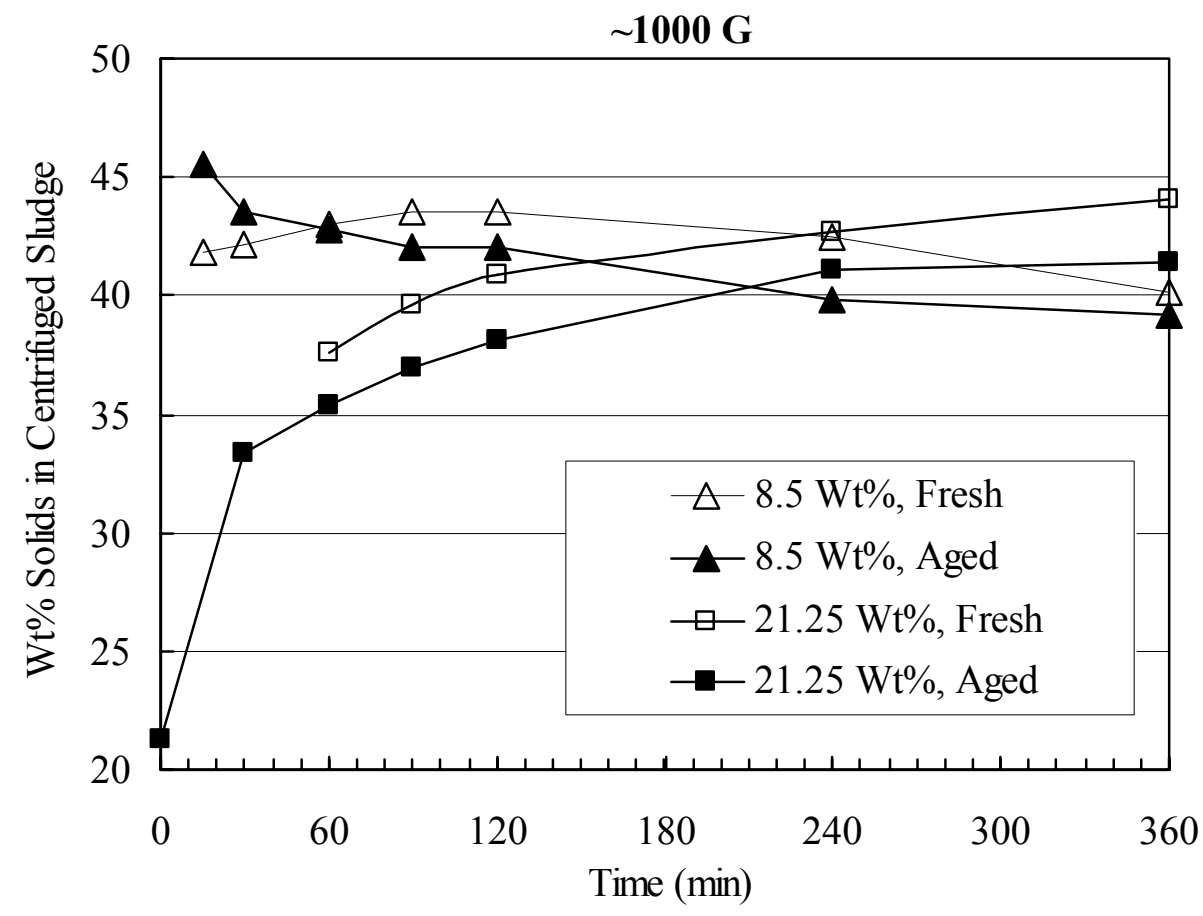

Figure 4.7. Effect of Aging on Centrifuged ( 1000 G) Kaolin:Bentonite Simulant Solids Content as a Function of Centrifugation Time for Diluted Simulants (validation studies)

G centrifugation. Aged samples that provide sufficient time for complete water adsorption by the bentonite allow even less kaolin segregation and tend to centrifuge to lower solids contents. The sample with only $8.5-\mathrm{wt} \%$ solids (1.7-wt $\%$ bentonite) is dilute enough that the larger kaolin and bentonite particles can segregate and quickly centrifuge producing a high-solids-loaded centrifuged sludge. Longer centrifuge times remove smaller, less dense particles that effectively reduce the centrifuged sludge solids loading. The aging effect probably also occurs in higher solids content starting materials, but it is masked by the slower centrifuging rate. This aging effect suggests that the vendor should consider preparing simulant batches a minimum of one week prior to use in any verification testing.

As mentioned above, the settling rate in a centrifuge depends on particle size and density. This leads to particle separation, resulting in a stratified centrifuged sludge that tends to have the largest and densest particles at the bottom and the smaller, less dense particles at the top of the material. Solids with a bimodal distribution can produce separations where a relatively large fraction of solids from the nominally large-particle material (e.g., kaolin) settle more readily in the centrifuged sludge, while a small portion of the smaller particles (e.g., bentonite) remain suspended in the liquid fraction, forming turbid liquids that are difficult to clarify. Centrifuged samples of the 80:20 kaolin:bentonite/water simulants had turbid liquids over a broad range of starting solids contents and in a few cases took as long as 60 minutes to generate an acceptably clear liquid. Samples with lower initial solids contents generally took longer to produce clear liquids except for the highly diluted sample ( $8.5 \mathrm{wt} \%$ solids) that produced relatively clear liquid in 30 minutes. Data from samples that contained very turbid liquids were not included in Figures 4.6 and 4.7 because it was not possible to accurately account for the solids that remained in the 
separated liquid. Data from samples that had a slight turbidity were used because the quantity of solids in the liquid was small. The actual TRU waste composites generally showed clear, slightly colored liquids after 15 minutes of centrifugation, and similarly, kaolin/water simulants covering a large range of solids content generated clear liquids in less than 5 minutes. Provided the vendor's process does not rely on filtration of the liquid following centrifugation, the presence of clay solids in the decanted liquid would not be expected to significantly impact process tests using the kaolin:bentonite simulant.

The data available from centrifugal settling studies of TRU sludges suggest that the 80:20 kaolin:bentonite/water system is a suitable centrifugal dewatering simulant. It is preferred over a kaolin/water system because the centrifuged kaolin:bentonite sludge properties (e.g., density) more closely match the TRU waste behavior.

\subsubsection{Gravity Settling Behavior}

The gravity setting behavior of the simulant relative to the TRU sludge is also important. Data in Rassat et al. (2003) showed that tank sludges with measured shear strengths as low as $200 \mathrm{~Pa}$ did not gravity settle (compact) to produce free liquids. However, a sample of Tank B-201 waste diluted 1:1 with water by volume produced slurry having a yield stress of $8.1 \mathrm{~Pa}$ that partially settled to a solids level of $92 \%$ of the diluted sample volume in 48 hours. Additional TRU waste gravity settling tests were recently conducted and reported by Tingey et al. (a) Samples from three B- and T-200 series tanks were diluted with water to obtain different initial solids contents and allowed to gravity settle. A Tank T-204 sample diluted to a solids content of $14.6 \mathrm{wt} \%$ (a $1: 1$ mass dilution) settled to a nearly constant solids level of $88 \%$ of the diluted sample volume in 48 hours. The settled T-204 sludge had a measured 20 Pa shear strength and $18 \mathrm{wt} \%$ solids. A sample of B-203 waste composite diluted to a solids content of $28.5 \mathrm{wt} \%$ and having shear strength of $60 \mathrm{~Pa}$ did not settle. The data suggest an onset of gravity settling for TRU wastes at relatively low shear strength (i.e., 20 to $60 \mathrm{~Pa}$ ).

Limited bench-scale laboratory tests were completed on kaolin and 80:20 wt $\%$ kaolin:bentonite simulants with varying water content to assess gravity-settling behavior. Initial results with the kaolin:bentonite mixtures indicate that this simulant is a less suitable match for TRU waste settling characteristics than pure kaolin-based simulants. A $50 \mathrm{~mL}$ sample of $21-\mathrm{wt} \%$ solids kaolin:bentonite slurry allowed to settle for more than two weeks (a 1:1 mass dilution of the typical shear strength simulant) produced $<4 \%$ clear supernatant liquid, leaving $>96-\mathrm{vol} \%$ settled sludge. A 4:1 mass dilution of the base 80:20 kaolin:bentonite simulant $(8.5-\mathrm{wt} \%$ solids in the diluted slurry) settled more substantially ( 25 -vol\% settled sludge), but the supernatant liquid remained turbid due to suspended solids for long times ( $>2$ weeks). These results plus the gravity-settling data for pure kaolin simulants presented below indicate that kaolin/water simulants should be used to evaluate TRU handling and packaging process steps relying on gravity settling.

Small-volume (35 to $50 \mathrm{~mL}$ ) kaolin/water samples were mixed and allowed to gravity settle in capped graduated centrifuged tubes. Table 4.3 summarizes results from the scoping and validation studies and shows the volume fraction of settled/compacted sludge for each kaolin/water formulation at a relatively long time ( $\sim 4$ days and $>1$ week). Figure 4.8 shows the time-dependent settling behavior for kaolin

(a) Tingey JM, J Gao, LM Bagaasen, and BE Wells. May 2003. Physical Property and Rheological Testing of Actual Transuranic Waste from Hanford Single-Shell Tanks, letter report ST03.016, PNNL. 
Table 4.3. Long-Time Gravity-Settling Characteristics of Kaolin/Water Simulants

\begin{tabular}{|c|c|c|c|c|}
\hline \multirow{3}{*}{$\begin{array}{c}\text { Kaolin-Water } \\
\text { Formulation } \\
\text { wt\% kaolin } \\
\text { (est. shear strength, } \mathrm{Pa} \text { ) }\end{array}$} & \multicolumn{4}{|c|}{ Volume\% Settled Sludge } \\
\hline & \multicolumn{2}{|c|}{ Scoping Studies } & \multicolumn{2}{|c|}{ Validation Studies } \\
\hline & $\sim 4$ days & 7.5 days & $\sim 4$ days & 7-10 days \\
\hline $15-15.5(\mathrm{NA})$ & 37 & NA & 34 & 33 \\
\hline $20-21$ (NA) & 53 & NA & 45 & 45 \\
\hline $30(<10)$ & NA & NA & 71 & 70 \\
\hline $40(\sim 30)$ & 91 & 86 & 94 & 94 \\
\hline $45(\sim 70)$ & 97 & 96 & 98 & 98 \\
\hline $50(\sim 160)$ & $100^{(a)}$ & 100 & $>99^{(\mathrm{b})}$ & $>99^{(\mathrm{b})}$ \\
\hline $50(\sim 240)$ & 100 & 100 & NA & NA \\
\hline $55(\sim 370)$ & 100 & 100 & NA & NA \\
\hline $60(\sim 870)$ & 100 & 100 & 100 & 100 \\
\hline
\end{tabular}

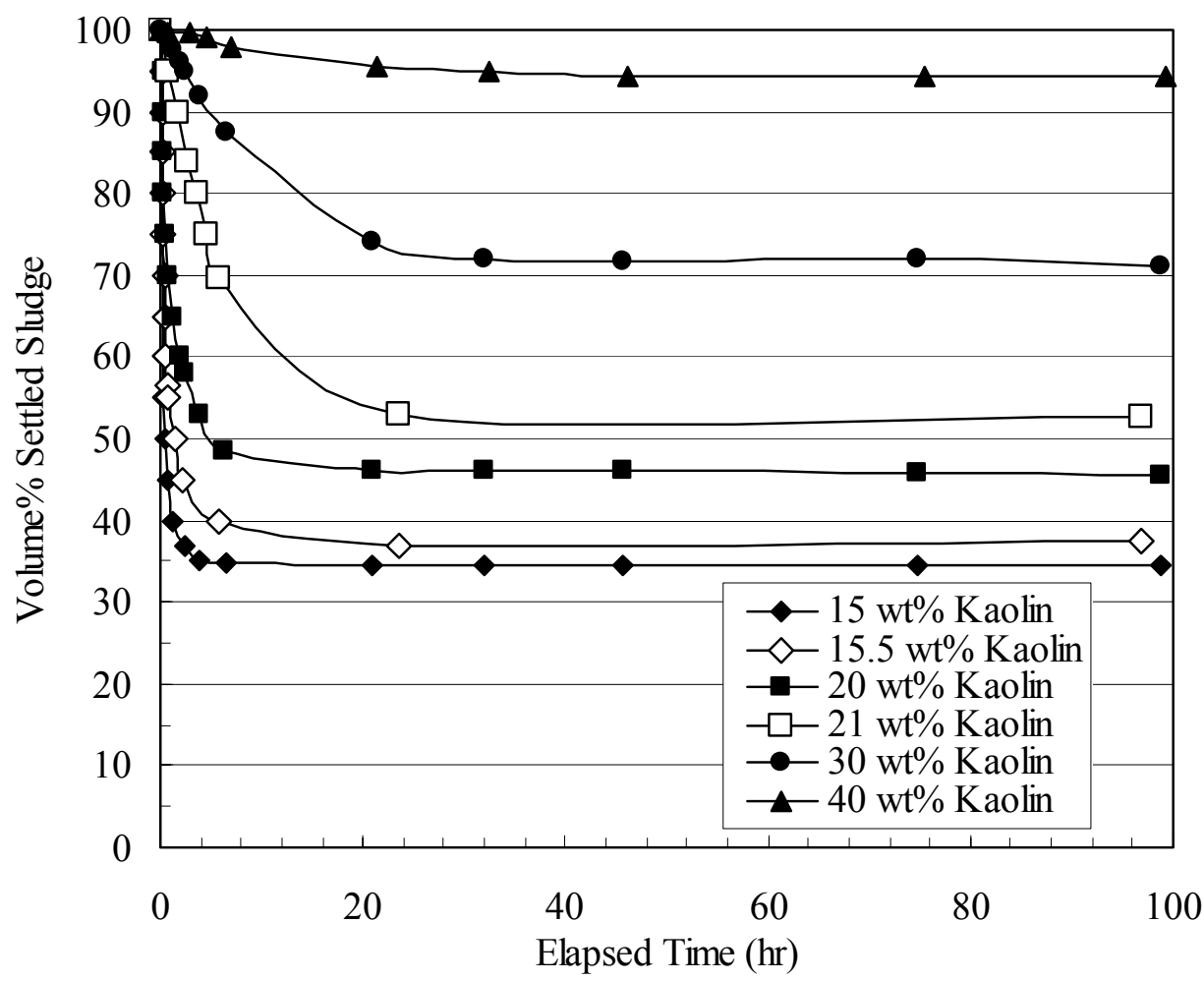

Figure 4.8. Gravity Settling of Kaolin Simulants of Varying Initial Solids Content. Open symbols show results of initial scope studies and filled symbols indicate subsequent QA validation test results. 
samples with $15-$ to $40-\mathrm{wt} \%$ solids. No significant differences were noted in the scoping and validation tests data shown in Table 4.3 and Figure 4.8. The estimated shear strength of each formulation in Table 4.3 was determined from best-fit data for as-prepared simulants (see Figure 4.13). Kaolin formulations with shear strengths of $\sim 240 \mathrm{~Pa}$ and greater showed no tendency to dewater, and a transition to minimal dewatering was noted for $\sim 160$-Pa shear strength materials. This corresponds well with the lack of settling noted in the TRU waste samples of $>200$-Pa shear strength (Rassat et al. 2003). A 40-wt $\%$ kaolin simulant formulation with estimated shear strength of $\sim 30 \mathrm{~Pa}$ settled to a sludge level of $91 \mathrm{vol} \%$ after 3.5 days and 86 vol\% in 7.5 days. This compares reasonably with the $92-\mathrm{vol} \%$ settled solids for the 8.1 Pa yield stress B-201 slurry in 48 hours reported in earlier work and the 88 -vol\% settled solids for a 20-Pa shear strength T-204 sludge sample in 48 hours reported by Tingey et al. ${ }^{\text {(a) }}$

Figure 4.8 shows the variation in settled sludge volume over time for kaolin slurries with 15 to $40 \mathrm{wt} \%$ solids. This range of samples includes 15 to $15.5 \mathrm{wt} \%$ and 20 to $21 \mathrm{wt} \%$ kaolin slurries that represent $\sim 3: 1$ and $\sim 2: 1$ dilutions by mass with water of a representative kaolin simulant (60 to $62.5 \mathrm{wt} \%$ solids, $\sim 1000 \mathrm{~Pa}$ shear strength). As observed by Tingey et al. for TRU waste slurries, the more highly diluted kaolin simulants settle faster than less diluted material. For 4:1 mass-basis diluted TRU samples, Tingey et al. observed that the majority of the settling occurred within several hours after initiation of the tests. On the other hand, 1:1 mass dilutions continued to settle for 48 hours or more. As shown in Figure 4.8, the long-time settled sludge volume of the $2: 1$ diluted kaolin $(21.0 \mathrm{wt} \%)$ is $\sim 53 \mathrm{vol} \%$ and the $3: 1$ diluted kaolin (15.5 wt\%) is $\sim 37$ vol\%. For comparison, 4:1 diluted B-203, T-203, and T-204 TRU samples had final settled sludge volumes of $\sim 45 \mathrm{vol} \%$ (Tingey et al.). By controlling the weight fraction of solids in the kaolin simulant, the volume fraction of settled simulant sludge could be made to represent the gravitysettling characteristics (i.e., volume and time-dependence) of diluted TRU waste.

As noted above, the available data indicate that kaolin materials have gravity-settling behavior that is similar to the TRU waste. On the other hand, the gravity-settling behavior of the 80:20 kaolin:bentonite simulant does not match the behavior of the waste as well. If gravity settling/compaction is an important part of the vendor's process, the kaolin/water simulants should be used in performance tests.

\subsubsection{Strengths of Centrifuged Products}

The simulants should also be able to simulate the strength of the dewatered TRU sludges as they exit the centrifuge. No data are available on the strengths of dewatered TRU sludges, so the only estimates of these strengths are based on inference from in-tank properties and recent experimental studies. Data in Rassat et al. (2003) show that only a small amount of solids separation occurs when materials with shear strengths of 1300 to $1400 \mathrm{~Pa}$ are centrifuged at $>1000 \mathrm{G}$ for one hour. This indicates that centrifuged TRU waste is not likely to have shear strengths significantly greater than several thousand $\mathrm{Pa}$, consistent with the estimated shear strengths of compacted SST TRU wastes in the tanks (Rassat et al. 2003). However, Tingey et al. found that centrifuging at $>1000 \mathrm{G}$ for 90 minutes could remove $12-16$ vol\% liquid from waste samples with shear strengths as high as $3770 \mathrm{~Pa} .{ }^{(b)}$ Although Tingey was not able to

(a) Tingey JM, J Gao, LM Bagaasen, and BE Wells. May 2003. Physical Property and Rheological Testing of Actual Transuranic Waste from Hanford Single-Shell Tanks, letter report ST03.016, PNNL.

(b) Tingey JM, J Gao, LM Bagaasen, and BE Wells investigated TRU waste shear strength as a function of water content and solids loading in Physical Property and Rheological Testing of Actual Transuranic Waste from Hanford Single-Shell Tanks, letter report ST03.016, May 2003, PNNL. 
measure the strength of centrifuged materials, the reduced moisture content indicates that strengths of centrifuged product may be significantly higher than $3800 \mathrm{~Pa}$.

Data in Section 4.2.1 show that kaolin:bentonite/water mixtures are preferred simulants for centrifuge process testing because they better match the centrifuged sludge volume/solids content relationship observed for B- and T-200 series TRU tank wastes. Kaolin/water simulants were also investigated, and consistent centrifugal dewatering was observed. Since the kaolin/water system showed early promise as a dewatering simulant, the shear strength of centrifuged sludges was studied. Information for the shear strength of centrifuged products for both simulant systems is presented below.

The kaolin/water data in Figure 4.3 indicate that a centrifugation process could produce dewatered simulants with solids contents between $\sim 60$ and $70 \mathrm{wt} \%$ by controlling the applied settling force and the time in the centrifuge. Similarly, Figure 4.6 shows that 40 to $55 \mathrm{wt} \%$ solids loading might be typical for centrifuged kaolin:bentonite/water sludge. If these dewatered materials have the same shear strengths as freshly prepared sludges of the same bulk composition (see Figures 4.13 and 4.14), shear strengths from $\sim 400$ to $>5000 \mathrm{~Pa}$ in a centrifugal dewatering process using the simulants would be expected.

A limited number of laboratory tests were conducted to determine whether centrifuging produced settled simulant sludges with shear strengths similar to as-prepared materials. In order to obtain a centrifuged sample large enough for a direct shear strength measurement, a centrifuge with a 500-mL sample capacity was used. A 45-wt \% kaolin sample was centrifuged at $250 \mathrm{G}$ for 30 minutes, resulting in a centrifuged product with 58.4-wt\% solids. Using a Haake viscometer with an M5 head and a shear vane, the directmeasured shear strength of the sludge in the centrifuge container was $630 \mathrm{~Pa}$. The centrifuged product showed some layering with weaker materials present at the surface where the shear measurement was obtained. The centrifuged product was removed from the centrifuge container and remixed without the addition of any water. The measured shear strength of the mixed material was $960 \mathrm{~Pa}$.

A $45-\mathrm{wt} \%$ kaolin sample was centrifuged at $\sim 2200 \mathrm{G}$ for 30 minutes to produce a centrifuged product with $70.3 \mathrm{wt} \%$ solids. Attempts to measure the shear strength of the centrifuged sludge directly in the container indicated it had shear strength in excess of 25,000 Pa. The centrifuged product again showed significant layering, with stronger materials at the bottom. Because the depth of settled sludge was small, the shear vane penetrated layers with vastly different shear strengths. The centrifuged product was removed from the centrifuge container and remixed without adding any water. The measured shear strength of the mixed material was $22,000 \mathrm{~Pa}$. The $70.3 \mathrm{wt} \%$ sample was reconstituted with water in steps back to solids contents of 65,60 , and $55-\mathrm{wt} \%$ kaolin. Shear strength measurements were taken at each step.

Figure 4.9 shows shear strength data from the large centrifuged kaolin samples along with the best-fit curve for as-prepared kaolin/water simulants (see Figure 4.13). The sample centrifuged to $58.4 \mathrm{wt} \%$ solids had a shear strength close to that expected for an as-prepared sample with the same solids content. The shear strength of the remixed $58.4 \mathrm{wt} \%$ sample was slightly higher but well within the measurement uncertainty of the as-prepared materials. The sample centrifuged to $70.3 \mathrm{wt} \%$ solids had much higher shear strength than the as-prepared samples with the same solids content, even after it was removed from the centrifuge container and remixed. Adding water to the $70.3 \mathrm{wt} \%$ sample quickly brought the sample back to the expected as-prepared shear strengths. The results from these experiments indicate that centrifuged kaolin/water mixtures will act like as-prepared materials up to solids contents of $\sim 60 \mathrm{wt} \%$ (900 Pa) 


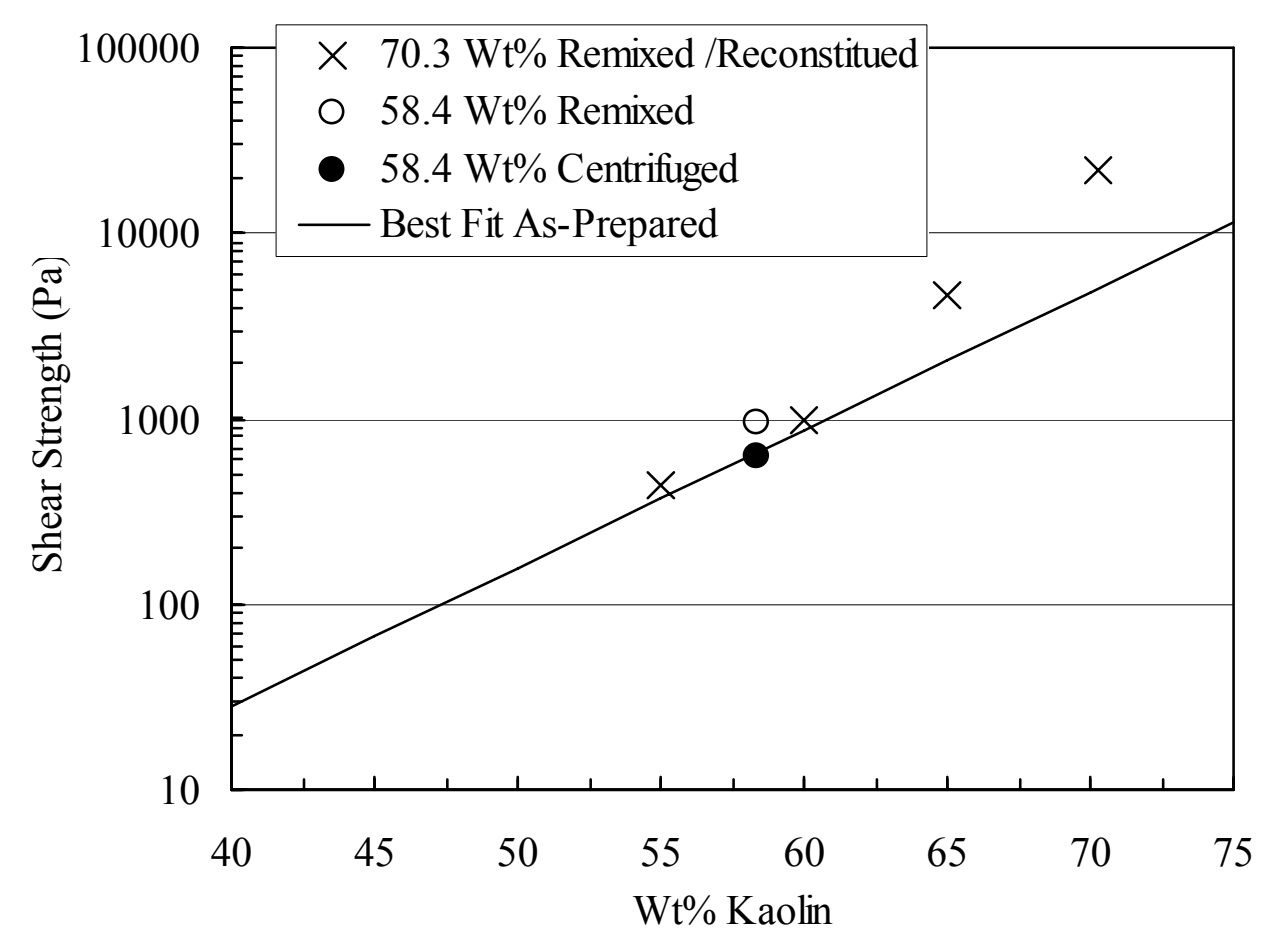

Figure 4.9. Measured Shear Strengths for Centrifuged, Remixed, and Reconstituted Kaolin/Water Simulants (best fit line from Figure 4.13)

but will have greater than expected shear strengths at higher solids content. However, the higher shear strengths appear to be related to packing of the centrifuged material, and the properties of the kaolin are not permanently changed because reconstituting with water returns shear strength to anticipated levels.

A similar large-sample centrifuge experiment was conducted with an 80:20 kaolin:bentonite/water simulant. A 40-wt\% solids mixture was centrifuged for 120 minutes at $2200 \mathrm{G}$, producing a settled sludge with $52.3 \mathrm{wt} \%$ solids. Shear strengths measured in the undisturbed sample ranged from 3600 to $8800 \mathrm{~Pa}$, with the highest measured deeper in the sample. Although it was not possible to access the deepest part of the sample with the shear vane, centrifugation of the kaolin:bentonite simulant does not appear to produce the extremely strong compacted material observed for kaolin/water (e.g., >25,000 Pa).

The measured strengths of the centrifuged kaolin:bentonite simulant are compared with the shear strengths of as-prepared materials in Figure 4.10. (The two best fit as-prepared curves, representing shear strength measurements taken 10 minutes and 6 to 8 days after preparation, are discussed in Section 3.3.1 and reproduced from Figure 4.14). The measured shear strength of the centrifuged and remixed material was $\sim 6100 \mathrm{~Pa}$, somewhat higher than expected for a 52.3-wt\% solids simulant ( 4000-5000 Pa). The centrifuged sludge was reconstituted with water in steps back to 50 and $45-w t \%$ solids, with shear strength measurements made within minutes after each step. As with the kaolin/water simulants, Fig ure 4.10 shows that adding water to the centrifuged kaolin:bentonite simulant readily returns the sample back to the expected as-prepared shear strengths. 


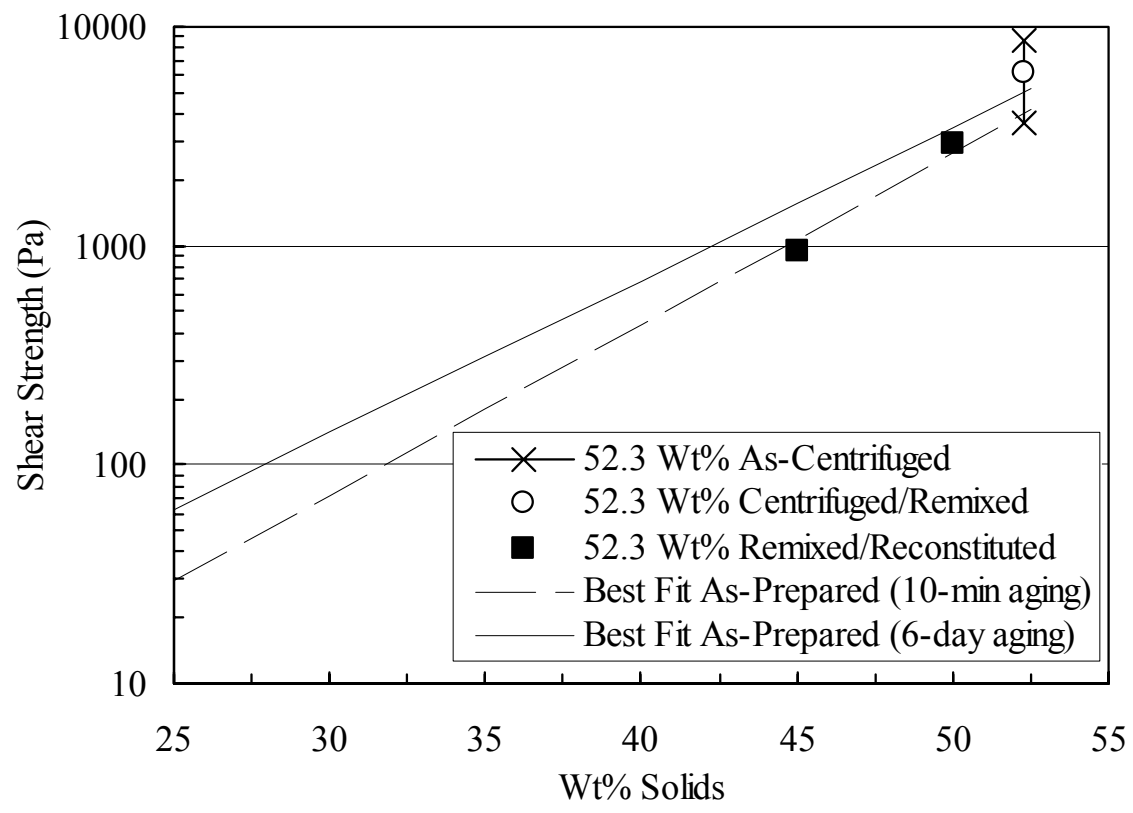

Figure 4.10. Measured Shear Strengths for Centrifuged, Remixed, and Reconstituted 80:20 Kaolin:Bentonite/Water Simulants (best fit lines from Figure 4.14)

Without shear strength data for dewatered TRU sludges, an assessment of the adequacy of the kaolin/ water mixtures as dewatered shear strength simulants is not possible. However, the data in Figures 4.9 and 4.10 indicate that the vendor should be able to produce dewatered simulant that has shear strength similar to that expected for the TRU sludges. Vendors might also be able to produce centrifuged materials much stronger than that expected for the TRU sludges to demonstrate a wider operating window. Making higher shear strength materials does not appear to affect the ability to recycle the simulant for extended tests.

\subsubsection{Simulant Reuse}

A practical matter associated with the dewatering simulant is that the specified acceptance testing period is one week of operation for 24 hours a day. If operated at full capacity (500 gal $/ \mathrm{hr}$ of diluted tank sludge), a total of 84,000 gal of simulant will be required for testing. If the kaolin:bentonite/water mixtures can be dewatered in the centrifuge and reconstituted with recycled (or fresh) water multiple times while producing a consistent dewatering behavior, this will reduce the quantity of simulant needed for continuous operations to 1-2 thousand gallons. The same potential benefit applies to kaolin/water simulant mixtures used for gravity settling (and/or centrifugal dewatering) process tests.

Figure 4.11 shows the residual kaolin content of several kaolin/ water mixtures centrifuged for 10 minutes at $\sim 1000 \mathrm{G}$. After centrifuging, the samples in the centrifuge tube were reconstituted to their original moisture content by mixing with a spatula, and the process was repeated. The dewatering behavior 


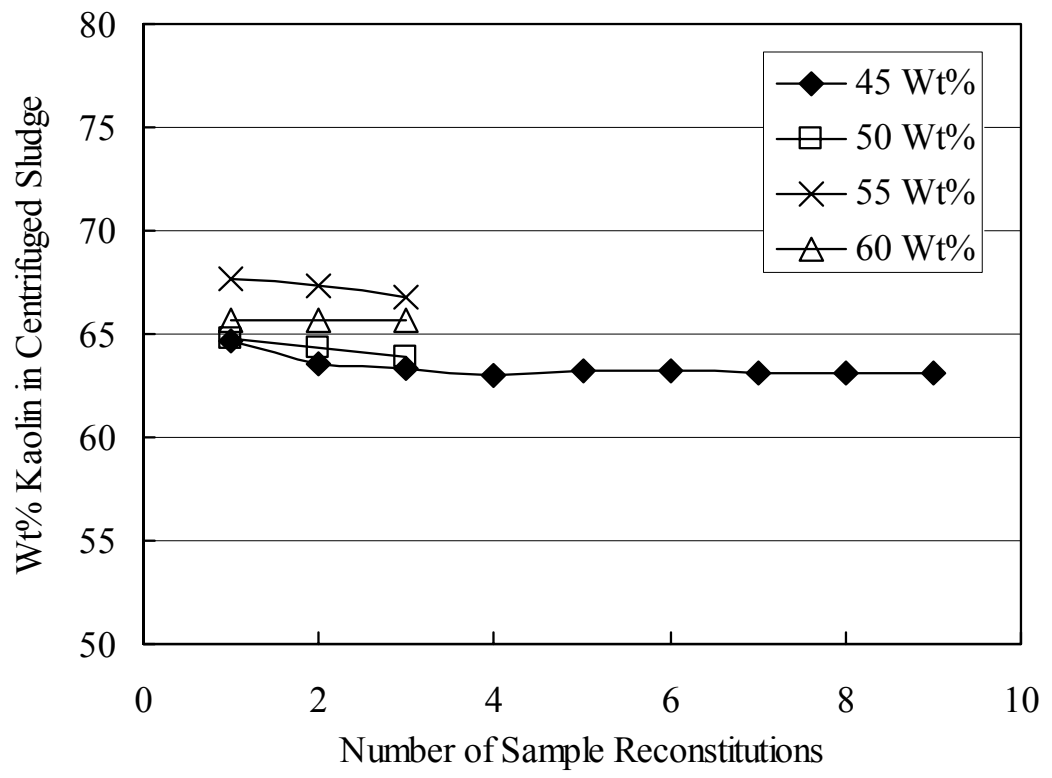

Figure 4.11. Consistency of Centrifuged Dewatering Behavior of Kaolin/Water Mixtures after Multiple Centrifuge (10 min, $1000 \mathrm{G}$ ) and Reconstitution Cycles

remained consistent for nine centrifuge/reconstitution cycles for each sample. Because more sludge compaction results when the centrifugal force is greater than the force of gravity-settling, comparable reconstitution consistency is expected for kaolin/water mixtures in gravity-settling process tests.

Figure 4.12 shows the results for similar reconstitution experiments using $1: 1$ and $4: 1$ (water mass:simulant mass) dilutions of a representative $80 \mathrm{wt} \%: 20 \mathrm{wt} \%$ kaolin:bentonite simulant (42.5 wt $\%$ solids, $\sim 1000 \mathrm{~Pa}$ shear strength). These samples were centrifuged for 120 minutes at $\sim 1000 \mathrm{G}$ to approach maximum compaction. It should be noted, however, that the liquid fraction of the centrifuged 1:1 diluted sample remained turbid after 120 minutes. In spite of this, reconstitution using the turbid liquid (not fresh water) to maintain constant solids content results in consistent dewatering behavior as evidenced in Figure 4.12. The data in Figures 4.11 and 4.12 indicate that the kaolin:bentonite/water and kaolin/water simulants can be recycled numerous times to support dewatering tests.

\subsection{Transport Simulants}

The purpose of the physical transport simulants is to represent important rheological properties, primarily strength and viscosity, of the TRU waste at different points in the TRU waste handling and packaging process. There are two main locations in the TRU handing and packaging process where transport may be an issue. During retrieval and transport, the TRU waste may be diluted with water or recycled liquid from the dewatering process. The diluted waste must be received, stored, and then transported to the dewatering system in a consistent manner. Mixing in the storage tank and pumping to the dewatering system may be a problem if the slurry is too viscous for the transfer and mixing equipment. Waste transport might also be an issue for transferring the product resulting from dewatering process equipment into the disposal package. For example, as noted above in the section describing dewatering simulant 


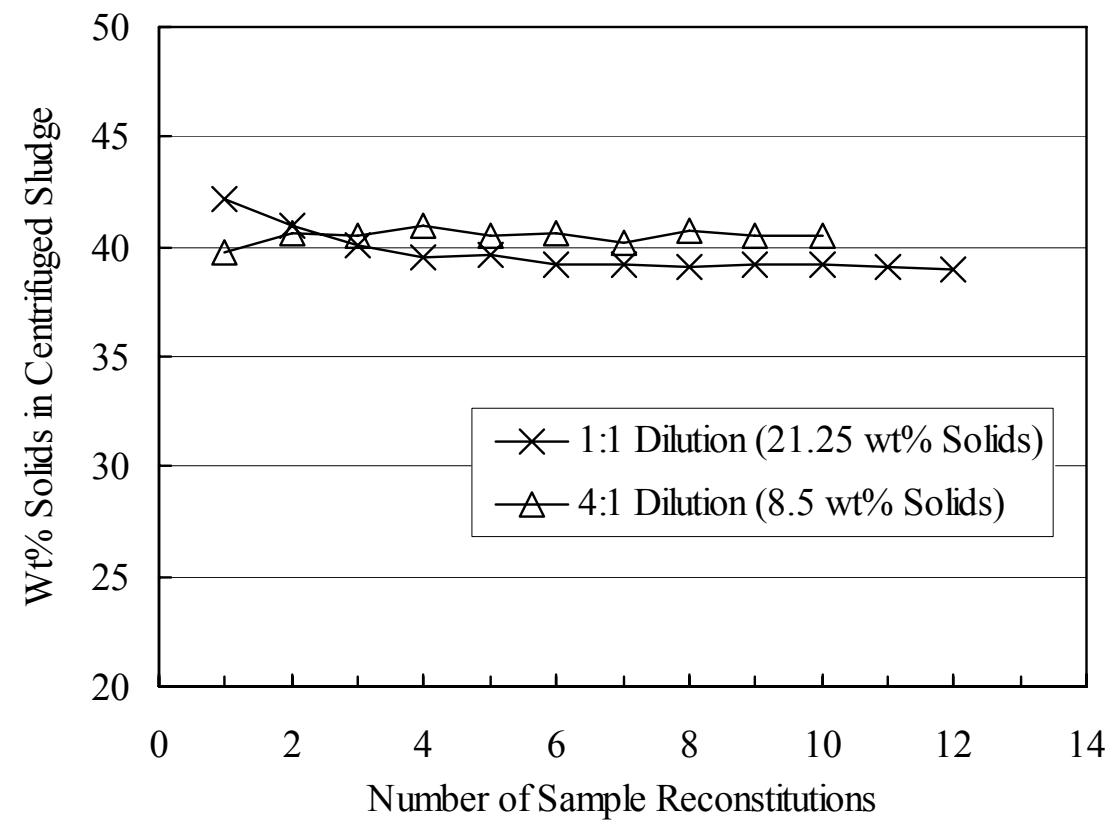

Figure 4.12. Consistency of Centrifuged Dewatering Behavior of Diluted Kaolin:Bentonite/Water Simulant after Multiple Centrifuge (120 min, $\sim 1000 \mathrm{G}$ ) and Reconstitution Cycles

performance, centrifugation may result in strong sludges that are difficult to remove and transport from the centrifuge. Higher strength materials may also be difficult to combine with sorbent materials prior to packaging and difficult to package without excessive voids, reducing the packaging efficiency.

Waste slurry and sludge rheological properties and pipeline transport and hydraulic mixing performance are a function of many factors including sample history/settling duration, solids loading, particle/agglomerate size, solid, liquid and bulk densities, and liquid viscosity. Like the physical dewatering simulants, no attempt was made to match all these properties individually. Rather, a general match of the significant actual waste characteristics was sought, focusing on sludge shear strength and slurry viscosity as a function of solids loading. As with the investigations of dewatering simulants noted above, pure bentonite, pure kaolin, and mixtures of these clays in different proportions with water were considered as physical transport simulants. The information presented here indicates that incorporation of some bentonite produces simulants that better match the physical transport properties of CH-TRU waste than pure kaolin/water simulants. In keeping with the goal of producing a relatively simple simulant formulation that functions for both centrifugal dewatering and physical transport processes, the preferred transport simulant is an 80:20 kaolin:bentonite solids mixture with water. Because kaolin/water is a better simulant for gravity settling (and could be a less-ideal centrifugal dewatering simulant), its physical transport properties are also described.

\subsubsection{Shear Strength and Solids Content}

An optimum physical transport simulant would be able to consistently supply the same range of shear strengths as expected for the dewatered TRU waste. The ideal simulant would also match the solids 
content and density of TRU waste. Figure 4.13 shows that kaolin/water mixtures can reproduce the same shear strengths even when prepared by different operators at different times. The figure shows the measured shear strengths of kaolin/water mixtures with kaolin mass fractions ranging from 30 to $70 \mathrm{wt} \%$. The plot includes data reported in Powell et al. (1995) and Gauglitz et al. (2001) and both scoping and validation measurements made on simulants prepared for this study. The method of simulant preparation and shear strength measurement (Haake viscometer, M5 head and shear vane) (Powell et al. 1995) is the same in all these studies. The kaolin shear strength data obtained in the current experiments are tabulated in the appendix (A.2).

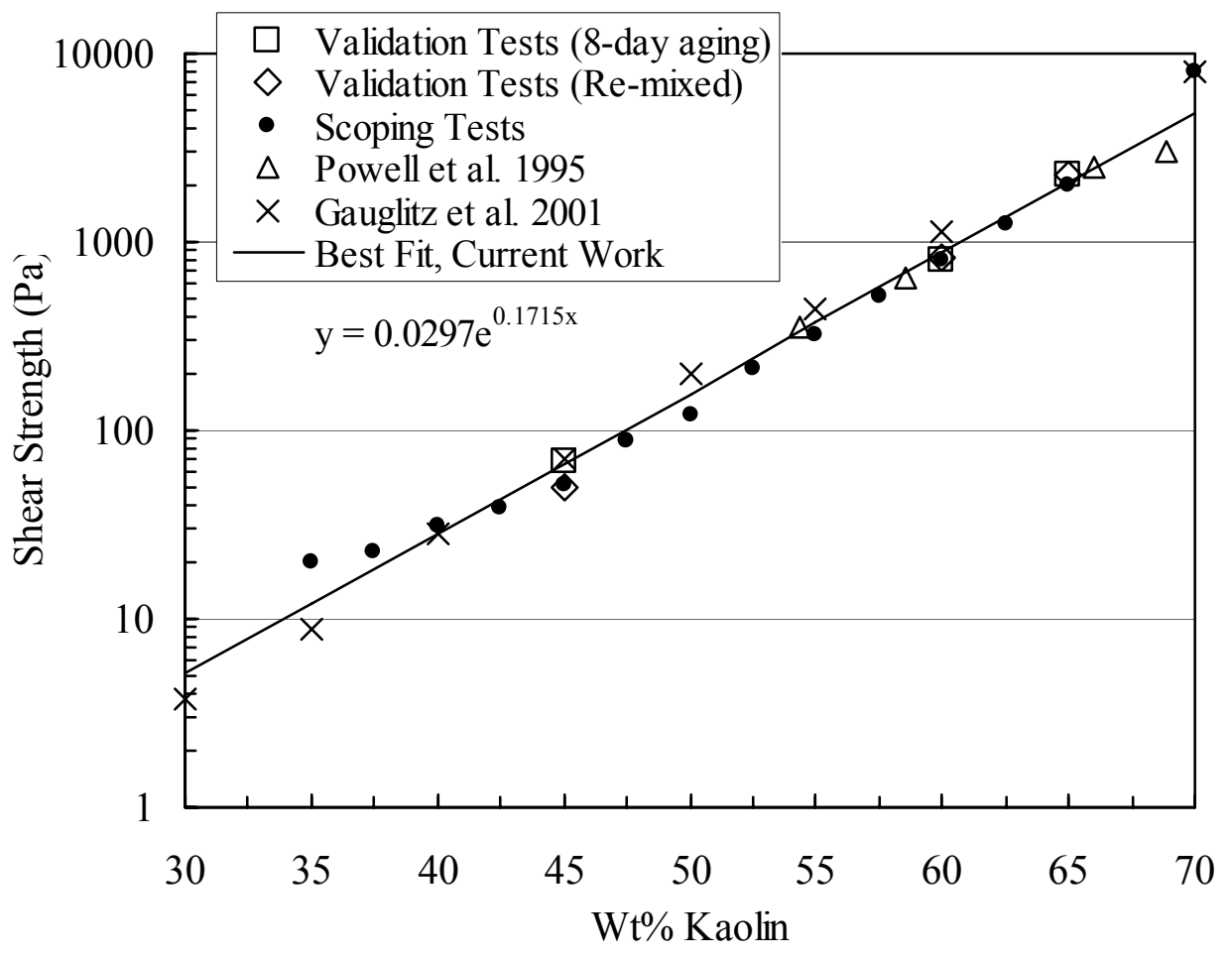

Figure 4.13. Measured Shear Strength for Kaolin/Water Mixtures Prepared by Different Operators

Validation experiments were completed for simulants containing 45-, 60-, and 65-wt $\%$ kaolin covering a measured shear strength range of 50 to $2300 \mathrm{~Pa}$. With the exception of the $45-\mathrm{wt} \%$ material, the shear strengths of simulants aged eight days agree within the standard deviation of the measurements with the results for the same preparation after it was re-mixed (and settled to remove void). The aged 45 -wt $\%$ sample had a small layer of supernatant liquid due to gravity settling (see Section 4.2.2). A shear strength of $69 \mathrm{~Pa}$ was measured in the settled sludge layer, and after re-mixing the shear strength was expectedly reduced $(50 \mathrm{~Pa})$. The general agreement of the results for scoping and validation tests shown in Figure 4.13 indicates consistency in the measurement techniques and instrument performance and in the batches of kaolin clay used to prepare the simulants.

Figure 4.14 shows the variation in measured shear strength as a function of total solids content for simulants prepared from $80 \mathrm{wt} \%$ kaolin: $20 \mathrm{wt} \%$ bentonite mixed with water. [The data are tabulated in the appendix (A.2).] While a long history of preparing this specific simulant formulation has not been 

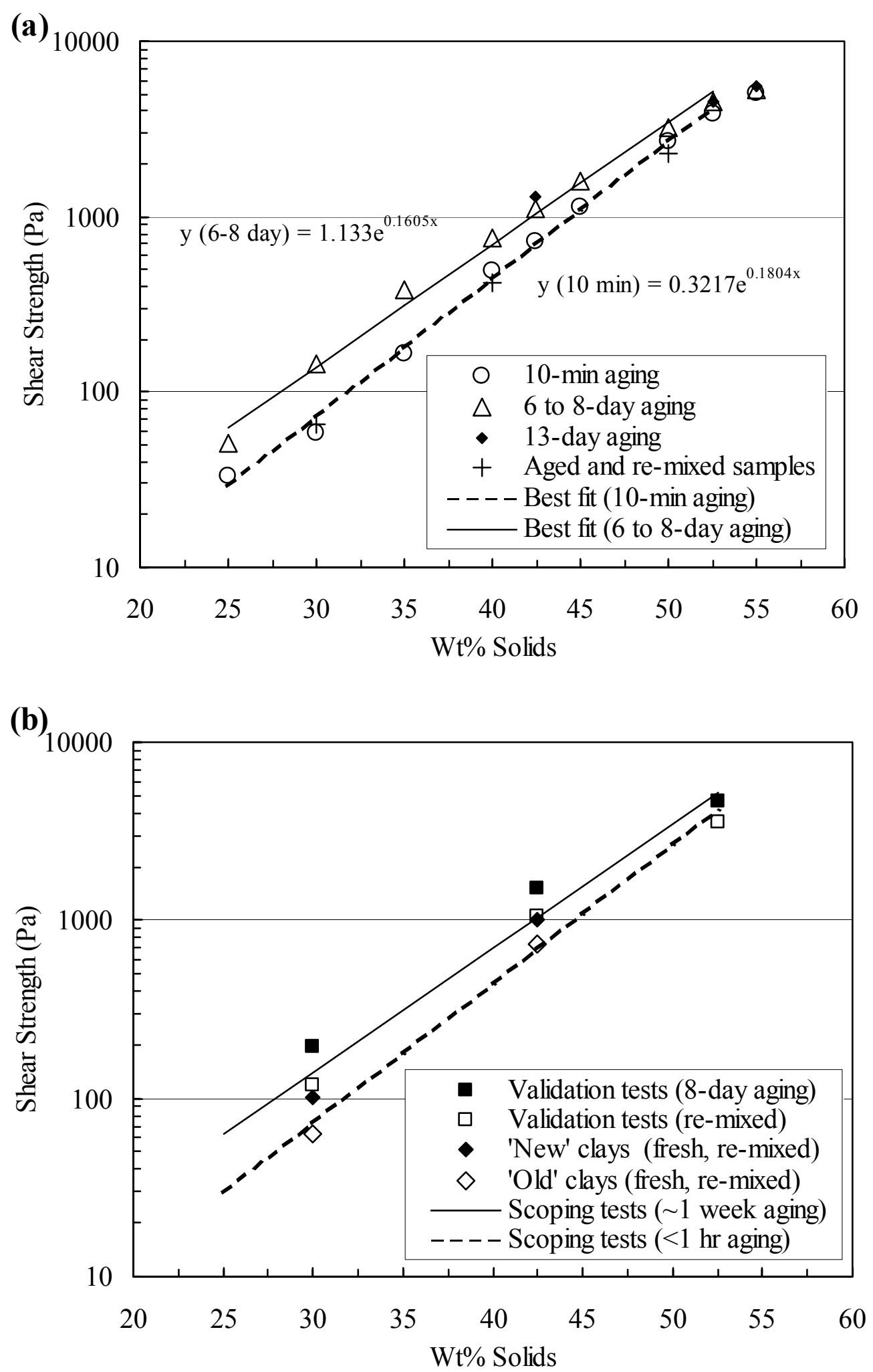

Figure 4.14. Measured Shear Strength for 80:20 Kaolin:Bentonite Solids and Water Mixtures: (a) scoping tests; and (b) validation and follow-on tests compared to scoping tests 
established, there is no reason to expect it will be any less reproducible than the pure kaolin simulants when similar materials are used for all tests. As an early indicator of preparation consistency, several of the samples shown in Figure 4.14a (e.g., 42.5, 52.5, and $55 \mathrm{wt} \%$ ) were prepared and tested on a different day than the others. The scoping test results of all preparations line up well in the plot (Figure 4.14a) indicating good consistency for samples prepared at different times. The figure also indicates that the simulant strength is a function of aging. The simulant shear strength measured shortly after preparation ( $\sim 10$ minutes) is less than the value measured on the same batch six to eight days after preparation. This is indicative of a time-dependent structural transformation within the simulant. Samples allowed to age for 13 days did not generally result in strength increases beyond that seen for the samples aged for 6 to 8 days. Also, re-mixing the aged simulant samples by hand and measuring shear strength within minutes restored the strengths to near the 10-minute aged values. This suggests that the structural transformation in the simulant does not continue indefinitely and that re-mixing is sufficient to destroy the structure and reduce the simulant strength.

Due to the aging effects, the kaolin:bentonite simulant shear strength data for 10-min and 6- to 8-day aging were separately fit to exponential functions over the 25 to $52.5-\mathrm{wt} \%$ solids range. The fit equations for the scoping tests are displayed in Figure 4.14a. While the shear strengths for a $55-\mathrm{wt} \%$ solids preparation are higher as expected ( $\sim 5000$ to $5600 \mathrm{~Pa}$ depending on age), the data appear to deviate from the exponential trend and are not included in the fit. Although additional tests at higher solids loading would be required for confirmation, it appears that the exponential trend does not continue for solids loadings greater than $52.5 \mathrm{wt} \%$ and the strength at higher solids content tends to level out.

Figure $4.14 \mathrm{~b}$ shows the variation in measured shear strength as a function of total solids content for validation study simulants prepared from water and newly acquired clay materials mixed at the 80:20 kaolin:bentonite ratio. The validation experiments were conducted on three samples aged 8 days and on the same samples within an hour after thoroughly re-mixing the simulants. In scoping studies (Figure 4.14a) it was observed that re-mixed samples have shear strength comparable to freshly prepared materials $(<1$-hr aging). The validation results show the same aging effects as the scoping studies with the aged samples having higher strengths than the re-mixed aged samples and other 'new' clay samples prepared on the day of testing and re-mixed. Also, like the scoping study results, the validation test data in Figure 4.14b indicate an exponential trend that appears to level out at higher loadings.

Figure 4.14b also includes the scoping study curve fits from Figure 4.14a. The scoping and validation tests differ in the magnitude of the shear strength with the validation results being $\sim 40 \%$ stronger for 30 and $42.5-\mathrm{wt} \%$ clay solids preparations. At $52.5-\mathrm{wt} \%$ solids, the shear strengths for validation and scoping study samples are about equal ( $4600 \mathrm{~Pa}$ for 8 -day aged samples). Additionally, as shown in Figure 4.14b, the shear strength of 80:20 kaolin:bentonite samples prepared with the 'old' clays and tested after validation studies were completed are comparable to the scoping test results. These follow-on tests with the 'old' clay samples were run in the same suite of experiments with the 'new' clay results presented in Figure 4.14b. As with the kaolin shear strength results (Figure 4.13), this further indicates consistency in simulant batch preparation and the shear strength measurement techniques.

Therefore, differences in the shear strengths measured in scoping and validation studies for kaolin:bentonite simulants is thought to be related to the different bentonite materials for the two experiments. The bentonite for both the scoping and validation tests was acquired from the same supplier (Section 4.1.2), but the bentonite used in the scoping tests was several years old. It is not known if the 
shear strength variation is due to the age of the bentonite used in the scoping studies or normal lot-to-lot variations in the bentonite material. As indicated previously, the two lots of bentonite had comparable moisture content. Variation in particle size distribution or other physical or chemical properties of the bentonite clays may contribute to the range of observed performance. For a given lot of bentonite material, the strength and aging behavior is predictable and would allow easy adjustment of simulant test batches once the bentonite source has been identified and a few strength measurements have been completed.

Other than as noted here, all simulant test mixes were prepared with $>17-\mathrm{M} \Omega-\mathrm{cm}$ resistivity deionized water to reduce variability associated with the water source. Although this reduces a source of experimental variability, it may not be practical for the vendor to use high purity water for their large simulant batches. In order to determine if the strength of the simulant is sensitive to the type of water used, simulants were prepared with the 80:20 kaolin:bentonite mixtures and two types of water. One set of samples used deionized water while the second set of samples used potable tap water from the laboratory. Solid contents of 30 and $42.5 \mathrm{wt} \%$ were chosen to target shear strengths of $\sim 100$ and $\sim 1000$ $\mathrm{Pa}$. Table 4.4 shows that the samples mixed with potable water had strengths that were only slightly lower $(<5 \%)$ than the samples made with deionized water at the same solid content. These data indicate that the vendor may be able to use potable water to produce the test simulants without major changes to the simulant properties. However, other potable water sources may have impurities or characteristics (e.g., $\mathrm{pH}$ ) that could impact the simulant properties. Prior to conducting equipment verification tests, the vendor should take the clay materials purchased and water from the identified source and measure shear strengths on a series of samples covering a range of solid contents to verify that their simulant produces the desired shear strength (and other physical properties). Adjustments in the water source and/or solid contents may be required.

Table 4.4. Effects of Water Type on 80:20 Kaolin:Bentonite Simulant Shear Strength

\begin{tabular}{|c|c|c|}
\hline $\begin{array}{c}\text { Solids Loading } \\
\text { (wt\%) }\end{array}$ & Water Type & $\begin{array}{c}\text { Shear Strength } \\
\text { (Pa) }\end{array}$ \\
\hline 30.0 & Deionized & 101 \\
\hline 30.0 & Potable & 95 \\
\hline 42.5 & Deionized & 1010 \\
\hline 42.5 & Potable & 960 \\
\hline
\end{tabular}

The simulant strengths shown in Figures 4.13 and 4.14 completely encompass the range of strengths anticipated for dewatered TRU waste, including relatively high shear strength materials that can be used to test the upper bounds of the system operating window (e.g., $55 \mathrm{wt} \%$ kaolin:bentonite and 70 -wt $\%$ kaolin, both $>5000 \mathrm{~Pa}$ ). The shear strengths of the simulants as a function of solids (and water) content are compared to results for TRU waste samples in Figure 4.15. The results shown for B-203, T-203, and T-204 were obtained by Tingey et al. ${ }^{(a)}$ Starting from homogenized waste samples, they added water quantitatively to portions of the samples and measured the shear strength with a shear vane after allowing the samples to age ( $>48 \mathrm{hr}$ ). In the case of T-204, the three points are well fit by an exponential function,

(a) Tingey JM, J Gao, LM Bagaasen, and BE Wells. May 2003. Physical Property and Rheological Testing of Actual Transuranic Waste from Hanford Single-Shell Tanks. Letter report ST03.016, PNNL. 


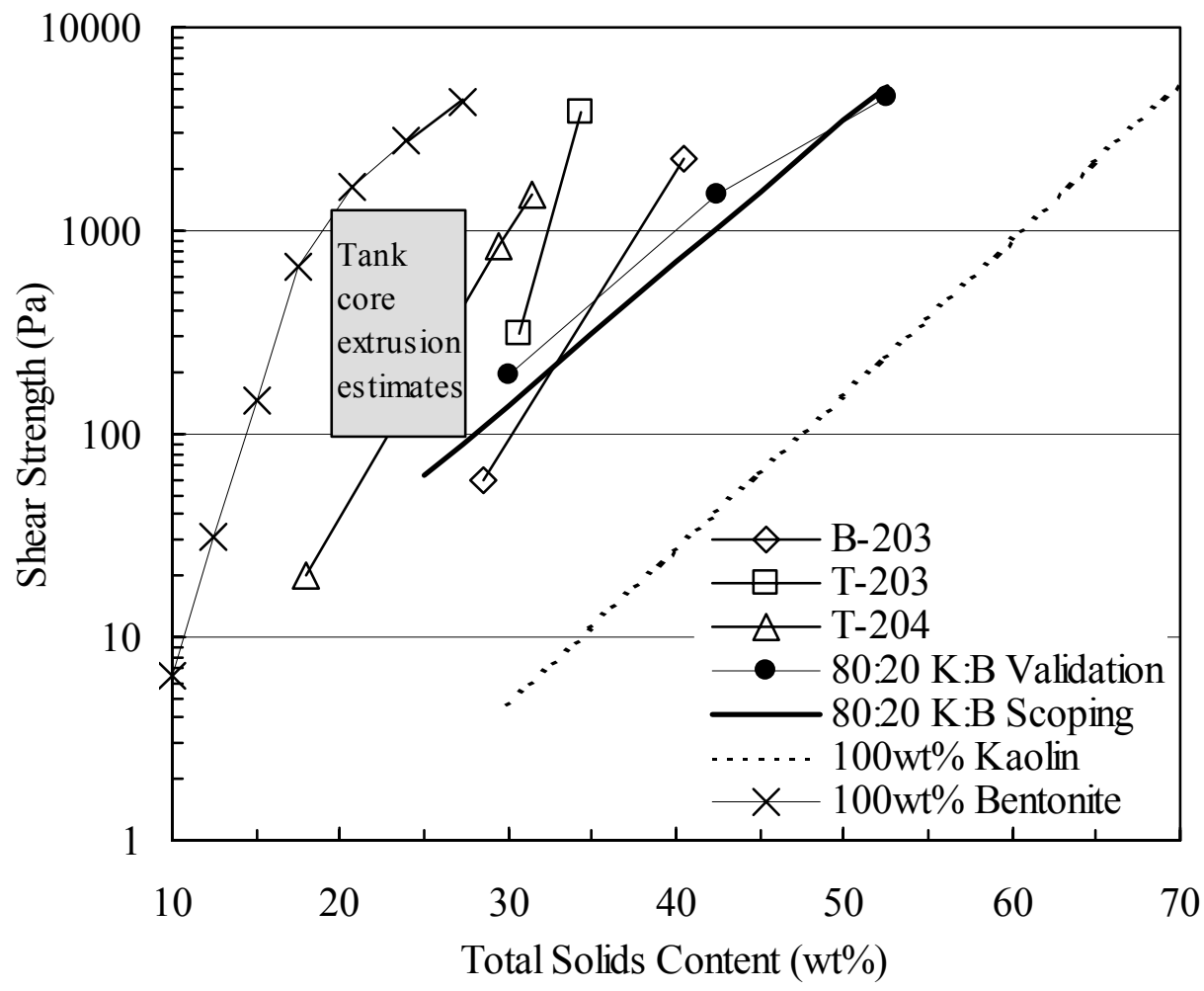

Figure 4.15. Shear Strength as a Function of Solids Content in TRU Waste Samples and Clay Simulants [shaded box represents core extrusion shear strength estimate/solids content relationship for majority of CH-TRU waste samples (Rassat et al. 2003)]

exhibiting a shear strength/solids content functional dependence similar to that noted for kaolin and kaolin:bentonite simulants in Figures 4.13 and 4.14. While the shear strength of actual waste (and simulants) is clearly related to the solids content, it should also be noted that other factors such as waste handling, chemistry, material microstructure, and time can affect waste strength.

The shaded box in Figure 4.15 captures the shear strength/solids content behavior for the majority of the CH-TRU waste samples assessed in Rassat et al. (2003, Figure 5.5). They estimated the waste shear strengths from videotapes of tank core extrusions and correlated the results to the reported water content for the same core segment. As shown in Figure 4.15, the Tingey et al. results for T-204 intersect the window of the TRU waste extrusion-based estimates.

The fit equations of shear strength as a function of solids content for the kaolin-based simulants given in Figures 4.13 and 4.14a are reproduced in Figure 4.15. For the kaolin:bentonite mixtures, the scoping and validation test data for six- to eight-day aged material are shown. Previously reported shear strength data for bentonite/water simulants are also reproduced in the figure (Gauglitz and Aiken 1997; Gauglitz et al. 2001). The series of simulant plots indicates that increasing the fraction of bentonite solids produces higher shear strength materials at lower overall solids content. In the extreme, the shear strengths of pure bentonite simulants are greater than the TRU wastes at a given solids content. While the series of curves for $80 \mathrm{wt} \%: 20 \mathrm{wt} \%$ kaolin:bentonite mixtures overlap a large portion of the TRU waste behavior at lower solids levels $(<30 \mathrm{wt} \%)$, the data suggest that higher fractions of bentonite $(>20 \mathrm{wt} \%)$ in kaolin:bentonite 
simulants would provide a better overall match of the TRU waste data. However, the 80:20 formulation is clearly an improvement over pure kaolin. Because of the increased difficulty in dewatering materials with greater bentonite content, the 80:20 kaolin:bentonite mixture is the recommended compromise for a single centrifugal dewatering and physical transport simulant.

Rassat et al. (2003) estimated from core extrusions that the majority of Hanford TRU waste in single-shell tanks has shear strengths in the range of $200-2000 \mathrm{~Pa}$, and $\sim 1000 \mathrm{~Pa}$ is a typical value. As shown in Figures 4.13 and $4.14, \sim 1000 \mathrm{~Pa}$ shear strength is obtained with $60-62.5 \mathrm{wt} \%$ kaolin simulants and 42.5 wt \% 80:20 kaolin:bentonite simulants. Using these clay solids fractions in Eq. 4.2, the bulk density of the typical strength kaolin simulant is $\sim 1.6-1.65 \mathrm{~g} / \mathrm{mL}$ and it is $\sim 1.35 \mathrm{~g} / \mathrm{mL}$ for the kaolin:bentonite base simulant. The latter is significantly closer to the $1.15-1.3 \mathrm{~g} / \mathrm{mL}$ range generally reported for CH-TRU waste core samples (Rassat et al. 2003) and is further justification for the use of 80:20 kaolin:bentonite as the centrifugal dewatering and physical transport simulant of choice.

\subsubsection{Viscous Properties}

The ideal transport simulant would also have viscous properties comparable to that of typical TRU waste when equivalently diluted. As noted above, a typical $\sim 1000 \mathrm{~Pa}$ shear strength is obtained with $60-62.5$ wt $\%$ kaolin simulants and $\sim 42.5 \mathrm{wt} \% 80: 20$ kaolin:bentonite simulants. The viscous properties of these simulants when diluted with water are compared to diluted samples of Tank B-201 core 26, segment 8 waste (1220 Pa shear strength; see Rassat et al. 2003) and Tank B-203 waste composite (2280 Pa shear strength as reported in Tingey et al. $\left.{ }^{(a)}\right)$. The data indicate that in the appropriate dilution, both 80:20 kaolin:bentonite and pure kaolin simulants could provide a reasonable match to the apparent viscosity of diluted TRU waste. However, on volume dilution basis, the 80:20 kaolin:bentonite simulant provides a slightly better match.

The rheology of diluted CH-TRU waste and clay simulant samples were both characterized with Haake viscometers and concentric-cylinder geometry. The samples consistently show shear-thinning behavior in which the apparent viscosity decreases with increasing shear rate as is characteristic of Bingham plastic and pseudoplastic materials. Rheograms obtained in the viscometer experiments give the measured shear stress $(\tau, \mathrm{Pa})$ as a function of applied shear or strain rate $\left(\gamma, \mathrm{s}^{-1}\right)$. For Bingham plastic and pseudoplastic materials, these experimental data can be fit to curves of the general functional form

$$
\tau=\tau_{\mathrm{o}}+\mathrm{K} \gamma^{\mathrm{n}}
$$

where $\tau_{\mathrm{o}}$ is the yield stress $(\mathrm{Pa}), \mathrm{K}$ is the consistency factor $\left(\mathrm{Pa}-\mathrm{s}^{\mathrm{n}}\right)$, and $\mathrm{n}$ is the power law index. As written, Eq. 4.3 is a model for yield power-law materials exhibiting a finite yield stress. Bingham plastics are a special case of Eq. 4.3 where the index $n=1$. Likewise, when $\tau_{\mathrm{o}}$ is set to 0, Eq. 4.3 is a model for power-law fluids exhibiting no yield stress. In terms of Eq. 4.3 , a Newtonian fluid is characterized by $\tau_{0}=$ 0 and $\mathrm{n}=1$ with $\mathrm{K}$ being the viscosity.

(a) Tingey JM, J Gao, LM Bagaasen, and BE Wells. May 2003. Physical Property and Rheological Testing of Actual Transuranic Waste from Hanford Single-Shell Tanks. Letter report ST03.016, PNNL. 
The model parameters obtained by fitting the experimental results for two diluted TRU waste samples (B-201 core 26 segment 8 and a B-203 composite), two diluted kaolin simulant samples (20 and $30 \mathrm{wt} \%$ solids), and two diluted samples of the 80:20 kaolin:bentonite formulation (14.2 and 21.25 -wt $\%$ solids) are summarized in Table 4.5. (The simulant data are for the $2^{\text {nd }}$ run up of the $1^{\text {st }}$ of 2 tests as shown in Section A.3.) These simulant samples represent 1:1 and 2:1 dilution by mass of baseline simulants of typical shear strength $(\sim 1000 \mathrm{~Pa})$. Table 4.5 also provides details of the dilution level expressed as the relative amount of water to "original" sludge in both volume and mass terms, and the estimated, measured, or formulated solids content of the diluted samples. The dilution information is provided because some experimental sample dilutions were made on a volume basis (i.e., B-201) and others were made on a mass basis. The solids content provides a common footing for comparison.

Table 4.5. Rheological Properties of Diluted TRU Waste Samples and Clay Simulants [Kaolin (K) and Bentonite (B)]

\begin{tabular}{|c|c|c|c|c|c|c|}
\hline Properties & $\begin{array}{c}\text { B-201 } \\
\text { Core } 26 \\
\text { Segment } 8^{(\mathrm{a})} \\
\end{array}$ & $\begin{array}{c}\text { B-203 } \\
\text { Composite }^{(b)}\end{array}$ & $\begin{array}{c}80 \% \text { K: } \\
20 \% \text { B }\end{array}$ & $\begin{array}{c}80 \% \text { K: } \\
20 \% \text { B }\end{array}$ & $\begin{array}{c}100 \% \\
\text { Kaolin }\end{array}$ & $\begin{array}{c}100 \% \\
\text { Kaolin }\end{array}$ \\
\hline $\begin{array}{l}\text { Effective Dilution, } \\
\text { volume water : volume sludge }\end{array}$ & $1: 1$ & $1.3: 1$ & $1.4: 1$ & $2.7: 1$ & $1.6: 1$ & $3.2: 1$ \\
\hline $\begin{array}{l}\text { Effective Dilution, } \\
\text { mass water : mass sludge }\end{array}$ & $0.8: 1$ & $1: 1$ & $1: 1$ & $2: 1$ & $1: 1$ & $2: 1$ \\
\hline $\begin{array}{l}\text { Measured, formulated, or } \\
\text { estimated solids content ( } \mathrm{wt} \% \text { ) }\end{array}$ & $\leq 20^{(\mathrm{c})}$ & 19.7 & 21.2 & 14.2 & 30 & 20 \\
\hline Rheogram model used & $\begin{array}{l}\text { Yield Power } \\
\text { Law }\end{array}$ & $\begin{array}{l}\text { Bingham } \\
\text { Plastic }\end{array}$ & $\begin{array}{l}\text { Yield } \\
\text { Power } \\
\text { Law } \\
\end{array}$ & $\begin{array}{c}\text { Yield } \\
\text { Power } \\
\text { Law } \\
\end{array}$ & $\begin{array}{c}\text { Yield } \\
\text { Power } \\
\text { Law } \\
\end{array}$ & $\begin{array}{c}\text { Yield } \\
\text { Power } \\
\text { Law } \\
\end{array}$ \\
\hline Model fit shear rate range $\left(\mathrm{s}^{-1}\right)$ & $0-500$ & $100-1000$ & $0-1000$ & $0-1000$ & $0-1000$ & $0-720$ \\
\hline Yield stress, $\tau_{\mathrm{o}}(\mathrm{Pa})$ & 8.1 & 3.15 & 5.43 & 0.93 & 6.02 & 1.25 \\
\hline Consistency factor, $\mathrm{K}\left(\mathrm{Pa}-\mathrm{s}^{\mathrm{n}}\right)$ & 0.047 & 0.00465 & 0.450 & .0708 & 1.259 & .0246 \\
\hline Power law index, $\mathrm{n}$ & 0.80 & $1^{(\mathrm{d})}$ & 0.52 & .65 & .34 & 0.72 \\
\hline $\begin{array}{l}\text { Apparent viscosity at } 500 \mathrm{~s}^{-1} \\
\text { (cP) }\end{array}$ & 30 & 11 & 34 & 10 & 33 & 7 \\
\hline \multicolumn{7}{|c|}{$\begin{array}{l}\text { (a) As reported in Rassat et al. (2003). } \\
\text { (b) As reported or derived from data in Tingey et al., Physical Property and Rheological Testing of Actual } \\
\text { Transuranic Waste from Hanford Single-Shell Tanks, letter report ST03.016, May 2003, PNNL. } \\
\text { (c) Solids content estimated at } 20 \mathrm{wt} \% \text { using a calculated undiluted sample density of } 1.33 \mathrm{~g} / \mathrm{mL} \text { and assuming a } \\
\text { maximum } 35 \mathrm{wt} \% \text { solids in the undiluted sample based on the extreme values reported for other B- and T-200 } \\
\text { series tank wastes (Rassat et al. 2003). } \\
\text { (d) One by definition. }\end{array}$} \\
\hline
\end{tabular}

The rheological parameters of Table 4.5 were used with Eq. 4.3 to calculate the apparent viscosity, defined as the shear stress divided by the shear rate $(\tau / \gamma)$. The viscosity values of the diluted TRU waste and simulant samples as a function of shear rate are shown in Figures 4.16 and 4.17. The results are presented on a linear plot in Figure 4.16 and on a log-log plot in Figure 4.17. The log-log format shows the relatively high apparent viscosities at low shear rates (e.g., $>120 \mathrm{cP}$ at $10 \mathrm{~s}^{-1}$ for all samples) and differences in shear thinning behavior. In particular, note that the 14.2-wt \% 80:20 kaolin:bentonite 


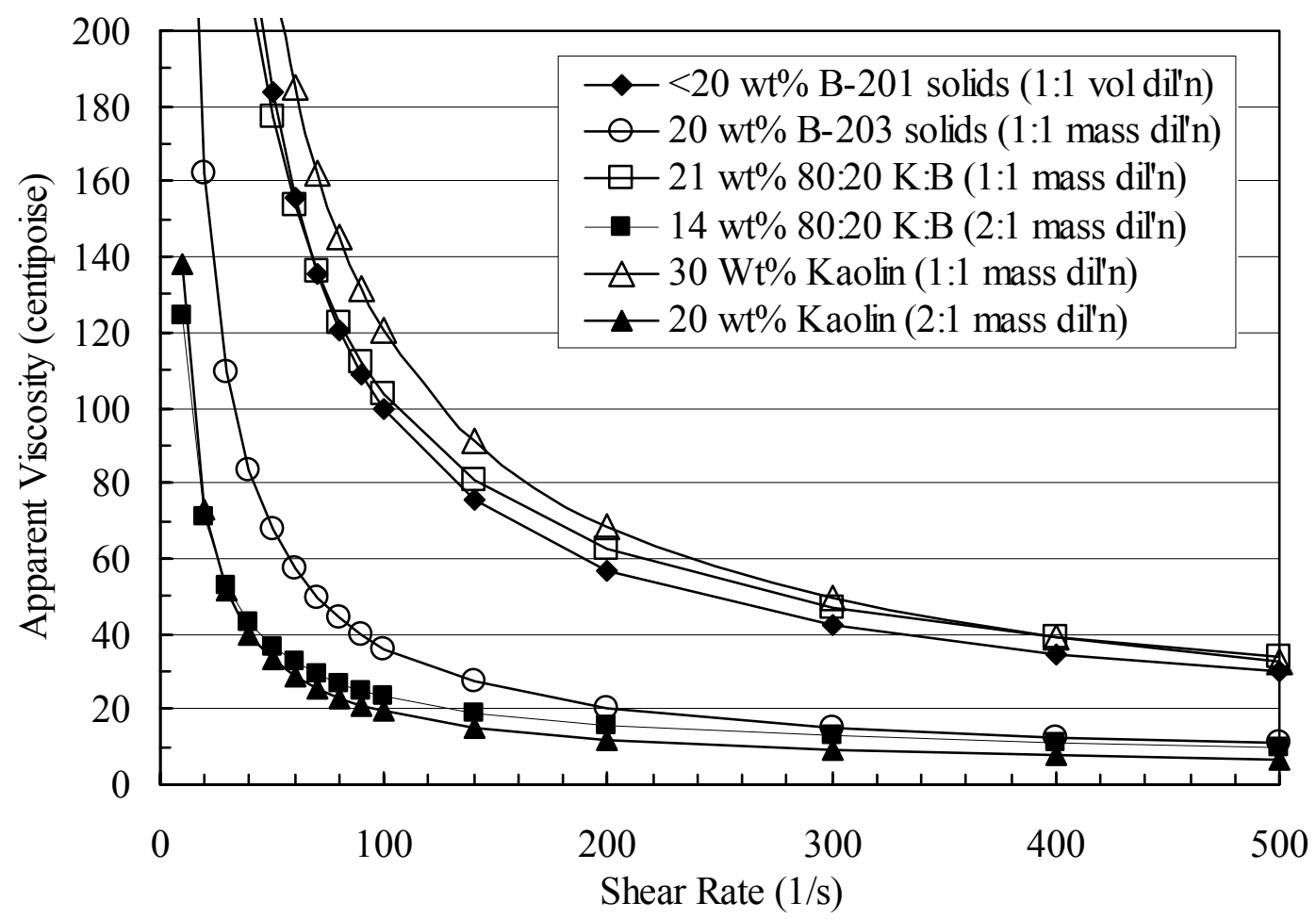

Figure 4.16. Apparent Viscosity of Diluted TRU Samples and Diluted Clay Simulants (linear scales)

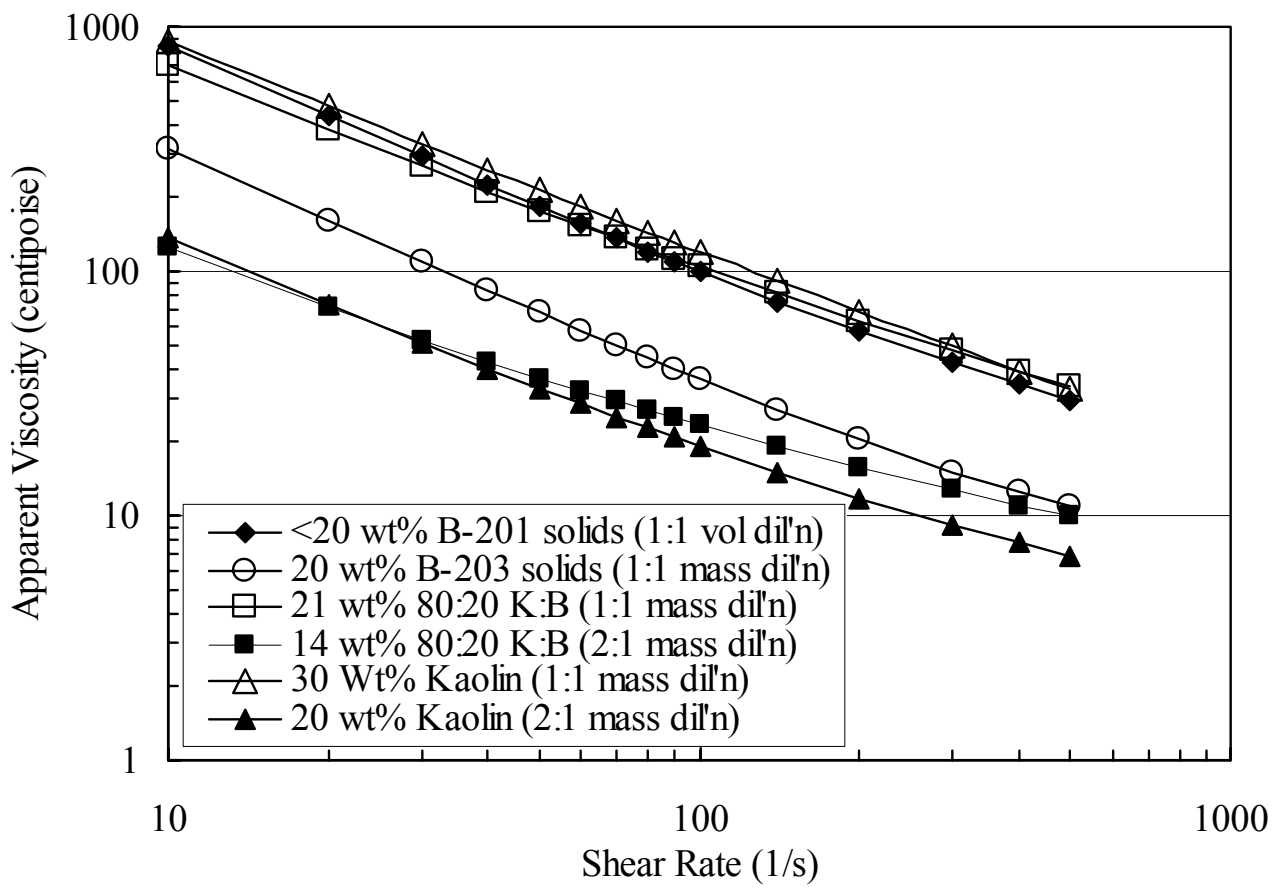

Figure 4.17. Apparent Viscosity of Diluted TRU Samples and Diluted Clay Simulants (logarithmic scale) 
simulant (2:1 mass basis or 2.7:1 volume basis dilution) has a shallower slope than the diluted TRU waste and kaolin simulant indicating that it is somewhat less shear thinning.

Figures 4.16 and 4.17 indicate a range of apparent viscosity values for diluted TRU waste samples. For example, at $500 \mathrm{~s}^{-1}$ the calculated apparent viscosity of the diluted B-201 sample is $30 \mathrm{cP}$, whereas the $\mathrm{B}-203$ composite value is $11 \mathrm{cP}$. This difference results at least in part from differences in the degree of dilution of the samples - the B-201 sample was diluted 1:1 water to waste on a volume basis $(\sim 0.8: 1$ mass basis), and the B-203 sample was diluted 1:1 on a mass basis ( 1.3:1 volume basis). However, other unspecified differences in the samples may contribute to the relatively high apparent viscosity in the B-201 sample. Of six samples from Tanks B-201 and B-202 diluted 1:1 on a volume basis, the apparent viscosity of the B-201, core 26, segment 8 sample is the highest (Rassat et al. 2003). Therefore, the apparent viscosity for this sample is shown in Figures 4.16 and 4.17 to represent waste viscosity levels approaching an unknown upper bound. The B-203 composite results are representative of the highest apparent viscosity values recently reported for comparably diluted samples from Tanks T-110, T-203, T-204, and B-203. ${ }^{\text {(a) }}$

Figures 4.16 and 4.17 show that 1:1 mass dilutions of typical shear strength kaolin simulant $(60-62.5-\mathrm{wt} \%$ solids) and 80:20 kaolin:bentonite simulant ( $42.5 \mathrm{wt} \%$ solids) have apparent viscosity values comparable to a 1:1 volume based dilution of the B-201 sample. The 2:1 mass dilutions of the baseline shear strength kaolin and kaolin:bentonite samples have apparent viscosity values less than the 1:1 mass based dilution of B-203 waste, and again the results for the two simulants are comparable on the basis of mass dilution. However, because the baseline kaolin simulant is more dense $(\sim 1.6 \mathrm{~g} / \mathrm{mL})$ than the 80:20 kaolin:bentonite simulant $(\sim 1.36 \mathrm{~g} / \mathrm{mL})$, the volume basis of the dilutions of pure kaolin are about $20 \%$ greater than for the kaolin:bentonite simulant as shown in Table 4.5. A 3:1 volume dilution $(\sim 1.8: 1$ mass basis) of the kaolin simulant is sufficient to bring the apparent viscosity within the range of the diluted TRU waste samples. The data suggest that the 80:20 kaolin:bentonite simulant represents the viscous properties of diluted TRU waste better than the kaolin simulant if considered on a volume basis. However, both simulant types can reasonably reproduce the range of apparent viscosity of the actual TRU waste samples with only modest adjustments in dilution.

(a) Tingey JM, J Gao, LM Bagaasen, and BE Wells. 2003. Physical Property and Rheological Testing of Actual Transuranic Waste from Hanford Single-Shell Tanks, letter report ST03.016, PNNL. 


\subsection{References}

Cooke GA. 2003. Tanks241-B-203, 241-T-110, 241-T-203, and T-204: MAI TRU Composite Preparation and Analytical Results for the Final Report. HNF-15703 Rev. 0, Fluor Hanford Inc., Richland, WA.

Gauglitz PA and JT Aikin. 1997. Waste Behavior During Horizontal Extrusion: Effect of Waste Strength for Bentonite and Kaolin/Ludox Simulants and Strength Estimates for Wastes from Hanford Tanks 241SY-103, $A W-101, A N-103$, and S-102. PNNL-11706, Pacific Northwest National Laboratory, Richland, WA.

Gauglitz PA, G Terrones, SJ Muller, MM Denn, and WR Rossen. 2001. Final Report-Mechanics of Bubbles in Sludges and Slurries. PNNL-13748, Pacific Northwest National Laboratory, Richland, WA.

Powell MR, CM Gates, CR Hymas, MA Sprecher, and NJ Morter. 1995. Fiscal Year 1994 1/25-Scale Sludge Mobilization Testing. PNL-10582, Pacific Northwest National Laboratory, Richland, WA.

Powell MR, GR Golcar, and JGH Geeting. 1997. Retrieval Process Development and Enhancements Waste Simulant Compositions and Defensibility. PNNL-11685, Pacific Northwest National Laboratory, Richland, WA.

Rassat SD, LA Mahoney, BE Wells, DP Mendoza, and DD Caldwell. 2003. Assessment of Physical Properties of Transuranic Waste in Hanford Single-Shell Tanks. PNNL-14221, Pacific Northwest National Laboratory, Richland, WA. 


\section{Appendix}

Additional Details of Physical Simulant Property Measurements 


\section{Appendix:}

\section{Additional Details of Physical Simulant Property Measurements}

The appendix includes additional details of scoping and validation experiments to assess physical simulant properties. The three sections provide 1) data for centrifugal dewatering of kaolin simulants, 2) shear strength values for kaolin and 80:20 kaolin:bentonite simulants, and 3) rheograms and viscosity data for diluted kaolin and kaolin:bentonite simulants.

\section{A.1 Centrifugal Dewatering of Kaolin Simulants}

Prior to the inclusion of bentonite with kaolin clay in the formulation of the TRU physical simulants, pure kaolin in varying proportions with water was identified as a promising candidate simulant system for centrifugal dewatering. This section provides results from early centrifugal dewatering scoping studies using kaolin/water simulants.

Figures A.1 through A.3 show the centrifugal dewatering behavior of kaolin/water mixtures as a function of applied settling force and time for $35-$ to $50-\mathrm{mL}$ samples in $50-\mathrm{mL}$ centrifuge tubes. At approximately $250 \mathrm{G}$, as presented in Figure A.1, kaolin/water mixtures with initial solids contents ranging from 45 to $60 \mathrm{wt} \%$ showed significant differences in settled sludge dewatering levels (about $3 \mathrm{wt} \%$ ) at 30 and 90 minutes, so tests were continued to 210 minutes. At 210 minutes, all samples had dewatered to about $67 \mathrm{wt} \%$ kaolin. At $\sim 500 \mathrm{G}$ (Figure A.2), the kaolin/water mixtures showed little change (about $1 \mathrm{wt} \%$ ) in

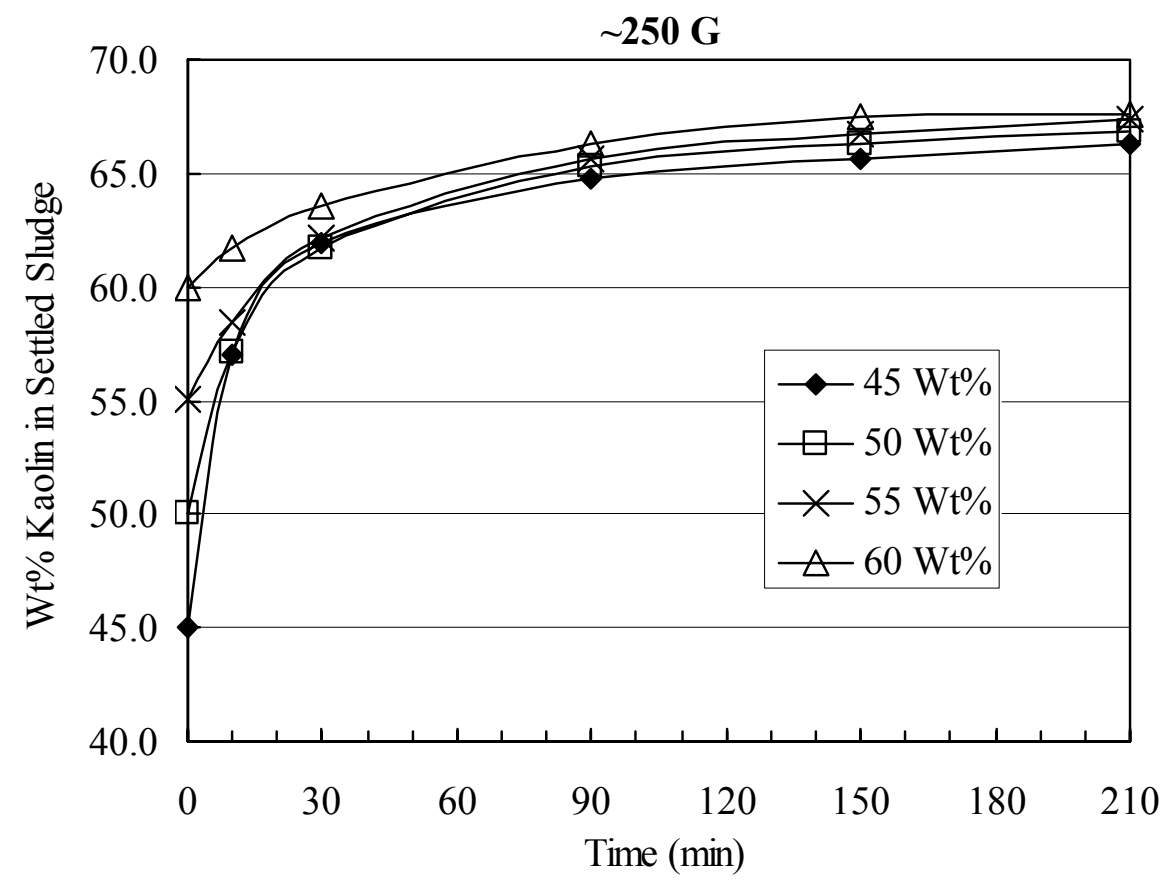

Figure A.1. 250-G Centrifuged Simulant Solids Content for Various Initial Simulant Formulations (kaolin wt \%) 


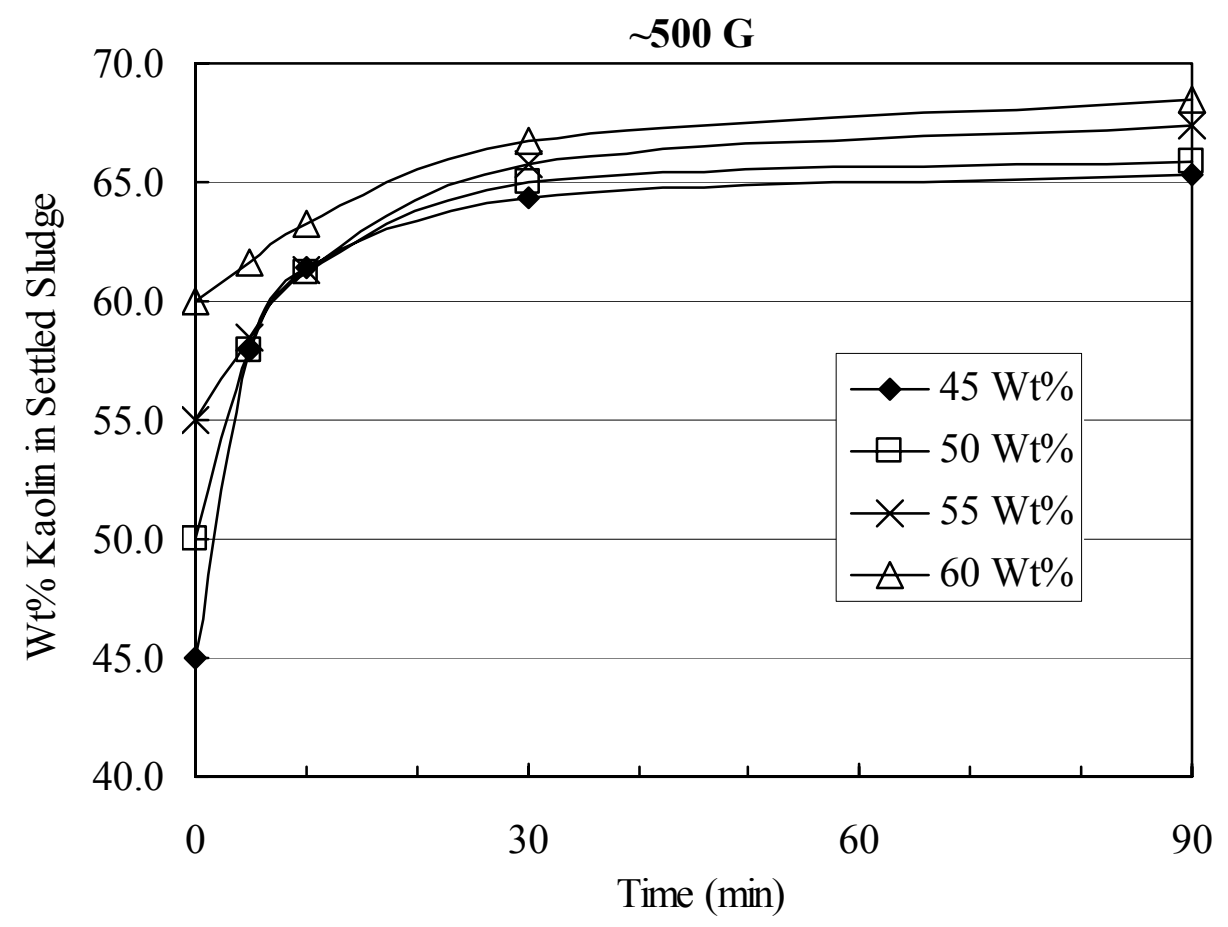

Figure A.2. $~ \quad 500-G$ Centrifuged Simulant Solids Content for Various Initial Simulant Formulations (kaolin wt\%)

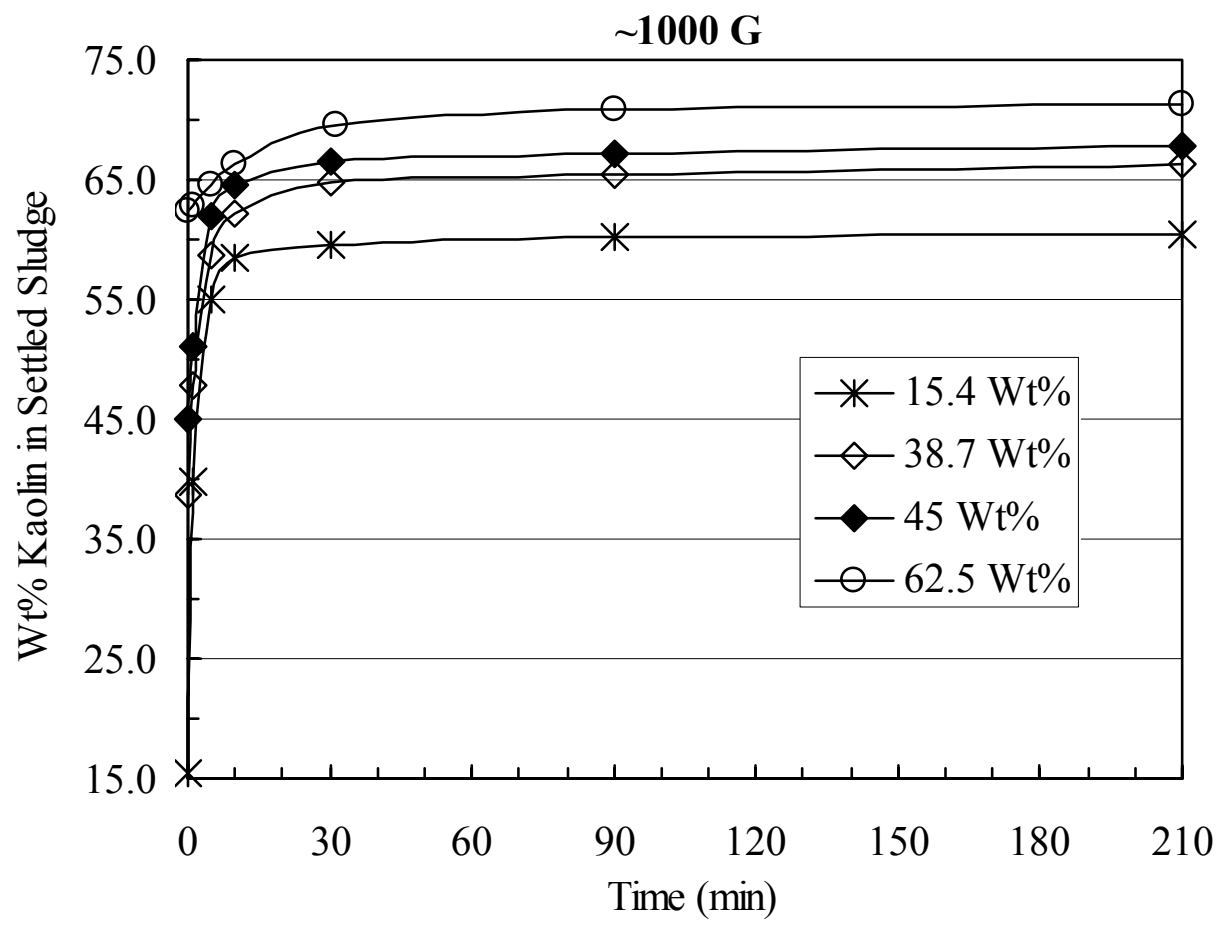

Figure A.3. 1000-G Centrifuged Simulant Solids Content for Various Initial Simulant Dilutions (kaolin wt\%) 
the dewatering level between 30 and 90 minutes, so tests were terminated after 90 minutes. At the higher settling force, all samples dewatered to levels of 65 to $68 \mathrm{wt} \%$ kaolin in 90 minutes, but a trend in dewatering level with initial starting solids content is also apparent. Samples with lower initial solids content dewater to slightly lower solids content in the given time.

The dewatering behavior at $\sim 1000 \mathrm{G}$ for kaolin/water mixtures with initial solids contents ranging from 15.4 to $62.5 \mathrm{wt} \%$ are shown in Figure A.3. (The 15.4-wt\% kaolin/water slurry represents a 5:1 dilution by volume with water of $62.5-\mathrm{wt} \%$ kaolin sludge.) Like the $500-\mathrm{G}$ tests, the $1000-\mathrm{G}$ experiments showed little change in the dewatering level between 30 and 90 minutes. However, additional tests were conducted to 210 minutes to verify that little additional dewatering was occurring at longer times. The results for the wider range of initial solids content and the higher setting force show a more pronounced effect where lower initial solids contents dewater to lower settled solids contents. For example, the 15.4-wt\% kaolin slurry settled to a solids content of $60 \mathrm{wt} \%$, while the $62.5-\mathrm{wt} \%$ kaolin sludge settled to over $70 \mathrm{wt} \%$. This variation may be due to the higher solids content samples having a deeper layer of settled solids that exert more force on the lower segments of the settled layer, resulting in greater compaction and higher solids loading.

\section{A.2 Shear Strength of Kaolin and Kaolin:Bentonite Simulants}

The shear strength data for kaolin and 80:20 kaolin:bentonite simulants in Section 4.3 of the report are tabulated in Tables A.1 and A.2. As described in Section 4.1.3, the shear strength measurements were made on a Haake rheometer with an M5 head using shear vanes submerged into the simulant samples. The shear strength $\tau$ is determined from the maximum torque $T$ measured while rotating the shear vane in the sample. For submerged shear vanes, the shear strength is related to the torque as follows:

$$
\tau=\frac{T}{K}=\frac{T}{\frac{\pi D^{3}}{2}\left(\frac{H}{D}+\frac{1}{3}\right)}
$$

The geometric constant $\mathrm{K}$ is a function of the shear vane height $H$ and diameter $D$. For all validation studies and follow-on tests, a $1.6-\mathrm{cm} \times 1.6-\mathrm{cm}(H \mathrm{x} D)$ vane was used. This vane was also used in some scoping tests. Two other vanes were used in scoping studies: 1 ) a nominal $7 / 8$-in $\mathrm{x} 7 / 8$-in. vane was used for weak to moderate strength materials; and 2) a $1.6-\mathrm{cm} \times 0.8-\mathrm{cm}(H \times D)$ vane was used for some strong to very strong materials.

Unless otherwise specified, opened bags of ('old') kaolin and bentonite available in the laboratory were used in all scoping tests, and previously unopened bags of clay, identified as 'new', were used in all QA validation studies. In Tables A.1 and A.2, the shear strengths of fresh or re-mixed samples were tested within $1 \mathrm{hr}$ of preparation or within an hour after thoroughly mixing an aged sample with a spoon or spatula. Void was removed from the samples as best as possible by pressing the sample into the container and tapping the container repeatedly on a hard surface. For aged samples, the void was removed before storing at room temperature in a laboratory. Where standard deviations are reported, three or four measurements were taken in the same sample (with the exception of only two measurements in one case). 
Table A.1. Measured Shear Strength of $80 \mathrm{wt} \%$ Kaolin:20 wt $\%$ Bentonite/Water Simulants

\begin{tabular}{|c|c|c|c|c|c|}
\hline \multirow{2}{*}{$\begin{array}{l}\text { Wt } \% \\
\text { Clay }\end{array}$} & \multirow{2}{*}{ Test Description } & \multicolumn{2}{|c|}{$\begin{array}{c}\text { Fresh or Re-mixed Samples } \\
(<1 \mathrm{hr})\end{array}$} & \multicolumn{2}{|c|}{ Aged Samples } \\
\hline & & State & \begin{tabular}{|l|} 
Shear Strength \\
\pm Std. Dev. (Pa)
\end{tabular} & Age & $\begin{array}{l}\text { Shear Strength } \pm \\
\text { Std. Dev. (Pa) }\end{array}$ \\
\hline 25 & Scoping test & Fresh & 33 & $\sim 6$ day & 51 \\
\hline 30 & Scoping test & Fresh & 58 & NA & NA \\
\hline 30 & Scoping test & Re-mixed & 65 & $\sim 6$ day & 140 \\
\hline 30 & QA validation test & Re-mixed & $118 \pm 4$ & $\sim 8$ day & $196 \pm 2$ \\
\hline 30 & $\begin{array}{c}\text { Scoping test following QA } \\
\text { validation test, 'new' clays/DI } \\
\text { water }\end{array}$ & $\begin{array}{c}\text { Fresh, } \\
\text { Re-mixed }\end{array}$ & $101 \pm 4$ & NA & NA \\
\hline 30 & $\begin{array}{c}\text { Scoping test following QA } \\
\text { validation test, 'new' clays/tap } \\
\text { water }\end{array}$ & $\begin{array}{c}\text { Fresh, } \\
\text { Re-mixed }\end{array}$ & $95 \pm 8$ & NA & NA \\
\hline 30 & $\begin{array}{c}\text { Scoping test following QA } \\
\text { validation test, 'old' clays/DI } \\
\text { water }\end{array}$ & $\begin{array}{c}\text { Fresh, } \\
\text { Re-mixed }\end{array}$ & $63 \pm 12$ & NA & NA \\
\hline 35 & Scoping test & Fresh & 160 & $\sim 6$ day & 380 \\
\hline 40 & Scoping test & Fresh & 490 & NA & NA \\
\hline 40 & Scoping test & Re-mixed & 420 & $\sim 6$ day & 750 \\
\hline 42.5 & Scoping test & Fresh & 720 & $\sim 8$ day & $1120 \pm 10$ \\
\hline 42.5 & Scoping test & NA & NA & $\sim 13$ day & 1290 \\
\hline 42.5 & QA validation test & Re-mixed & $1050 \pm 10$ & $\sim 8$ day & $1520 \pm 40$ \\
\hline 42.5 & $\begin{array}{c}\text { Scoping test following QA } \\
\text { validation test, 'new' clays/DI } \\
\text { water }\end{array}$ & $\begin{array}{c}\text { Fresh, } \\
\text { Re-mixed }\end{array}$ & $1010 \pm 10$ & NA & NA \\
\hline 42.5 & $\begin{array}{c}\text { Scoping test following QA } \\
\text { validation test, 'new' clays/tap } \\
\text { water }\end{array}$ & $\begin{array}{c}\text { Fresh, } \\
\text { Re-mixed }\end{array}$ & $960 \pm 30$ & NA & NA \\
\hline 42.5 & $\begin{array}{c}\text { Scoping test following QA } \\
\text { validation test, 'old' clays/DI } \\
\text { water }\end{array}$ & $\begin{array}{c}\text { Fresh, } \\
\text { Re-mixed }\end{array}$ & $740 \pm 20$ & NA & NA \\
\hline 45 & Scoping test & Fresh & 1140 & $\sim 6$ day & 1600 \\
\hline 50 & Scoping test & Fresh & 2700 & NA & NA \\
\hline 50 & Scoping test & Re-mixed & 2290 & $\sim 6$ day & 3230 \\
\hline 52.5 & Scoping test & Fresh & 3890 & $\sim 8$ day & 4570 \\
\hline 52.5 & Scoping test & NA & NA & $\sim 13$ day & $4510 \pm 30$ \\
\hline 52.5 & QA validation test & Re-mixed & $3530 \pm 60$ & $\sim 8$ day & $4610 \pm 80$ \\
\hline 55 & Scoping test & Fresh & 5020 & $\sim 8$ day & $5300 \pm 90$ \\
\hline 55 & Scoping test & NA & NA & $\sim 13$ day & $5560 \pm 370$ \\
\hline
\end{tabular}


Table A.2. Measured Shear Strength of Kaolin/Water Simulants

\begin{tabular}{|c|c|c|c|}
\hline $\begin{array}{l}\text { Wt\% } \\
\text { Clay }\end{array}$ & Test Description & State & $\begin{array}{l}\text { Shear Strength } \\
\pm \text { Std. Dev. (Pa) } \\
\end{array}$ \\
\hline 35 & Scoping test & NA & $20 \pm 3$ \\
\hline 37.5 & Scoping test & NA & $23 \pm 1$ \\
\hline 40 & Scoping test & $\mathrm{NA}$ & $31 \pm 0.3$ \\
\hline 42.5 & Scoping test & NA & $39 \pm 1$ \\
\hline 45 & Scoping test & NA & $52 \pm 1$ \\
\hline $45^{\text {(a) }}$ & QA validation test & $\sim 8$ day aged & $69 \pm 4$ \\
\hline 45 & QA validation test & Re-mixed & $50 \pm 1$ \\
\hline 47.5 & Scoping test & NA & $89 \pm 1$ \\
\hline 50 & Scoping test & NA & $122 \pm 6$ \\
\hline 52.5 & Scoping test & NA & $210 \pm 10$ \\
\hline 55 & Scoping test & NA & $321 \pm 6$ \\
\hline 57.5 & Scoping test & NA & $516 \pm 8$ \\
\hline 60 & Scoping test & NA & $810 \pm 10$ \\
\hline 60 & QA validation test & $\sim 8$ day aged & $790 \pm 20$ \\
\hline 60 & QA validation test & Re-mixed & $840 \pm 40$ \\
\hline 62.5 & Scoping test & NA & $1270 \pm 40$ \\
\hline 65 & Scoping test & $\mathrm{NA}$ & $2010 \pm 60$ \\
\hline 65 & QA validation test & $\sim 8$ day aged & $2300 \pm 90$ \\
\hline 65 & QA validation test & Re-mixed & $2250 \pm 180$ \\
\hline 70 & Scoping test & NA & $8000 \pm 690$ \\
\hline
\end{tabular}

(a) The aged sample had a small layer of supernatant liquid due to gravity settling. The shear strength was measured in the settled sludge layer.

\section{A.3 Viscosity of Kaolin and Kaolin:Bentonite Simulants}

The viscosity of two diluted kaolin simulants (30 and $20 \mathrm{wt} \%$ ) and two diluted 80:20 kaolin:bentonite simulants (21.25 and $14.2 \mathrm{wt} \%)$ were measured in validation studies. As noted previously, these samples represent 1:1 and 2:1 dilution by mass of baseline simulants of typical shear strength $(\sim 1000 \mathrm{~Pa})$. Details of the experimental method are provided in Section 4.1.3, and the experimental results are discussed in Section 4.3.2 of the report. Each of the four viscosity samples was run in duplicate, cleaning the viscometer cup and cylinder between replicates. The consistency of the duplicate tests was very good as is demonstrated by the reproducibility of the curve fit parameters for the tests shown in Tables A.3 through A.6 (20-wt\% kaolin, 30-wt\% kaolin, 14.2-wt\% 80:20 kaolin:bentonite, and 21.25-wt\% kaolin:bentonite, respectively). The tables show the shear rate range over which the data were fit. Although power law and Bingham plastic models also fit the data quite well in most cases, the yield power law model (Herschel-Bulkley) consistently provided the best fit of the experimental rheograms (shear stress measured as a function of shear rate). The rheograms and calculated apparent viscosity (shear stress divided by shear rate) for the first of two tests of each simulant are shown in Figures A.4 to A.7. 
Table A.3. Summary of Hershel-Bulkley Curve Fit Parameters of $20-w t \%$ Kaolin Clay in Water (Test temperature: $25^{\circ} \mathrm{C} \pm 0.1^{\circ} \mathrm{C}$ )

\begin{tabular}{|c|c|c|c|c|c|c|}
\hline $\begin{array}{l}\text { Test } \\
\text { No. }\end{array}$ & Test Run Status & $\begin{array}{c}\text { Shear Rate } \\
\text { Range } \\
\gamma(1 / \mathbf{s})\end{array}$ & $\begin{array}{c}\text { Yield } \\
\text { Stress } \\
\tau_{0}(\mathrm{~Pa})\end{array}$ & $\begin{array}{c}\text { Consistency } \\
\text { Factor } \\
\mathbf{K} \times \mathbf{1 0}^{3}\left(\mathbf{P a} \cdot \mathbf{s}^{\mathbf{n}}\right)\end{array}$ & $\begin{array}{c}\text { Index } \\
\quad \mathbf{n}\end{array}$ & $\mathbf{R}^{2}$ \\
\hline \multirow{4}{*}{1} & $1^{\text {st }}$ run-up & \multirow{4}{*}{$0-720$} & 0.63 & 15.9 & 0.78 & 0.9962 \\
\hline & $1^{\text {st }}$ run-down & & 1.15 & 42.9 & 0.63 & 0.9992 \\
\hline & $2^{\text {nd }}$ run-up & & 1.25 & 24.6 & 0.72 & 0.9984 \\
\hline & $2^{\text {nd }}$ run-down & & 1.43 & 46.7 & 0.63 & 0.9992 \\
\hline \multirow{4}{*}{2} & $1^{\text {st }}$ run-up & \multirow{4}{*}{$0-730$} & 0.71 & 36.7 & 0.67 & 0.9954 \\
\hline & $1^{\text {st }}$ run-down & & 1.24 & 40.9 & 0.64 & 0.9992 \\
\hline & $2^{\text {nd }}$ run-up & & 1.30 & 31.0 & 0.69 & 0.9980 \\
\hline & $2^{\text {nd }}$ run-down & & 1.41 & 50.0 & 0.62 & 0.9994 \\
\hline
\end{tabular}

Table A.4. Summary of Hershel-Bulkley Curve Fit Parameters of $30-w t \%$ Kaolin Clay in Water (test temperature, $25^{\circ} \mathrm{C} \pm 0.1^{\circ} \mathrm{C}$ )

\begin{tabular}{|c|c|c|c|c|c|c|}
\hline $\begin{array}{l}\text { Test } \\
\text { No. }\end{array}$ & Test Run Status & $\begin{array}{c}\begin{array}{c}\text { Shear Rate } \\
\text { Range } \\
\gamma(1 / s)\end{array} \\
\end{array}$ & $\begin{array}{c}\text { Yield } \\
\text { Stress } \\
\tau_{0}(\mathbf{P a})\end{array}$ & $\begin{array}{c}\text { Consistency } \\
\text { Factor } \\
\mathbf{K} \times 10^{3}\left(\mathbf{P a} \cdot \mathbf{s}^{n}\right)\end{array}$ & $\begin{array}{c}\text { Index } \\
\text { n }\end{array}$ & $\mathbf{R}^{2}$ \\
\hline \multirow{4}{*}{1} & $1^{\text {st }}$ run-up & \multirow{4}{*}{$0-1000$} & 5.11 & 139 & 0.64 & 0.9884 \\
\hline & $1^{\text {st }}$ run-down & & 6.15 & 1,596 & 0.29 & 0.9904 \\
\hline & $2^{\text {nd }}$ run-up & & 6.02 & 1,259 & 0.34 & 0.9803 \\
\hline & $2^{\text {nd }}$ run-down & & 8.20 & 886 & 0.37 & 0.9950 \\
\hline \multirow{4}{*}{2} & $1^{\text {st }}$ run-up & \multirow{4}{*}{$0-1000$} & 3.91 & 542 & 0.45 & 0.9799 \\
\hline & $1^{\text {st }}$ run-down & & 6.28 & 1,233 & 0.31 & 0.9924 \\
\hline & $2^{\text {nd }}$ run-up & & 5.64 & 1,252 & 0.33 & 0.9813 \\
\hline & $2^{\text {nd }}$ run-down & & 7.69 & 741 & 0.39 & 0.9956 \\
\hline
\end{tabular}

Table A.5. Summary of Hershel-Bulkley Curve Fit Parameters of 14.2-wt\% Clay in Water (80:20 Kaolin:Bentonite; Test temperature: $25^{\circ} \mathrm{C} \pm 0.1^{\circ} \mathrm{C}$ )

\begin{tabular}{|c|c|c|c|c|c|c|}
\hline $\begin{array}{l}\text { Test } \\
\text { No. }\end{array}$ & Test Run Status & $\begin{array}{c}\text { Shear Rate } \\
\text { Range } \\
\gamma(1 / \mathbf{s})\end{array}$ & $\begin{array}{c}\text { Yield Stress } \\
\tau_{0}(\mathrm{~Pa})\end{array}$ & $\begin{array}{c}\text { Consistency } \\
\text { Factor } \\
\mathrm{K} \times 10^{3}\left(\mathrm{~Pa}^{\mathrm{n}} \mathbf{s}^{\mathrm{n}}\right)\end{array}$ & $\begin{array}{c}\text { Index } \\
\quad n\end{array}$ & $\mathbf{R}^{2}$ \\
\hline \multirow{4}{*}{1} & $1^{\text {st }}$ run-up & \multirow{4}{*}{$0-1000$} & -0.27 & 42.9 & 0.74 & 0.9988 \\
\hline & $1^{\text {st }}$ run-down & & 0.83 & 63.7 & 0.66 & 0.9994 \\
\hline & $2^{\text {nd }}$ run-up & & 0.93 & 70.8 & 0.65 & 0.9990 \\
\hline & $2^{\text {nd }}$ run-down & & 0.88 & 56.0 & 0.68 & 0.9982 \\
\hline \multirow{4}{*}{2} & $1^{\text {st }}$ run-up & \multirow{4}{*}{$0-1000$} & -0.18 & 26.0 & 0.82 & 0.9988 \\
\hline & $1^{\text {st }}$ run-down & & 0.83 & 72.6 & 0.64 & 0.9978 \\
\hline & $2^{\text {nd }}$ run-up & & 0.96 & 74.4 & 0.65 & 0.9990 \\
\hline & $2^{\text {nd }}$ run-down & & 0.84 & 65.4 & 0.66 & 0.9990 \\
\hline
\end{tabular}


Table A.6. Summary of Hershel-Bulkley Curve Fit Parameters of 21.25-wt\% Clay in Water (80:20 kaolin:bentonite; test temperature, $25^{\circ} \mathrm{C} \pm 0.1^{\circ} \mathrm{C}$ )

\begin{tabular}{|c|c|c|c|c|c|c|}
\hline $\begin{array}{l}\text { Test } \\
\text { No. }\end{array}$ & Test Run Status & $\begin{array}{c}\text { Shear Rate } \\
\text { Range } \\
\gamma(1 / \mathbf{s})\end{array}$ & $\begin{array}{c}\text { Yield Stress } \\
\tau_{0}(\mathbf{P a})\end{array}$ & $\begin{array}{c}\text { Consistency } \\
\text { Factor } \\
\mathbf{K} \times \mathbf{1 0}^{3}\left(\mathbf{P a} \cdot \mathbf{s}^{\mathbf{n}}\right)\end{array}$ & $\begin{array}{c}\text { Index } \\
\quad \mathbf{n}\end{array}$ & $\mathbf{R}^{2}$ \\
\hline \multirow{4}{*}{1} & $1^{\text {st }}$ run-up & \multirow{4}{*}{$0-1000$} & 1.26 & 1,356 & 0.40 & 0.9956 \\
\hline & $1^{\text {st }}$ run-down & & 5.34 & 271 & 0.59 & 0.9996 \\
\hline & $2^{\text {nd }}$ run-up & & 5.43 & 450 & 0.52 & 0.9982 \\
\hline & $2^{\text {nd }}$ run-down & & 4.96 & 261 & 0.60 & 0.9996 \\
\hline \multirow{4}{*}{2} & $1^{\text {st }}$ run-up & \multirow{4}{*}{$0-1000$} & 1.05 & 1,167 & 0.42 & 0.9942 \\
\hline & $1^{\text {st }}$ run-down & & 5.24 & 272 & 0.59 & 0.9996 \\
\hline & $2^{\text {nd }}$ run-up & & 5.31 & 452 & 0.52 & 0.9984 \\
\hline & $2^{\text {nd }}$ run-down & & 4.85 & 261 & 0.60 & 0.9996 \\
\hline
\end{tabular}



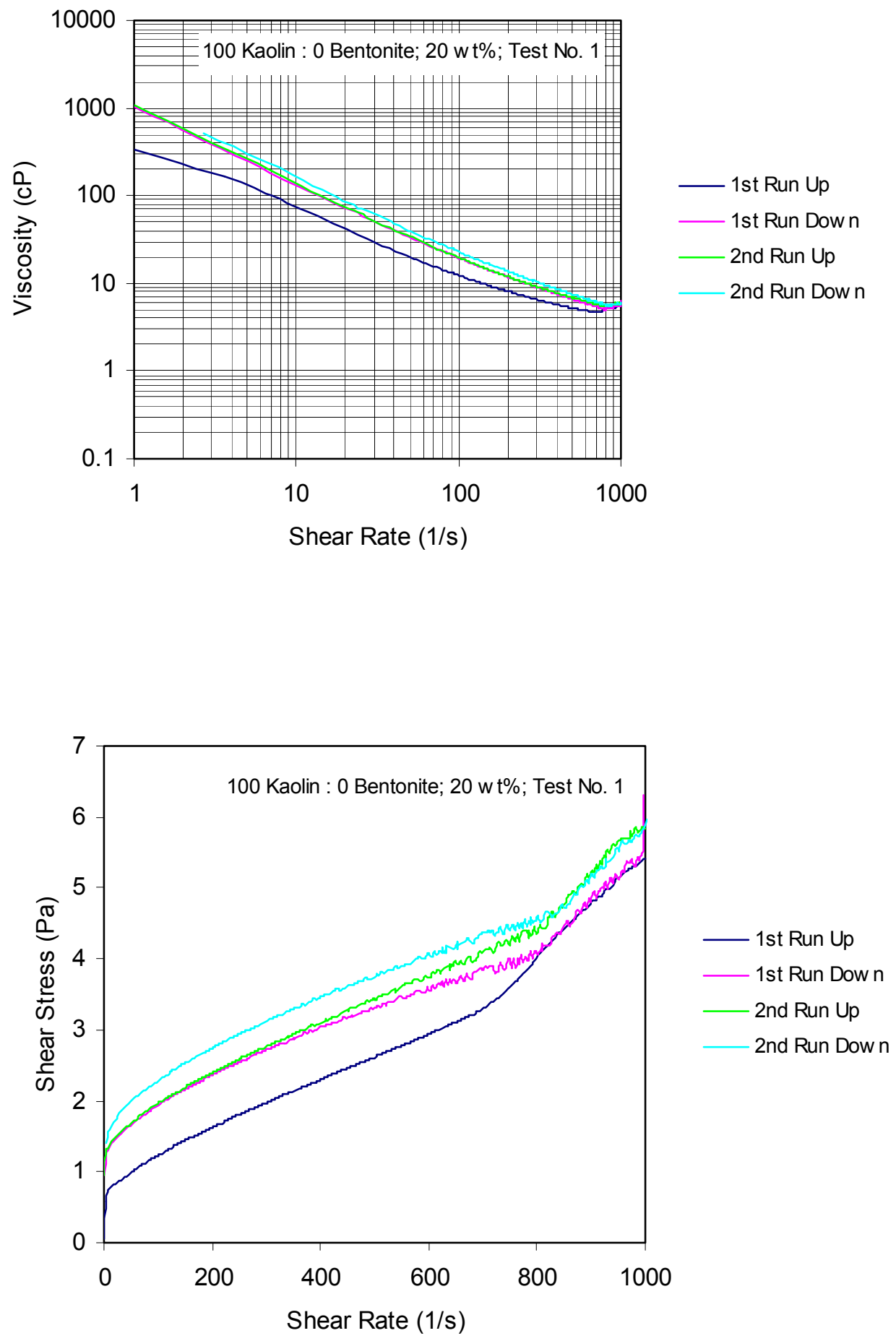

Figure A.4. Calculated Apparent Viscosity (upper) and Experimental Rheogram (lower) for a $20-w t \%$ Kaolin/Water Simulant 

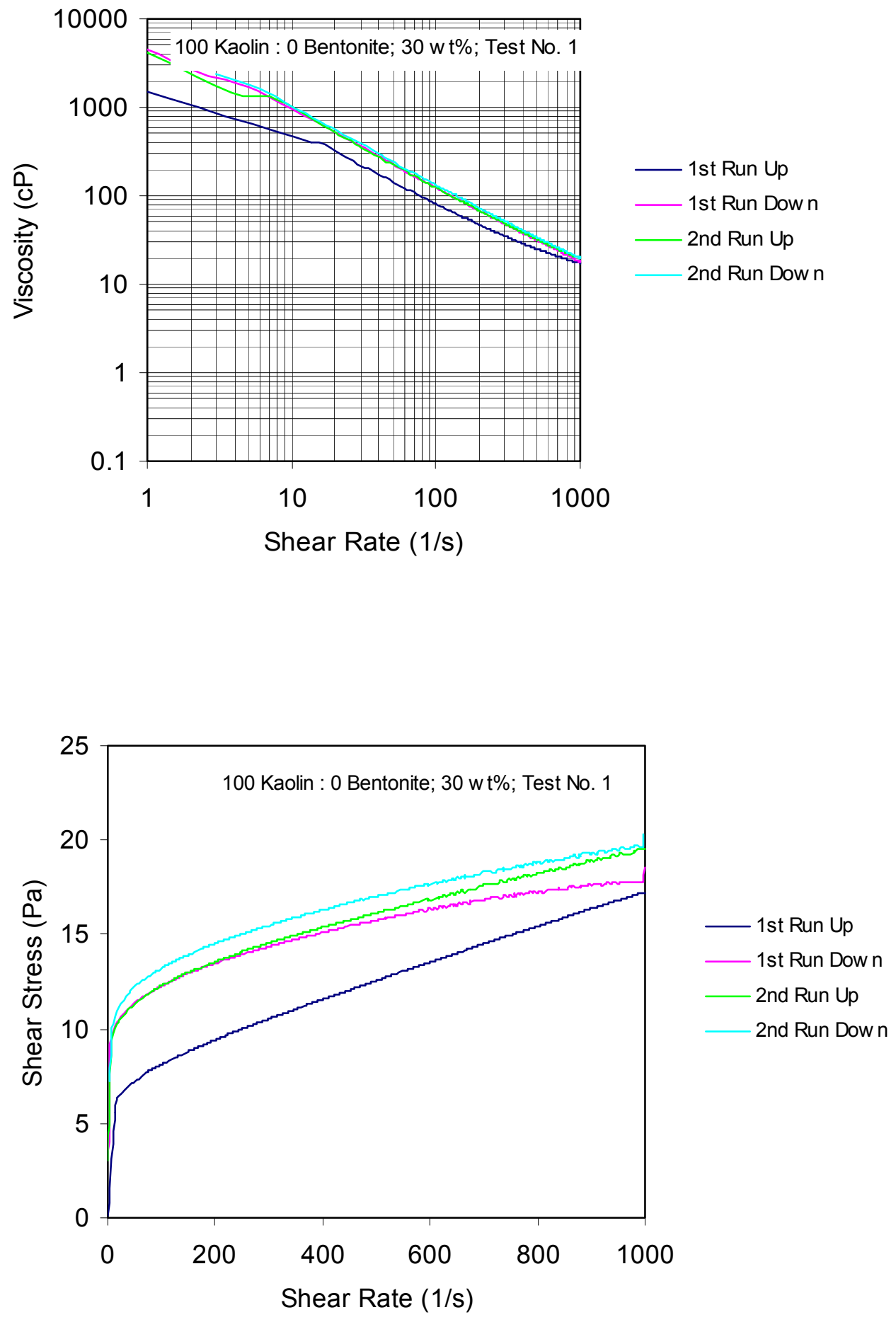

Figure A.5. Calculated Apparent Viscosity (upper) and Experimental Rheogram (lower) for a $30-w t \%$ Kaolin/Water Simulant 

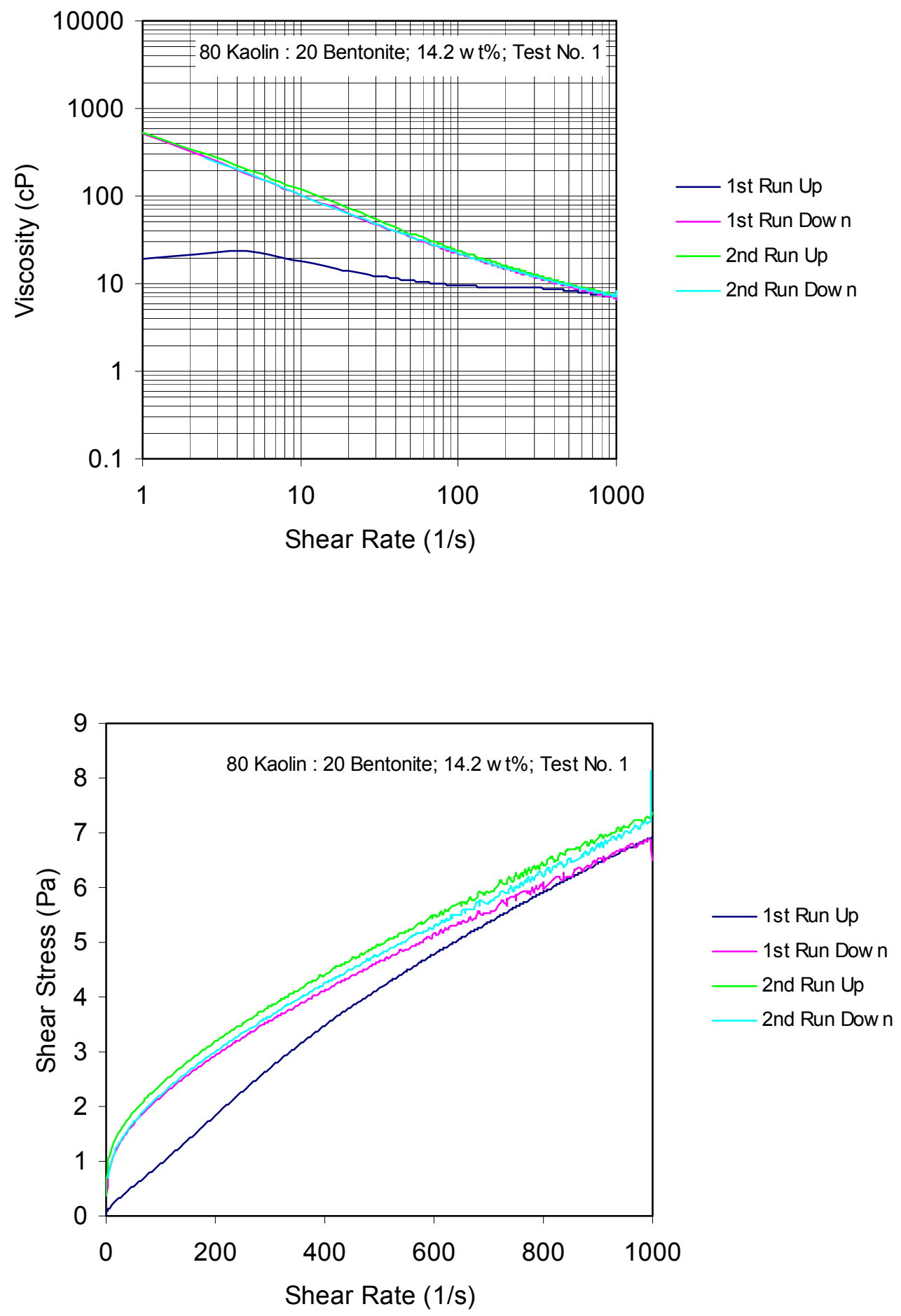

Figure A.6. Calculated Apparent Viscosity (upper) and Experimental Rheogram (lower) for a 14.2-wt\% 80:20 Kaolin:Bentonite/Water Simulant 

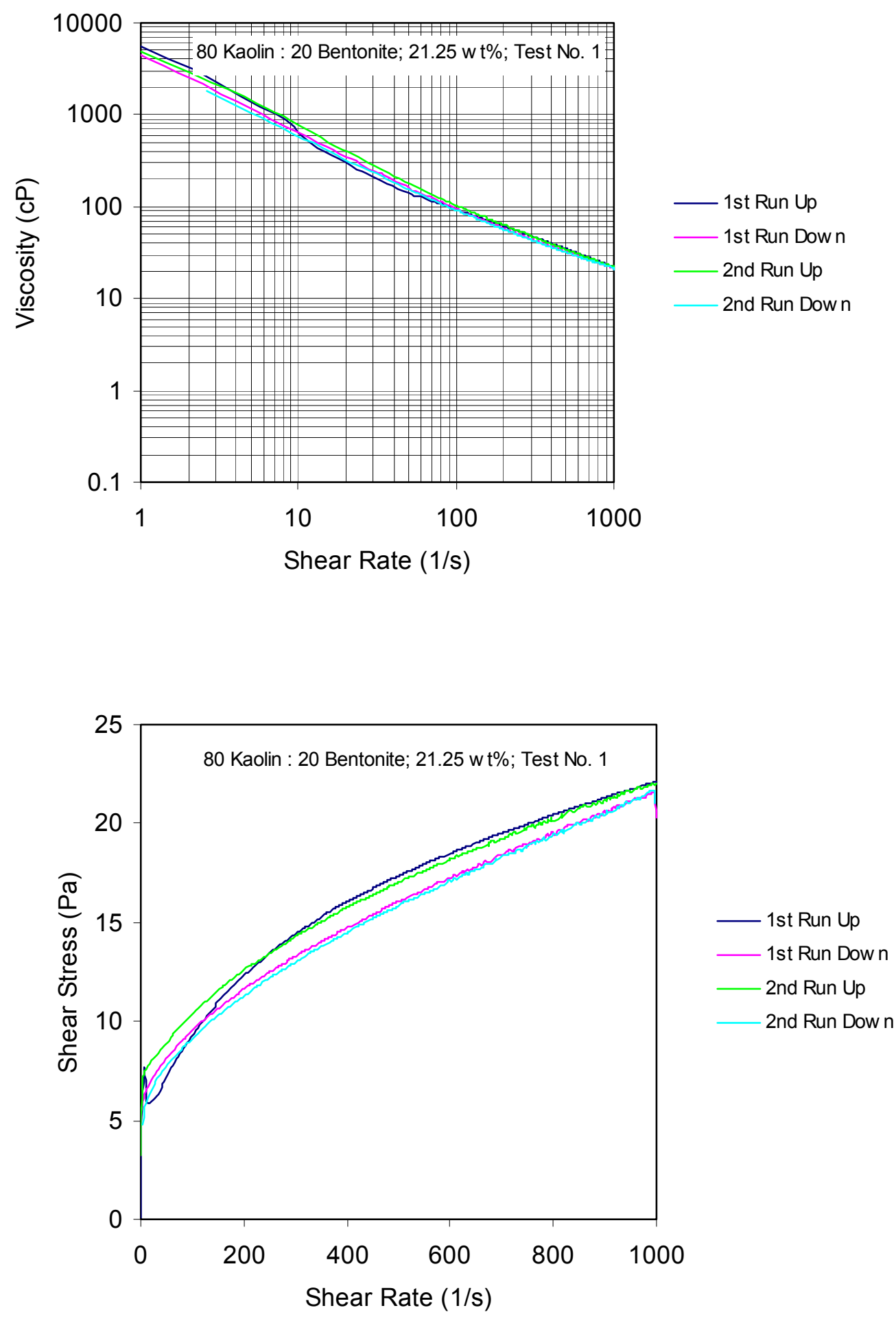

Figure A.7. Calculated Apparent Viscosity (upper) and Experimental Rheogram (lower) for a 21.25-wt\% 80:20 Kaolin:Bentonite/Water Simulant 


\section{Distribution}

No. of

Copies

ONSITE

DOE Richland Operations Office

T. P. Pietrok

DOE-Office of River Protection

B. M. Mauss

19 CH2M HILL

K. D. Boomer

L4-07

P. M. Branson

W. E. Bryan

D. W. Hamilton

M. E. Johnson

J. G. Kristofzski

M. W. Leonard

T. H. May

R. W. Powell (5)

R. E. Raymond

G. W. Reddick, Jr.

D. B. Smet

A. R. Tedeschi (3)
No. of

Copies

1 Numatec

C. M. Creze

S7-65

34 Pacific Northwest National Laboratory

L. M. Bagaasen

K6-28

S. Q. Bennett

K7-90

J. W. Brothers

K7-15

T. M. Brouns

K9-69

D. D. Caldwell

K6-28

C. H. Delegard

P7-25

J. Gao

K2-10

P. A. Gauglitz (3)

K6-28

L. K. Jagoda

K6-24

E. O. Jones

K6-24

G. B. Josephson

K6-69

M. E. Lerchen

K7-97

G. J. Lumetta

P7-22

L. A. Mahoney

K7-15

D. P. Mendoza

K6-81

A. P. Poloski

P7-25

B. M. Rapko

P7-25

S. D. Rassat (10)

K6-28

R. L. Russell

K6-24

J. M. Tingey

P7-25

B. E. Wells

K7-15

Information Release (2)

K1-06 